Digital Comprehensive Summaries of Uppsala Dissertations from the Faculty of Medicine 972

\title{
Physical Activity and Cardiovascular Disease
}

KASPER ANDERSEN

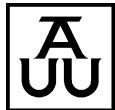

ACTA UNIVERSITATIS UPSALIENSIS UPPSALA 2014
ISSN 1651-6206

ISBN 978-91-554-8871-0

urn:nbn:se:uu:diva-217309 
Dissertation presented at Uppsala University to be publicly examined in Enghoffsalen, Akademiska Sjukhuset, Ing 50, Uppsala, Friday, 21 March 2014 at 13:15 for the degree of Doctor of Philosophy (Faculty of Medicine). The examination will be conducted in Swedish. Faculty examiner: Frieder Braunschweig.

\begin{abstract}
Andersen, K. 2014. Physical Activity and Cardiovascular Disease. Digital Comprehensive Summaries of Uppsala Dissertations from the Faculty of Medicine 972. 84 pp. Uppsala: Acta Universitatis Upsaliensis. ISBN 978-91-554-8871-0.

The aim was to investigate associations of fitness and types and levels of physical activity with subsequent risk of cardiovascular disease.

Four large-scale longitudinal cohort studies were used. The exposures were different measures related to physical activity and the outcomes were obtained through linkage to the Swedish In-Patient Register. In a cohort of 466 elderly men without pre-existing cardiovascular disease, we found that skeletal muscle morphology was associated with risk of cardiovascular events. A high amount of type I (slow-twitch, oxidative) skeletal muscle fibres was associated with lower risk of cardiovascular events and high amount of type IIx was associated with higher risk of cardiovascular events. This association was only seen among physically active men. Among 39,805 participants in a fundraising event, higher levels of both total and leisure time physical activity were associated with lower risk of heart failure. The associations were strongest for leisure time physical activity. In a cohort of 53,755 participants in the $90 \mathrm{~km}$ skiing event Vasaloppet, a higher number of completed races was associated with higher risk of atrial fibrillation and a higher risk of bradyarrhythmias. Further, better relative performance was associated with a higher risk of bradyarrhythmias. Among 1,26 million Swedish 18-yearold men, exercise capacity and muscle strength were independently associated with lower risk of vascular disease. The associations were seen across a range of major vascular disease events (ischemic heart disease, heart failure, stroke and cardiovascular death). Further, high exercise capacity was associated with higher risk of atrial fibrillation and a U-shaped association with bradyarrhythmias was found. Higher muscle strength was associated with lower risk of bradyarrhythmias and lower risk of ventricular arrhythmias.

These findings suggest a higher rate of atrial fibrillation with higher levels of physical activity. The higher risk of atrial fibrillation does not appear to lead to a higher risk of stroke. In contrast, we found a strong inverse association of higher exercise capacity and muscle strength with vascular disease. Further, high exercise capacity and muscle strength are related to lower risk of cardiovascular death, including arrhythmia deaths. From a population perspective, the total impact of physical activity on cardiovascular disease is positive.
\end{abstract}

Keywords: Physical activity, epidemiology, cohort study, heart failure, cardiovascular disease, arrhythmias, atrial fibrillation, bradyarrhythmias, sudden cardiac death, heart failure, stroke, ischemic heart disease, cardiovascular death, maximal exercise capacity, muscle strength, skeletal muscle morphology

Kasper Andersen, Department of Medical Sciences, Akademiska sjukhuset, Uppsala University, SE-75185 Uppsala, Sweden.

(C) Kasper Andersen 2014

ISSN 1651-6206

ISBN 978-91-554-8871-0

urn:nbn:se:uu:diva-217309 (http://urn.kb.se/resolve?urn=urn:nbn:se:uu:diva-217309) 
"Promise me you'll always remember: You're braver than you believe, and stronger than you seem, and smarter than you think."

Winnie-the-Pooh 



\section{List of Papers}

This thesis is based on the following papers, which are referred to in the text by their Roman numerals.

I Andersen K., Lind L., Ingelsson E., Ärnlöv J., Byberg L., Michaëlsson K., Sundström J. (2013) Skeletal muscle morphology and risk of cardiovascular disease in elderly men. European Journal of Preventive Cardiology, Epub ahead of print.

II Andersen K., Mariosa D., Adami HO., Held C., Ingelsson E., Lagerros YT., Nyren O., Weimin Y., Bellocco R., Sundström J. (2014) Dose-response relations of total and leisure-time physical activity to risk of heart failure: a prospective cohort study. Manuscript

III Andersen K., Farahmand B., Ahlbom A., Held C., Ljunghall, Michaëlsson K., Sundström J. (2014) Risk of arrhythmias in 52,755 long-distance cross-country skiers: a cohort study. European Heart Journal 34 (47): 3624-3631

IV Andersen K., Held C., Neovius M., Tynelius P., Rasmussen F., Sundström J. (2014) Exercise capacity and muscle strength and risk of vascular disease and arrhythmias - A cohort study of 1.26 million young men. Manuscript

Reprints were made with permission from the respective publishers. 



\section{Contents}

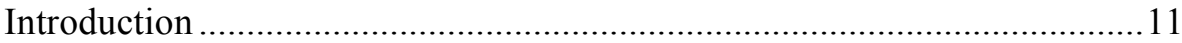

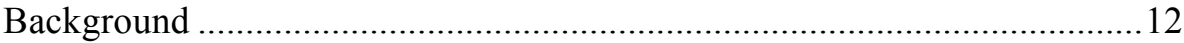

Physical activity, cardiovascular disease and mortality ....................... 12

Athlete's heart................................................................................ 14

The effect of physical activity on risk factors for vascular disease.......... 15

Skeletal muscle ............................................................................ 17

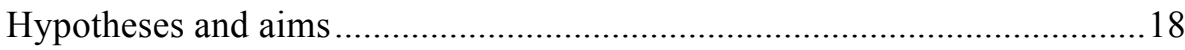

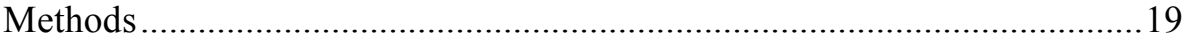

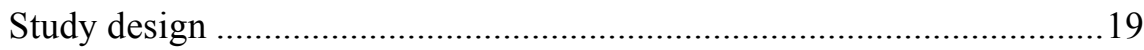

Study samples ........................................................................ 19

Measurements of physical activity, exercise and cardiovascular fitness.. 24

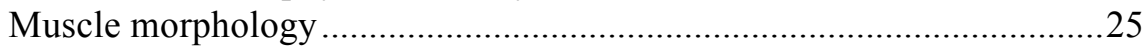

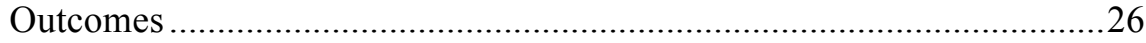

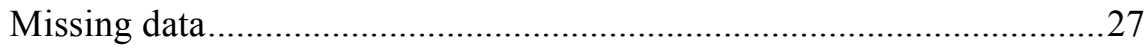

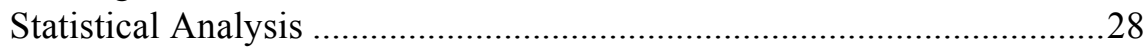

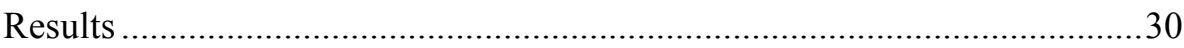

Skeletal muscle morphology is associated with risk of cardiovascular disease (Study I) .................................................................. 30

High levels of total- and leisure time physical activity is associated with lower risk of heart failure (Study II)......................................... 36

Performance and numbers of participations in Vasaloppet are associated with higher risk of arrhythmias (Study III) .........................4 41

Exercise capacity and muscle strength in adolescence and risk of vascular disease and arrhythmias (Study IV) .....................................4 46

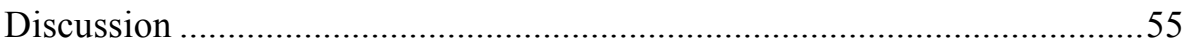

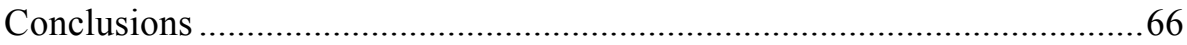

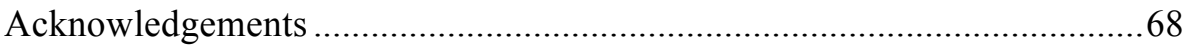

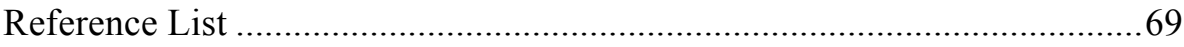




\section{Abbreviations}

$\begin{array}{ll}\text { AV block } & \text { Atrioventricular block } \\ \text { AF } & \text { Atrial fibrillation } \\ \text { AMPK } & \text { Adenosine monophosphate kinase } \\ \text { ANOVA } & \text { Analysis of variance } \\ \text { ATPase } & \text { Adenosine triphosphatase } \\ \text { BMI } & \text { Body mass index } \\ \text { Bpm } & \text { Beats per minute } \\ \text { CI } & \text { Confidence interval } \\ \text { CRP } & \text { C-reactive protein } \\ \text { DBP } & \text { Diastolic blood pressure } \\ \text { ECG } & \text { Electrocardiogram } \\ \text { GLUT4 } & \text { Glucose transporter type 4 } \\ \text { HR } & \text { Hazard ratio } \\ \text { ICD } & \text { International classification of disease } \\ \text { IL-6 } & \text { Interleukin 6 } \\ \text { IQR } & \text { Inter quartile range } \\ \text { LVMI } & \text { Left ventricular mass } \\ \text { METh } & \text { Metabolic equivalent turnover hours } \\ \text { NO } & \text { Nitric oxide } \\ \text { PYAR } & \text { Person years at risk } \\ \text { Rpm } & \text { Revolutions per minute } \\ \text { SBP } & \text { Systolic blood pressure } \\ \text { SD } & \text { Standard deviation } \\ \text { SES } & \text { Socioeconomic status } \\ \text { SCD } & \text { Sudden cardiac death } \\ \text { SVT } & \text { Supra ventricular tachyarrhythmia } \\ \text { TNF- } \alpha & \text { Tumor-necrosis-factor- } \alpha \\ \text { ULSAM } & \text { The Uppsala Longitudinal Study of Adult Men } \\ \text { VF } & \text { Ventricular fibrillation } \\ \text { VT } & \text { Ventricular tachycardia } \\ \text { WHO } & \text { World Health Organization } \\ & \end{array}$




\section{Definitions}

Physical activity - any form of body movement that requires a substantial, metabolic demand. In this definition physical activity encompasses all activity during a day like strenuous physical occupation, household activities, certain types of transportation (walking or cycling) and strenuous leisure time activities. ${ }^{1}$

Exercise - the voluntary component of a person's physical activity inventory. Exercise is often performed with a specific objective in view e.g. preparation for competition, rehabilitation after injury or maintenance of personal fitness. ${ }^{1}$

Fitness - the optimal combination of those characteristics (physical, physiological, biomechanical and psychological) that contribute to competitive success. Normally, repeated bouts of exercise can enhance a person's fitness. The cardiorespiratory component can be measured as maximal oxygen consumption alternative maximal exercise capacity. ${ }^{1}$

Endurance training - the act of exercising to increase endurance. The term endurance training generally refers to training the aerobic system as opposed to anaerobic. Examples of endurance sports are long distance running, crosscountry skiing and cycling. ${ }^{1}$

Resistance training - a type of exercise, where the body's musculature moves against an opposing force. The force is usually presented as some kind of equipment but resistance training also encompasses e.g. plyometrics and hill running. ${ }^{2}$

Cardiovascular disease - Pathological conditions involving the cardiovascular system including the heart, the blood vessel, or the pericardium. In this thesis the term cardiovascular disease is used for all pathological conditions of the heart and vascular system including arrhythmias.

Vascular disease - Pathological conditions involving the blood vessels of the body. In this thesis the term is used for a group of diseases that includes ischemic heart disease, heart failure, stroke and cardiovascular death. 



\section{Introduction}

As the Western World has developed to highly industrialized societies, there has been a parallel, rapid change in living circumstances as well as in medical sciences. This has resulted in a transition in risk factor patterns and a shift in disease patterns from dominance by infectious diseases such as diarrhoea and pneumonia to increasing prevalence of non-communicable diseases such as cardiovascular disease and cancer. In low-income countries, risk factors like under-nutrition, unsafe sex, indoor air pollution, poor water supply and hygiene are important. In middle- and high-income countries risk factors such as smoking, overweight and lack of physical activity are the predominant risk factors. In 2004 The World Health Organization concluded that hypertension, tobacco use, high blood glucose, physical inactivity and obesity are the five principal global risk factors for mortality. ${ }^{3}$ They can all be improved by lifestyle interventions. Consequently, the general focus is to reduce these risks by promoting non-smoking, non-fatty, low-caloric diet and increased physical activity. Furthermore, much effort has been put into treating hypertension and diabetes both with lifestyle changes and pharmacologically.

This thesis focuses on effects of physical activity on cardiovascular disease. Although efforts to promote increased physical activity are of unquestionable public health importance, the mechanisms whereby physical activity exerts its beneficial effects are largely unknown, as are the optimal levels of physical activity. Does it matter which type and which level of physical activity we promote? Are some modes of physical activity more beneficial than others, and could too much physical activity be harmful?

The first study focuses on the relationship between skeletal muscle morphology, physical activity and the risk of developing cardiovascular disease. The second study investigates associations of total and leisure time physical activity with risk of heart failure of any- or non-ischemic cause. The third study investigates associations of physical fitness level with risk of arrhythmias. The fourth study examines associations of cardiorespiratory fitness and muscle strength with risk of vascular disease and arrhythmias. 


\section{Background}

\section{Physical activity, cardiovascular disease and mortality}

In 1953 Jeromy N Morris and co-workers presented a study conducted among bus personnel in London's double-decker busses. They found that the incidence of coronary heart disease was higher among the sedentary bus drivers than among the more physical active conductors who moved around constantly in the bus (Figure 1). ${ }^{4}$ They hypothesized that there was a protective effect of physical activity. During the following years they also found lower incidence among people with other occupations with high activity level such as postmen. ${ }^{5}$ At the time when this hypothesis was formulated, it was met with great scepticism among other researchers and the epidemiological tools to evaluate the result were limited. Today, numerous studies on physical activity have been published, and there is consistent epidemiological evidence of a protective effect of physical activity on risk of cardiovascular disease ${ }^{6,7}$ A recent meta-analysis investigated the dose-response curve of physical activity on cardiovascular disease, and found protective effects of $150 \mathrm{~min} /$ week moderate-intensity leisure time physical activity, and even higher protection of up to $300 \mathrm{~min} / \mathrm{week}$. The additional effect of higher amount of physical activity was modest. ${ }^{8}$

Lack of physical activity has been estimated to account for 3.5 million deaths annually or $5.5 \%$ of deaths worldwide and being sedentary is even more prominent in middle- and high-income countries. ${ }^{3}$ Epidemiological studies have demonstrated a protective effect of physical activity on mortality ${ }^{9}$ and a recent meta-analysis showed $41 \%$ lower all-cause mortality in the highest vs. the lowest fitness level, and 29\% lower all-cause mortality in highest vs. lowest self-reported physical activity level. The effect was even stronger on cardiovascular mortality. ${ }^{6}$

As a consequence of this researchers began to evaluate the relation of cardiorespiratory fitness to mortality. In two large epidemiological studies an almost sigmoidal response curve of cardiorespiratory fitness on all-cause mortality was observed. ${ }^{10,11}$ Further, changes in level of cardiorespiratory fitness during life was associated with altered cardiovascular prognosis and mortality risk. ${ }^{12,13}$ Between two examinations of a person's exercise capacity had those who remained fit the lowest risk of mortality; those who 
changed from unfit to fit moderate risk and those who remained unfit the highest risk. ${ }^{13}$ Several mechanisms have been proposed, including better insulin sensitivity, lipid profile, body composition, blood pressure and autonomic balance. ${ }^{14}$ Furthermore, in children and adolescents, cardiorespiratory fitness has been related to lower incidence of obesity, better insulin resistance and lower incidence of cardiovascular risk factors. ${ }^{15-17}$

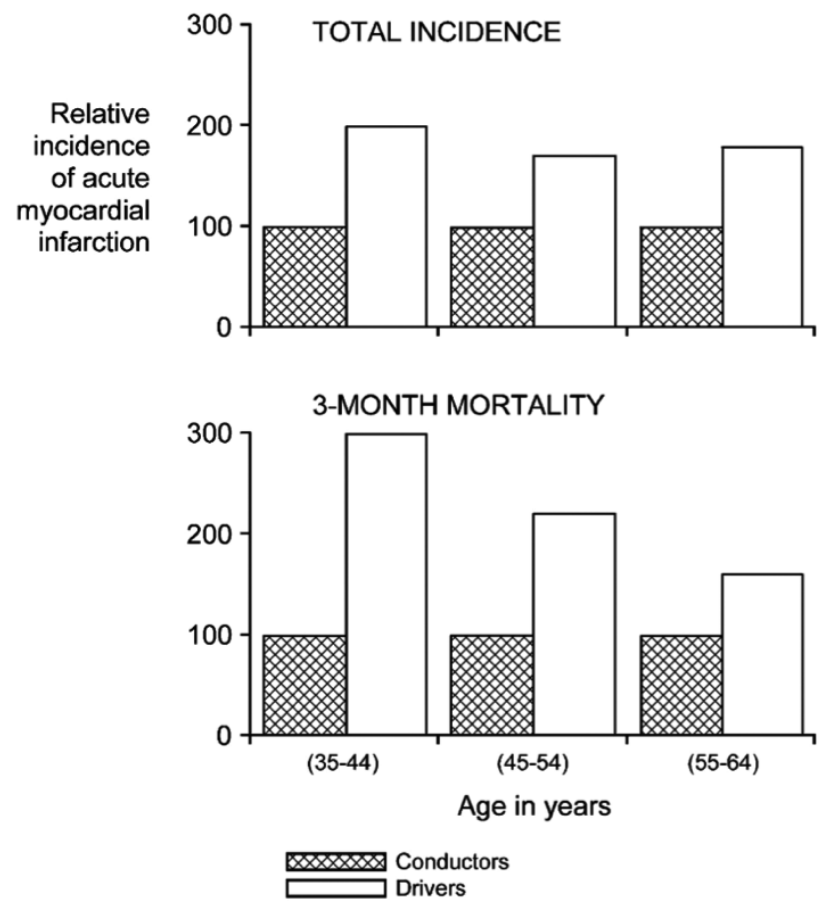

Figure 1. Age-adjusted relative incidence of acute myocardial infarction in London busmen, 1949-1958. Modified figure based on JN Morris original study ${ }^{4}$ from Paffenbarger et al. $2001^{5}$

Not only cardiorespiratory fitness, but also musculoskeletal fitness has been proposed as a risk factor for mortality and several studies have shown associations of higher muscle strength with lower risk of all-cause mortality and vascular disease even after adjusting for cardiorespiratory fitness. ${ }^{18-25}$ One of the largest studies is conducted using the cohort of Swedish conscripts that are also used in this thesis. This study shows that among Swedish 18-years old men muscle strength is inversely associated with suicide, all-cause and cardiovascular mortality. ${ }^{26}$ It has been speculated that the effect is mediated through a lower incidence of abdominal adiposity, weight gain, insulin resistance, metabolic syndrome, hypertension and chronic inflammation. ${ }^{27}$

Although the evidence of the protective of effect of physical activity on risk of cardiovascular disease and mortality seems robust, there are still gaps in 
our knowledge. Several studies have linked genetic factors to physical activity level, ${ }^{28}$ and we do not fully understand the interaction between genetic and environmental factors and how these factors predict physical activity and disease. Further, it is still unexplored how exercise capacity in different ages is related to cardiovascular outcomes.

\section{Athlete's heart}

The increased demands on the cardiovascular system during exercise lead to structural adaptations of the heart and eventually change of the conduction system of the heart. This has led to the suggestion of the existence of an athlete's heart phenotype.

Dynamic exercise (movement with no or minimal development of force) alters the hemodynamic conditions by increasing stroke volume and heart rate, the two components of cardiac output. The systemic vascular resistance is decreased partly compensating the increased cardiac output, which leads to a moderate increase in blood pressure. Thus, for dynamic exercise, the increased workload of the heart will mainly be a volume load. ${ }^{29}$ For static exercise (force with no or minimal movement) a minor increase in heart rate leads to a small increase of cardiac output. Due to increased systemic vascular resistance a large increase of blood pressure is observed ${ }^{30}$ leading to increased pressure load of the heart. ${ }^{31}$ Over time, this leads to specific adaptations of the heart related to the type of load. Volume load (as seen in endurance training) will lead to both an enlargement of the internal diameter and a thickening of the ventricular wall (eccentric heart geometry). Pressure load (associated with resistance training) will lead to a thickening of the ventricular wall, without any changes in internal diameter (concentric heart geometry). ${ }^{32}$ The latter condition mimics the changes seen in hypertensive patients who have developed hypertrophic left ventricular wall. ${ }^{33}$ However, most observations have been performed in cross-sectional studies, and other factors than the physical activity (e.g. genetic differences) could explain the athlete's heart phenotype. ${ }^{34}$ Nevertheless, recent longitudinal studies of the cardiac adaptations to different training programs supports the athlete heart hypothesis, at least partly. These studies suggest that stroke volume, left ventricular end-diastolic volume, left ventricular mass and wall thickness increases as response to endurance training, while resistance training only led to a minor increase in left ventricular end-diastolic volume. ${ }^{35,36}$

Strenuous physical exercise may induce life-threatening ventricular arrhythmias in patients with pre-existing heart disease. ${ }^{37-40}$ Indeed, a study of autopsies of 1,435 athletes suffering sudden cardiac death during training has revealed cardiac abnormalities in $97 \%$ of the cases. ${ }^{39}$ As described above 
endurance training can lead to a number of physiological structural cardiac changes, including left atrial and ventricular dilation and hypertrophy. ${ }^{41,42}$ These changes might have be related to both tachy- and bradyarrhythmias and a consistent finding among athletes is an increased risk of atrial fibrillation. Earlier case-control studies report higher incidence of atrial fibrillation in endurance-trained athletes and present odds ratios between 1.9 and 8.8 compared to non-athletes. ${ }^{43-46}$

As outlined before, most of the knowledge of the athlete's heart is gained from observational studies and little is known about dynamic changes in heart structure in response to exercise and after training cessation. Further, although the changes largely are reversible, we do not know if different types of extensive exercise are beneficial, neutral or even related to pathological conditions. Additionally, it could be speculated that the increased risk of atrial fibrillation seen among athletes could lead to an increased incidence of stroke since atrial fibrillation has been related to fivefold higher risk of stroke in population studies. ${ }^{47,}{ }^{48}$ However, it is unknown whether atrial fibrillation is related to increased risk of stroke in well-trained individuals.

\section{The effect of physical activity on risk factors for vascular disease}

The classical risk factors for vascular disease such as hypertension, diabetes hyperlipidaemia and to lesser extent smoking are all related to levels of physical activity. Some of the protective effect of physical activity is mediated through a reduction of these risk factors. Nevertheless, other risk factors such as endothelial function and inflammation are under current investigation.

Hypertension is in a global perspective the most important risk factor for death and cardiovascular disease, accounting of $12.8 \%$ of all deaths corresponding to 7.5 million deaths each year. ${ }^{3}$ An unfavourable diet, high BMI, high salt intake and lack of physical activity are suggested to be major causes of hypertension. ${ }^{49}$ After developing high blood pressure, endurance training can lower the blood pressure. ${ }^{50}$ Whether resistance training lowers blood pressure is still debated. On one hand weight lifting increases acute blood pressure to very high levels; ${ }^{30}$ on the other hand several studies suggest that resistance training may lower blood pressure in hypertensive patients to almost the same level as endurance training. ${ }^{51}$ 
Physical activity protects against type 2 diabetes and persons engaged in regular physical activity of moderate intensity have approximately $30 \%$ lower risk of developing type 2 diabetes than sedentary persons. ${ }^{52}$ Skeletal muscles act as a regulator of levels of blood glucose by translocation of GLUT4 receptors to the myocyte membrane as a response to insulin and exercise. ${ }^{53}$, ${ }^{54}$ The translocation of GLUT4 receptors is regulated by a plethora of molecular signalling thought to include calcium, stretch and energy stress signalling. In addition, exercise increases glucose transport-phosphorylation and glycogen-synthesis related to transport and storage of glucose in the myocyte. $^{55}$

Physical activity is also associated with a favourable lipid profile and exercise a beneficial effect on lipid profile in patients with dyslipidaemia. ${ }^{56,57}$ Interestingly, there seem to be an association between levels of slow-twitch skeletal muscle fibres and levels of high-density lipoproteins. ${ }^{58,59}$

A pivotal element for a normal endothelial function is the presence of the signalling molecule Nitric Oxide (NO). Thus, a reduction in the bioavailability of NO leads to endothelial dysfunction that often predates the clinical and/or morphological manifestations of atherosclerosis. ${ }^{60}$ Exercise of moderate intensity is known as stimulator of NO-release and cross sectional studies have shown positive correlations between physical activity and endothelial function. ${ }^{61,62}$ Furthermore, several studies have shown that physical exercise is capable to restore and improve endothelial function in patients with atherosclerosis, hypertension and hyperglycaemia. ${ }^{63}$

Chronic elevation of inflammatory markers such as IL-6, CRP and white blood count is known as chronic low-grade inflammation. This condition is associated with increased risk of developing diabetes, ${ }^{64-72}$ it is a strong, consistent and independent predictor of all-cause and cardiovascular mortality ${ }^{73-}$ ${ }^{83}$ and an increase in IL-6 and soluble TNF- $\alpha$-receptor- 2 are positively correlated to the amount of coronary artery calcification. ${ }^{84}$ It is likely that the protective effect of physical activity against obesity, hypertension, diabetes type- 2 and cardiovascular disease is at least partly mediated by reduced inflammation. ${ }^{85,86}$

It is evident that some of the effect of physical activity on the risk of atherosclerotic disease is mediated through a reduction of these traditional risk factors. However, it is consistent among studies of physical activity that after adjusting for these risk factors, ${ }^{87}$ a hitherto unexplained effect remains which should be explored further. 


\section{Skeletal muscle}

The primary function of skeletal muscle is to generate power, produce force and act as a break. ${ }^{88}$ These functions allow us to maintain body posture, walk and run and to do all everyday chores related to voluntary movement. Moreover, skeletal muscles have crucial functions related to glucose metabolism, thermoregulation and were recently discovered as an endocrine organ with anti-inflammatory properties.

Human skeletal muscle fibres are traditionally divided into three main types based on their ATPase activity: type-I (slow-twitch, oxidative), type-IIa (fast-twitch, oxidative-glycolytic) and type-IIx (previously IIb, very fasttwitch, glycolytic) ${ }^{89}$ The fibre type is closely related to the content of myosin heavy chain protein in the myocyte. ${ }^{89,90}$ Athletes performing endurance training generally have higher proportions of type-I fibre than athletes performing resistance training. ${ }^{1,91}$ Training studies shows that both endurance and resistance training may induce skeletal muscle fibre transition from type-IIx to type-IIa, but that transition is more prominent with endurance training than resistance training. ${ }^{88,92}$ This response seems to be general and unrelated to the age of the test person. ${ }^{93,94}$ The proportion of type-I fibres is less affected. ${ }^{88,92,94}$ Further, a transition from slow to fast type skeletal muscle fibres have been observed in completely inactive persons. ${ }^{95}$

As described above, skeletal muscle acts as regulator of levels of blood glucose by translocating GLUT4 receptors to the myocyte membrane as a response to insulin or exercise. ${ }^{53,54}$ Several differences in glucometabolic properties between muscle fibre types are known. In type-I muscle fibres, the GLUT4 receptor is more expressed than in type-IIa/IIx fibres. ${ }^{96}$ Further, AMP-activated kinase (AMPK) a protein that regulates skeletal muscle metabolic gene expression programs in response to changes in the energy status is expressed and activated in a fibre-specific manner. ${ }^{97,98}$

While the changes of skeletal muscle morphology in chronic diseases are well studied, ${ }^{99-101}$ little is known about the relations between skeletal muscle properties in healthy individuals and subsequent risk of disease. 


\section{Hypotheses and aims}

A:

Hypothesis: Skeletal muscle morphology may be an indicator of the type and amount of physical activity conducted in the near past and may play an important role in metabolic and anti-inflammatory effects of exercise. As such, muscle morphology is related to risk of cardiovascular events, and those relations may vary by physical activity level.

Aim: To investigate the associations of skeletal muscle morphology and physical activity with risk of cardiovascular disease in a community-based cohort of 466 elderly men.

B:

Hypothesis: Physical activity reduces the risk of heart failure, and the protective effect is stronger with higher intensity and/or frequency of physical activity. Moreover, the effects of total physical activity and leisure-time activity may differ.

Aim: To investigate non-linear associations of physical activity with risk of heart failure of any cause and of non-ischemic origin in a large prospective cohort study of 39,805 persons without history of heart failure.

C:

Hypothesis: Long-term increased workload as a consequence of prolonged endurance training may lead to structural changes in the heart and autonomic disturbances, which could increase arrhythmogenicity.

Aim: To investigate the association of number of completed races and finishing time in the race with long-term risk of hospitalization for arrhythmias, in a cohort of 52,755 participants in a long-distance cross-country skiing race, Vasaloppet.

D:

Hypothesis: Exercise capacity and muscle strength are each independently directly related to the risk of subsequent arrhythmias and inversely related to the risk of subsequent vascular disease.

Aim: We investigated these associations in a prospective cohort of 1.26 million Swedish young men examined at mandatory military conscription in 1972-1995. 


\section{Methods}

\section{Study design}

All of the included studies are designed as longitudinal cohort studies, with the purpose to examine the relation of a given exposure (or risk factor) to a given outcome (or disease). In three of the studies (study I, III and IV) the samples were collected in the general population, while the sample of participants in Vasaloppet were considered to represent persons with higher level of physical activity than the general population. The studies are summarized in Table 1.

\section{Study samples}

\section{The ULSAM Cohort (Study I)}

The Uppsala Longitudinal Study of Adult Men (ULSAM) is an on-going, longitudinal, epidemiological study based on all available men, born between 1920 and 1924, in Uppsala County, Sweden. In study I we used a reexamination of the cohort at age 71 as baseline. At this examination, blood pressure and ECG recordings were performed, various blood samples were collected and the participants completed a questionnaire on medical history and lifestyle. The dataset probably represents the world's largest collection of muscle biopsies among healthy elderly men. We excluded men with a prior history of cardiovascular disease, rendering a final sample of 466 men aged 71 years.

Medication use, smoking status and alcohol habits were determined in interviews and questionnaires. Socioeconomic group was determined using official registry data. Blood pressures (SBP and DBP), height, weight and waist circumference were measured and BMI were calculated. Diabetes mellitus was defined as fasting plasma glucose $\geq 7.0 \mathrm{mmol} / \mathrm{L}$, 2-hour postload glucose $\geq 11.1 \mathrm{mmol} / \mathrm{L}$, or the use of oral hypoglycemic agents or insulin. IL-6, CRP, fibrinogen and $\alpha$-tocopherol were determined by commercially available methods. Insulin sensitivity was represented by glucose disposal rate $(\mathrm{mg} / \mathrm{kg}$ body weight $/ \mathrm{min}$ ) at an euglycemic hyperinsulinaemic insulin clamp (insulin infusion rate $56 \mathrm{mU} / \mathrm{min}^{*} \mathrm{~m}^{2}$ ). Left ventricular mass index (LVMI) was cal- 
culated using echocardiographic M-mode. This study complies with the Declaration of Helsinki and all participants gave written informed consent. The Ethics Committee of Uppsala University approved the study.

Table 1. Summarizing table of the studies included the thesis

\begin{tabular}{|c|c|c|c|}
\hline Study & Sample & Exposure & Outcome \\
\hline I & $\begin{array}{l}46671 \text {-years old men } \\
\text { without cardiovascular } \\
\text { disease } \\
\text { (Population based } \\
\text { cohort) }\end{array}$ & $\begin{array}{l}\text { Skeletal muscle } \\
\text { fibre type in } \\
\text { total and by } \\
\text { physical exer- } \\
\text { cise level }\end{array}$ & Cardiovascular disease \\
\hline II & $\begin{array}{l}39,805 \text { persons without } \\
\text { heart failure who com- } \\
\text { pleted a questionnaire } \\
\text { of lifestyle factors and } \\
\text { medical history } \\
\text { (Population based } \\
\text { cohort) }\end{array}$ & $\begin{array}{l}\text { Total and lei- } \\
\text { sure time phys- } \\
\text { ical activity }\end{array}$ & $\begin{array}{l}\text { Heart failure of all-cause or } \\
\text { non-ischemic origin }\end{array}$ \\
\hline III & $\begin{array}{l}52,755 \text { participants in } \\
\text { the } 90 \mathrm{~km} \text { skiing even } \\
\text { Vasaloppet from 1989- } \\
1998 \\
\text { (Cohort at the upper } \\
\text { end of the physical } \\
\text { activity distribution) }\end{array}$ & $\begin{array}{l}\text { Number of } \\
\text { participations } \\
\text { and best rela- } \\
\text { tive perfor- } \\
\text { mance in } \\
\text { Vasaloppet } \\
\text { during the peri- } \\
\text { od }\end{array}$ & $\begin{array}{l}\text { Primary Outcome: } \\
\text { Any arrhythmias } \\
\text { Secondary outcomes: } \\
\text { Atrial fibrillation, brady- } \\
\text { arrhythmias, supraventricu- } \\
\text { lar arrhythmias, ventricular } \\
\text { arrhythmias/SCD }\end{array}$ \\
\hline IV & $\begin{array}{l}1.26 \text { million Swedish } \\
\text { men who participated } \\
\text { in mandatory military } \\
\text { conscription between } \\
1972 \text { and } 1995 \text { (at a } \\
\text { median age of } 18.2 \\
\text { years) } \\
\text { (Population based } \\
\text { cohort) }\end{array}$ & $\begin{array}{l}\text { Exercise ca- } \\
\text { pacity and mus- } \\
\text { cle strength } \\
\text { (measured as } \\
\text { hand grip } \\
\text { strength) at } \\
\text { conscription }\end{array}$ & $\begin{array}{l}\text { Primary outcome I: } \\
\text { Vascular disease } \\
\text { Secondary outcomes I: } \\
\text { Ischemic heart disease, heart } \\
\text { failure, stroke, cardiovascu- } \\
\text { lar death } \\
\text { Primary outcome II } \\
\text { Any arrhythmias } \\
\text { Secondary outcomes II } \\
\text { Atrial fibrillation, brady- } \\
\text { arrhythmias, supraventricu- } \\
\text { lar arrhythmias, ventricular } \\
\text { arrhythmias/SCD }\end{array}$ \\
\hline
\end{tabular}

SCD: Sudden cardiac death 
Participants were followed from the baseline examination in 1991-1995 to December 31, 2007, with a maximum of 16.3 years of follow-up (median 13.1 years, 4984 person-years at risk). We used the Swedish national inpatient and cause-of-death registries, which include all Swedish citizens, to define endpoints. To maximize statistical power, we investigated a combined endpoint of major adverse cardiovascular events comprising the first event of fatal and non-fatal myocardial infarction (International Classification of Diseases [ICD]-9 code 410, ICD-10 code I21), fatal or non-fatal stroke (ICD-9 codes 430-434, ICD-10 codes I60-64), a first hospitalization for heart failure (ICD-9 code 429, ICD-10 code I50) (validated through chart review) ${ }^{102}$ or cardiovascular death (ICD-9 codes 390-459, ICD-10 codes I00-99).

\section{The National March cohort (Study II)}

In September 1997 the Swedish Cancer Society organized a nation-wide fund-raising event, the National March (Riksmarschen), with venues in around 3,600 Swedish cities and villages. After paying a nominal starting fee, participants took a 2-3 km walk. They were also invited to complete a 32-page questionnaire with detailed questions on physical activity, diet, medical history and lifestyle factors. The walk was not mandatory for completing the questionnaire. In total, 43,880 participants completed and returned the questionnaire.

All baseline information except history of myocardial infarction was selfreported through the questionnaire. Gender, treatment of hypertension, diabetes and dyslipidaemia were recorded as binary variables. Height, weight, waist and hip circumference were recorded on a continuous scale and BMI $\left(\mathrm{kg} / \mathrm{m}^{2}\right)$ and waist-hip ratio were calculated. Smoking habits were classified into two variables (current smoker [daily smoking for the last six month] and numbers of pack-years) and alcohol habits were classified into four groups, based on quartiles of the alcohol intake distribution (grams per day). Participants who had taken snuff (smokeless tobacco) at least once a week since more than 6 months were classified as snuff users. Education level was categorized as "7-9 years", "10-12 years" or "More than 12 years". History of myocardial infarction before baseline or during follow-up until the heart failure diagnosis was assessed through linkage with the Swedish National In-patient Register (see below). The study complies with the declaration of Helsinki and was approved by the Regional Ethics Review Board at 'Karolinska Institutet'

Accurate record linkages, using the national registration numbers as unique personal identifiers, provided information about hospitalization discharge diagnoses (from the Swedish National Patient Register); emigration (from the Swedish Population Register); and date of death (from the Swedish 
Cause of Death Register). Follow-up was from October 1, 1997 to December 31,2010 . We investigated associations of total and leisure-time energy expenditure, respectively, with the risk of heart failure of any cause and of non-ischemic origin. We used ICD-10 codes I50.0-9 (or similar ICD-7 [434.1; 434.2], ICD-8 [427.0; 427.1] or ICD-9 [428.A; 428.B; 428.X] codes) to define heart failure of any cause. Cases of heart failure were considered of non-ischemic origin if the diagnosis was not at the same time or after a myocardial infarction (ICD-10 codes I21.0-9 or similar ICD-7 [420.10; 420.17] ICD-8 [410] or ICD-9 [410] codes). When studying non-ischemic heart failure only the subsample without myocardial infarction at baseline was considered for the statistical analysis, and follow-up was censored at time of myocardial infarction (if before diagnosis of heart failure).

\section{The Vasaloppet Cohort (Study III)}

All Swedish participants in the 90 kilometre skiing event Vasaloppet who completed the race during the period 1989-98 were included in the study. Vasaloppet takes place the first Sunday in March every year and is a crosscountry skiing event from Sälen to Mora in Dalarna, Sweden. Approximately 15,000 participants ranging from recreational to elite skiers complete 90 kilometres of cross-country skiing. The $90 \mathrm{~km}$ Vasaloppet has two competitions: (i) the main race on the first Sunday of March where participants start in a large group; (ii) for those who prefer avoiding the stress of the group start, there are two additional race days (Öppet spår) where participants can start any time within an hour. The trail completed is the same. This study includes both participants starting in the main race and in the Öppet spair race. During the inclusion period, one race was cancelled (1990, because of thawing). Participants with cardiovascular disease were excluded from the study. The final study sample comprised 47,477 men and 5,278 women.

Participants were followed from the last participation in the race during the period from 1989-1998 (the baseline date) to the date of first diagnosis of the outcome of interest, death, date of emigration, or the end of the follow-up (December $31^{\text {st }}, 2005$ ). As the national registries were used for follow-up, loss-to-follow-up was negligible. The primary outcome was for any arrhythmia (all of the diagnoses below, plus ICD-10: I47.9). As secondary endpoint we used 1) Bradyarrhythmias (ICD-10: I44.1, I44.2, I45.2, I45.3, I45.9, I49.5); 2) Atrial fibrillation or flutter (ICD-10: I48.9); 3) Other SVT (ICD-10: 45.6, I47.1); 4) VT/VF/SCD (ICD-10: I47.0, I47.2, I46.0, I46.1, I46.9, I49.0, R96.0). Both main diagnosis and secondary diagnoses were taken under consideration. Note the use of ICD-codes does not allow differentiation between Mobitz-types of AV-block grade II. 
We investigated finishing time as a categorical variable, divided into four groups of percentages of the winning time that year [100-160\%, 161-200\%, $201-240 \%$, and $>240 \%$ (reference group)]. Only the best relative finishing time for each individual during the 10 -year period was considered. In addition, we investigated number of races as a categorical variable [1 race (reference group); 2 races; $3-4$ races; and $\geq 5$ races]. Number of races and finishing time before 1989 or after 1998 were not considered in the exposure assessment. The cohort was linked to censuses for 1960, 1970, 1980, and 1990 to receive information on occupation and educational level. The latest, most updated information for each person was used in this study. Occupation was grouped into four categories (blue-collar, lower-middle, white-collar, high white-collar, and entrepreneur). Highest education level obtained was categorized as low (elementary school only), medium (secondary school), and high (university) levels. There were missing values for education in 3072 participants and for occupational status in 6331 participants. The study protocol was approved by the Regional Ethical Review Board, Karolinska Institutet, Stockholm, Sweden.

\section{The conscription cohort (Study IV)}

This cohort uses data of all Swedish males who underwent conscription between August $1^{\text {st }} 1972$ and December $31^{\text {st }} 1995$. During that period, military conscription was mandatory in Sweden and only $2-3 \%$ of all men were not conscripted (mainly because of severe disease or handicap). These conscriptions were performed in a standardized fashion, and 1,257,032 men were enrolled in the cohort in total. The conscripts had a median age of 18.2 years $\left(10^{\text {th }}\right.$ percentile $17.8 ; 90^{\text {th }}$ percentile 18.9$)$. We excluded 17,206 men with a history of prior vascular disease (ICD 10 code I.00-99 or similar ICD8/ICD-9 code). The study protocol was approved by the Regional Ethical Review Board, Karolinska Institutet, Stockholm, Sweden.

Using the registries, we defined two primary outcomes: Vascular disease (all ICD-codes mentioned in secondary outcomes) and arrhythmia (All ICDcodes mentioned in secondary outcomes, plus ICD 10 - I47.9). For vascular disease the secondary outcomes were 1) Ischemic heart disease (ICD-10: I20.0-I25.9), 2) Heart failure (ICD-10: I11.0; I50.0-I50.9), 3) Stroke (ICD10: I60.0-I60.9, I61.0-I61.9; I63.0-I63.9; I64.0-I64.9), and 4) Cardiovascular death (ICD-10: I00-I99). For arrhythmias, the secondary outcomes were 1) Atrial fibrillation/flutter (ICD-10: I48.9), 2) Bradyarrhythmias (ICD-10 I44.1; I44.2; I45.2; I45.3; I45.9; I49.5), 3) Supraventricular arrhythmias (I45.6; I47.1), and 4) Ventricular arrhythmias/Sudden Cardiac Death (I46.0; I46.1, I46.9; I47.0; I47.2; I49.0; R96.0). Corresponding codes for ICD-9 and ICD-8 were used. 


\section{Measurements of physical activity, exercise and cardiovascular fitness}

Study I uses physical activity as an important covariate and study II uses physical activity as the main exposure (Table 1). Physical activity is defined as any form of body movement that require a substantial metabolic demand and this covers all activity during the day. ${ }^{1}$

Study I and II both uses questionnaires to assess physical activity level but have different approaches. Questionnaires covering self-assessed level of physical activity, are regarded as adequate instruments to rank level of physical activity, but are shown to both over- and underestimate physical activity and give considerable errors on the individual level when validated with more objective measures of physical activity like calorimetry or motions sensors. ${ }^{103}$ Although the ULSAM cohort assess total physical activity level by four fairly simple questions (Table 2), questionnaire that has been externally validated ${ }^{104,}{ }^{105}$ and validated against an objective measurement of maximal exercise capacity in the present cohort. ${ }^{106}$

Table 2 Questions used in the ULSAM cohort to assess physical activity level.

1) Do you spend most of your time reading, watching TV, going to the cinema or engaging in other, mostly sedentary, activities?

2) Do you often go walking or cycling for pleasure?

3) Do you engage in any active sport or heavy gardening for at least $3 \mathrm{~h}$ every week?

4) Do you regularly engage in hard physical training or competitive sport

The highest positive answer of physical activity level was prevailing, and two categories: "physically inactive (no to questions 3 and 4)" and "physically active (yes to question 3 or 4 )" was created.

Study II uses a questionnaire of leisure time physical activity that also includes the intensity of the activity (Figure 2). This is complemented by a more complex questionnaire (Figure 3) to assess total physical activity. The questionnaire has been validated to have good reproducibility, ${ }^{107}$ but has not been validated by use of calorimetry or exercise capacity. By use of these two questionnaires we were able to estimate the amount ('dose') of respectively leisure time and total physical activity.

Study III and IV use fitness as exposure. Cardiorespiratory fitness is defined as the ability of the circulatory and respiratory system to supply skeletal muscle with oxygen. Cardiorespiratory fitness is the best predictor of performance in cross-country skiing ${ }^{1}$ and we therefore assume in Study III that performance in Vasaloppet is related to both cardiorespiratory fitness and duration of training; number of completed races during the period we assumed is related to duration of training. To get an objective measurement of 
cardiorespiratory fitness maximal oxygen consumption can be measured. This is typically done on a treadmill or an ergometer cycle with simultaneous measurement of gas exchange. ${ }^{1}$ However, this method is resource demanding and since a maximal exercise test without measuring gas exchange has very good correlation to maximal exercise capacity it can be used as an estimate. ${ }^{108,} 109$ In Study IV we had access to data of maximal exercise capacity and muscle strength from the conscription of 1.16 million 18 years old men. The exact protocols through all years were not available, but the protocol from 2001, which according to the conscription authority only has minor changes compared to the earlier protocols, was available. Using an ergometer bicycle test, maximal exercise capacity was evaluated. After 5 min of submaximal cycling at $60-70 \mathrm{rpm}$, the load was gradually increased by $25 \mathrm{~W}$ per min and the conscript continued to cycle to exhaustion. If the conscript did not obtain a maximal heart rate $>180 \mathrm{bpm}$, the instructor decided if the conscript should be re-tested. We found a minor shift in the distribution of maximal exercise capacity in August 1984 (probably due to a change of examination protocol) and the observations were standardized in groups (before and after August 1984). Of the available measurements of muscle strength, we used handgrip strength measured by a hand dynamometer, which has shown good correlation with lean body mass. ${ }^{110-112}$

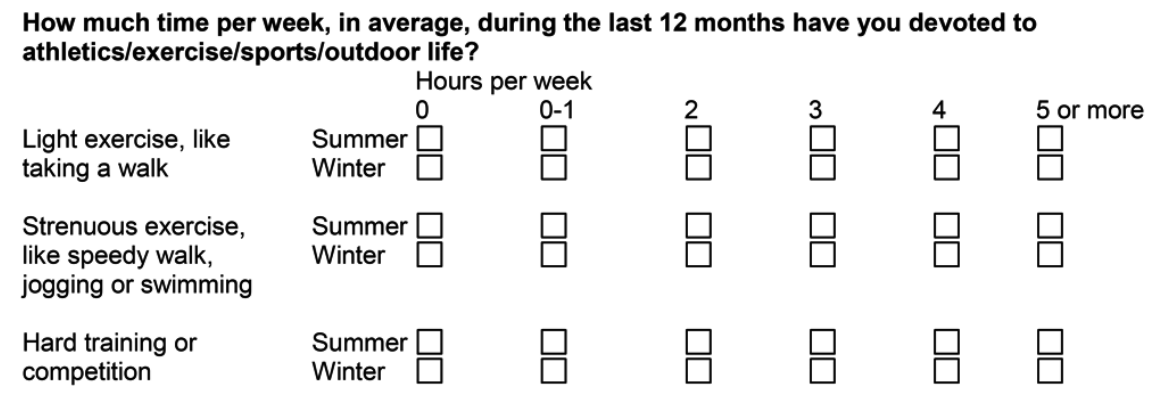

Figure 2. The questionnaire used for assessing the leisure time activity in the National March cohort.

\section{Muscle morphology}

Study I uses skeletal muscle fibre morphology as exposure (Table 1). Muscle biopsies were obtained by use of a Bergström needle from the right vastus lateralis muscle under local anaesthesia. Serial transverse sections were cut in a cryostat and stained for myofibrillar ATPase. By use of computerized image analysis equipment (Multisync II, BIO-RA SA, Richmond, CA, USA) linked to an optical microscope (Leitz, Germany) the proportion of type-I, IIa, or IIx were reported as percentage of total fibre area. 


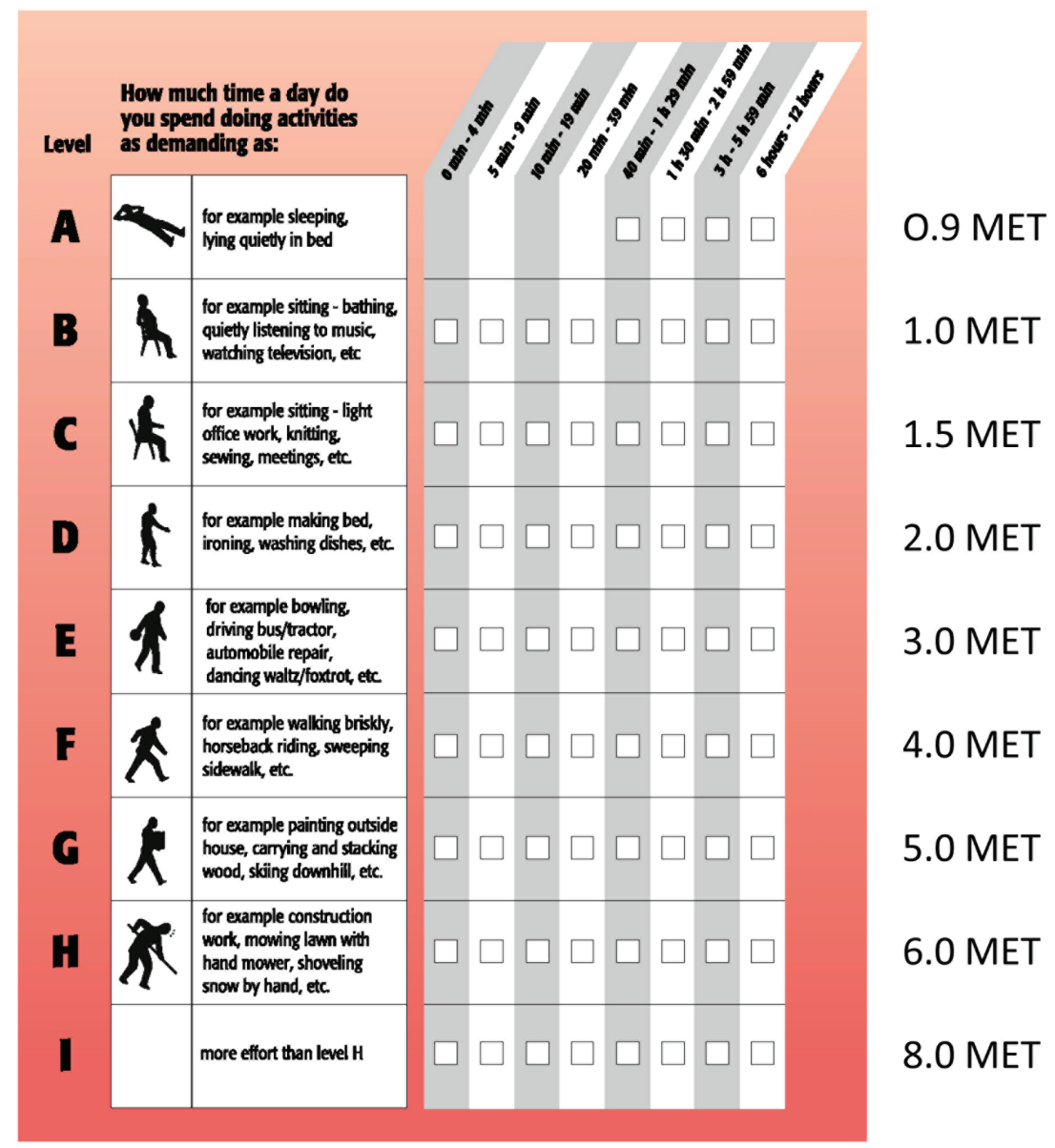

Figure 3. The energy expenditure questionnaire used to assess total physical activity in Study II. One METh corresponds to an energy expenditure of $3.5 \mathrm{ml} \mathrm{O} 2 \times \mathrm{kg}^{-1}$ $\times \min ^{-1}$ or $1 \mathrm{kcal} / \mathrm{kg}$ body weight per hour which is equal to the energy used by sitting quietly for one hour.

\section{Outcomes}

The unique Swedish national registration number makes it possible to link cohorts to different official registers to obtain outcomes and covariates. Since the registers cover the whole populations, loss-to-follow-up is minimized to only include emigrated subjects.

\section{The Swedish National Patient Register}

The Swedish National Patient Register is a register of all hospitalizations in Sweden. The register contains demographic information of the patients and administrative information of the admission. Further, it contains both prima- 
ry and secondary diagnoses related to the admission as coded by the discharging physician. The diagnoses were recoded using the Swedish Classification of Diseases which are based on WHO's international classifications of disease (ICD). ICD-8 was used from 1969; ICD-9 from 1987 and ICD-10 from 1997. The register was started in 1964 in selected counties and became nationwide in 1987. In 1997 day-surgery and 2001 non-primary outpatients were included. Information of primary care is not included.

\section{The Swedish Cause of Death Registers}

The Swedish Cause-of-Death Register contains data from 1961 and includes all information of all deceased registered in Sweden. The register contains information of time of death as well as information of cause of death coded according to the Swedish classification of Diseases.

\section{Statistics Sweden}

Statistics Sweden provided information of emigration, educational level and socioeconomic index. The registers of emigration and highest educational level are updated continuously while information on socioeconomic index is obtained at from the Swedish censuses. The latest information of socioeconomic index is from 1990.

\section{Missing data}

All epidemiological studies experience problems with missing data. If the data are not missing completely at random, it may introduce a selection mechanism. This mechanism has the potential to introduce bias in the analyses and has to be corrected for. In study I-III we used the approach of multiple imputations to account for the missing data. The first stage is to create multiple copies of the dataset with missing values replaced by imputed values. The imputations originate from the predicted distribution and hence accounts for the variability of the dataset. The second stage is at the time of statistical modelling, and implies pooling results of the model across all the imputed datasets to generate a single set of estimates and related standard errors from the model. In study IV the proportion of incomplete observations was only $1.2 \%$ and since we assumed observations to be missing at random, we decided to analyse only complete observations. This decision was also partly influenced by the large computer power needed for multiple imputations in this huge dataset. 


\section{Statistical Analysis}

All statistical analyses were calculated using the statistical software Stata version 12 or 13 (StataCorp LP, USA).

\section{Hypothesis testing}

In study I differences in baseline variables between strata of physical activity and dominant muscle fibre type were tested using t-tests, ANOVAs and chisquare tests. T-tests were used to test if two means differed from each other, and ANOVAs and Tukey's test for post hoc analysis to test for differences in more than two groups. Chi-square tests were used to test differences of proportions.

\section{Directed acyclic graphs}

All studies use the approach of directed acyclic graphs to develop biasminimized statistical models. Traditionally, epidemiologists have used their intuition, a priori knowledge and simple rules to decide which variables to include in the statistical models. That approach can lead to incorrect decisions and may introduce conditional associations (bias). By using directed acyclic graphs we attempted to minimize bias by ensuring that statistical models are specified as correctly as possible. An example of a directed acyclic graph is presented in figure 4.

\section{Cox proportional hazard models}

All of the studies use Cox regression to estimate hazard ratios (HR) between exposure groups. Cox regression compares events per time unit (hazard rates) between different groups in a sample and has the basic assumption that the ratio of the rates is constant during follow-up. The hazard rate can however vary over time. The proportionality assumption can be assessed by inspecting the cumulative incidence in Nelson-Aalen plots. Alternatively it is possible to use formal tests such as Schoenfeld's test. In study II and IV we used multivariate regression spline models (a piecewise fitting of polynomial equations) to investigate the shapes of the associations. This is a thorough way of assessing non-linear associations. 

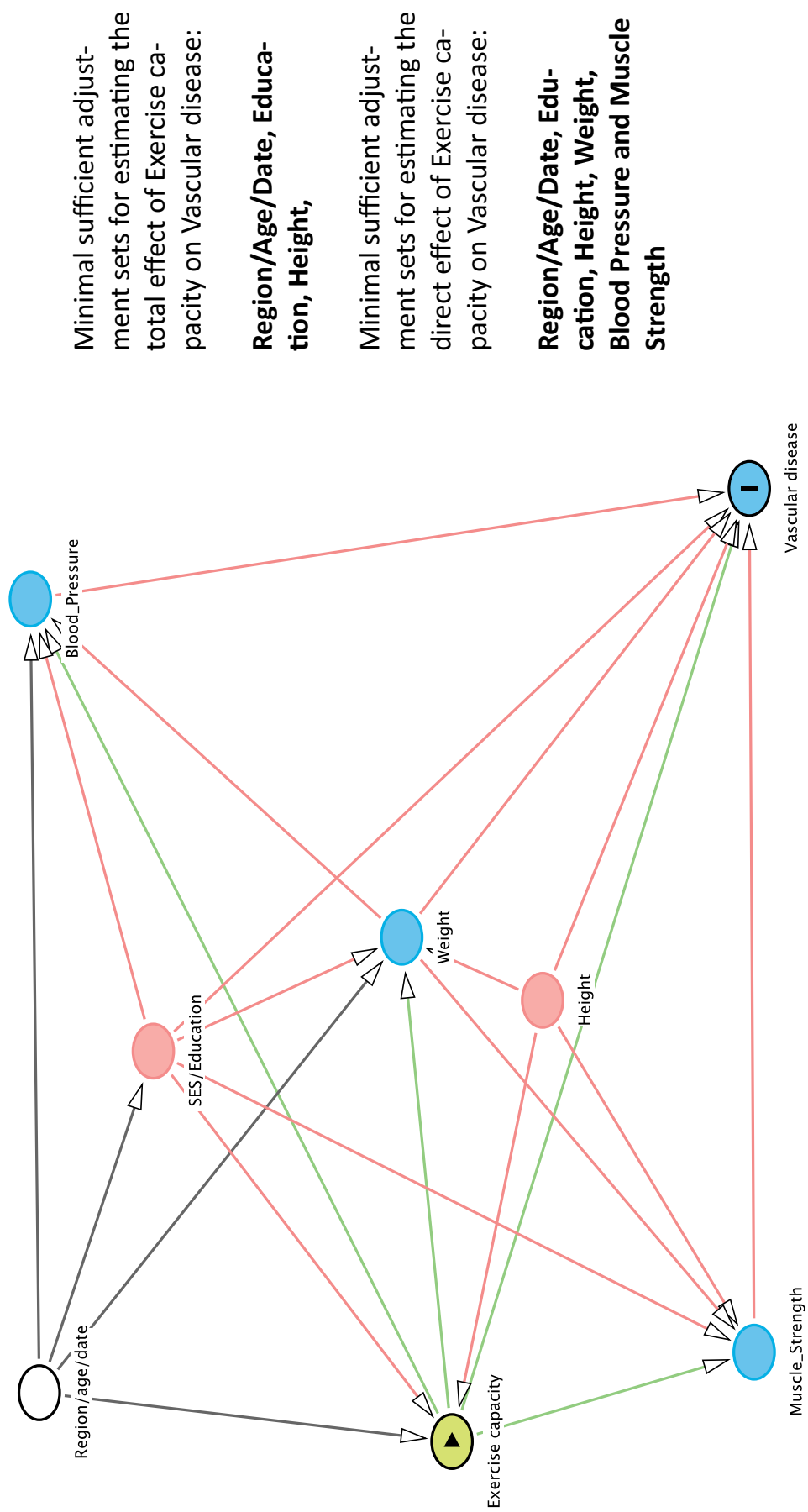

Figure 4. Example of a directed acyclic graph as used to proposed the statistical models in Study IV. Exposure: exercise capacity; Outcome: vascular disease. Green arrows indicate causal path; red arrows indicates confounding path. 


\section{Results}

\section{Skeletal muscle morphology is associated with risk of cardiovascular disease (Study I)}

In the ULSAM cohort of 466 71-years-old men without cardiovascular disease, $171(36.7 \%)$ men were characterized as physically inactive and 295 $(63.3 \%)$ as active. During median 13.1 years of follow-up, 173 of the 466 men experienced a cardiovascular event. Baseline characteristics are shown in Table 3. Plots of cumulative incidence of cardiovascular events by physical activity level and dominant muscle fibre type are shown in Figure 5, and corresponding incidence rates in 6 .

\section{Muscle morphology and risk of cardiovascular events}

In the age-adjusted models (model A), a higher proportion of type-I muscle fibres was associated with a lower rate of cardiovascular events ([HR] 0.88 [95\% CI $0.79-0.97$ ] per $10 \%$ proportional increase) while a higher proportion of type-IIx fibres was associated with a higher rate of cardiovascular events (HR 1.19 [95\% CI 1.05-1.34] per 10\% proportional increase). Adjusting additionally for physical activity (model $\mathrm{B}$ ) and socio-economic variables (model C), similar results were seen (Figure 7A). Further adjustment for variables in the potential, causal pathways (models D-G), and eventually for variables representing all investigated pathways (models $\mathrm{H}$ ), did not materially affect the results (Figure 7A). No association of proportion of type-IIa fibres with cardiovascular events was seen in any model.

We further compared the rate of cardiovascular events among those who had type-IIa or type-IIx as the dominant muscle fibre type to that among those who were type-I dominant. Type-IIx dominant men had a higher rate of cardiovascular events than type-I dominant men (HR 1.78 [95\% CI 1.13-2.82] in model A; similar results were observed in models B-H). Rates of cardiovascular events did not differ between type-IIa and type-I dominant men (Figure 7B). 
Table 3. Baseline characteristics

\begin{tabular}{|c|c|c|c|c|c|c|}
\hline & $\begin{array}{l}\text { Total sample } \\
(n=466)\end{array}$ & $\begin{array}{l}\text { Physically } \\
\text { inactive } \\
(n=|7|)\end{array}$ & $\begin{array}{l}\text { Physically } \\
\text { active } \\
(n=295)\end{array}$ & $\begin{array}{l}\text { Dominant } \\
\text { type-I } \\
(n=319)\end{array}$ & $\begin{array}{l}\text { Dominant } \\
\text { type-lla } \\
(n=107)\end{array}$ & $\begin{array}{l}\text { Dominant } \\
\text { type-IIx } \\
(n=40)\end{array}$ \\
\hline Age (years) & $70.8 \pm 0.6$ & $70.9 \pm 0.7$ & $70.8 \pm 0.6$ & $70.8 \pm 0.6$ & $70.7 \pm 0.6$ & $70.9 \pm 0.6$ \\
\hline Body mass index $\left(\mathrm{kg} / \mathrm{m}^{2}\right)$ & $26.2 \pm 3.3$ & $26.4 \pm 3.4$ & $26.0 \pm 3.2$ & $26.0 \pm 3.2$ & $26.4 \pm 3.0$ & $27.0 \pm 4.3$ \\
\hline Systolic blood pressure (mmHg) & $146.0 \pm 18.3$ & $146.6 \pm 18.3$ & $145.8 \pm 18.3$ & $146.4 \pm 18.1$ & $143.6 \pm 17.0$ & $149.9 \pm 22.3$ \\
\hline Diastolic blood pressure $(\mathrm{mmH})$ & $84.0 \pm 9.1$ & $84.1 \pm 8.3$ & $83.9 \pm 9.6$ & $84.2 \pm 8.9$ & $83.3 \pm 8.7$ & $84.4 \pm 11.9$ \\
\hline Pulse rate $(\mathrm{bpm})$ & $65.1 \pm 8.8$ & $65.5 \pm 7.7$ & $64.9 \pm 9.4$ & $64.6 \pm 8.6$ & $65.8 \pm 9.1$ & $66.9 \pm 9.4$ \\
\hline Left ventricular mass index $\left(\mathrm{g} / \mathrm{m}^{2.7}\right)$ & $46.1 \pm 10.0$ & $46.5 \pm 11.0$ & $45.9 \pm 9.5$ & $45.0 \pm 9.6$ & $49.3 \pm 10.4$ & $46.3 \pm 10.7$ \\
\hline LDL cholesterol $(\mathrm{mmol} / \mathrm{l})$ & $3.90 \pm 0.83$ & $3.88 \pm 0.89$ & $3.91 \pm 0.80$ & $3.93 \pm 0.85$ & $3.89 \pm 0.74$ & $3.73 \pm 0.90$ \\
\hline HDL cholesterol $(\mathrm{mmol} / \mathrm{l})$ & $\mathrm{I} .3 \mathrm{I} \pm 0.36$ & $1.28 \pm 0.36$ & $1.32 \pm 0.36$ & $1.33 \pm 0.36$ & $1.26 \pm 0.36$ & $1.28 \pm 0.3 \mid$ \\
\hline Triglycerides $(\mathrm{mmol} / \mathrm{l})$ & $1.27(0.88-1.70)$ & $1.45(0.97-1.90)^{\mathrm{a}}$ & $1.19(0.85-1.60)^{\mathrm{a}}$ & $1.21(0.84-1.65)$ & $1.28(1.01-1.86)$ & $1.46(1.13-1.84)$ \\
\hline Fasting glucose $(\mathrm{mmol} / \mathrm{l})^{*}$ & $5.4(5.0-5.9)$ & $5.4(5.1-6.0)^{\mathrm{a}}$ & $5.40(5.0-5.9)^{\mathrm{a}}$ & $5.4(5.0-5.8)^{\mathrm{a}}$ & $5.4(5.0-6.0)$ & $5.4(5.2-7.0)^{\mathrm{a}}$ \\
\hline 2-h oral glucose tolerance test $(\mathrm{mmol} / \mathrm{l})^{*}$ & $7.2(5.6-9.1)$ & $7.6(6.2-9.9)^{\mathrm{a}}$ & $6.7(5.4-8.6)^{\mathrm{a}}$ & $7.2(5.6-9.0)^{\mathrm{a}}$ & $6.8(5.6-8.7)$ & $7.9(6.0-12.0)^{\mathrm{a}}$ \\
\hline Glucose disposal rate $(\mathrm{mg} / \mathrm{kg} / \mathrm{min})^{*}$ & $5.27 \pm 1.96$ & $4.82 \pm 1.94^{\mathrm{a}}$ & $5.53 \pm 1.93^{\mathrm{a}}$ & $5.50 \pm 1.96^{\mathrm{a}}$ & $4.91 \pm 1.72$ & $4.5 \pm 2.25^{\mathrm{a}}$ \\
\hline C-reactive protein $(\mathrm{mg} /)^{*}$ & $1.79(0.92-3.77)$ & $1.87(1.07-4.06)$ & $1.63(0.86-3.55)$ & $1.81(0.88-3.90)$ & $1.65(0.96-3.13)$ & $1.79(0.99-4.24)$ \\
\hline Alpha tocopherol (mg/mmol) & $1.58 \pm 0.27$ & $1.52 \pm 0.28^{\mathrm{a}}$ & $1.61 \pm 0.26^{\mathrm{a}}$ & $1.58 \pm 0.28$ & $1.56 \pm 0.22$ & $1.57 \pm 0.29$ \\
\hline Interleukin-6 (ng/l)* & $3.53(2.21-5.84)$ & $3.61(2.28-6.29)$ & $3.41(2.14-5.73)$ & $3.22(2.10-5.65)$ & $4.04(2.65-6.89)$ & $4.41(2.52-7.19)$ \\
\hline Fibrinogen $(g / l)^{*}$ & $3.55(3.20-3.94)$ & $3.53(3.10-4.22)$ & $3.59(3.27-3.90)$ & $3.48(3.15-3.93)$ & $3.60(3.27-4.28)$ & $3.68(3.32-4.22)$ \\
\hline Diabetes & $69(14.8)$ & $35(20.5)^{\mathrm{a}}$ & $34(11.5)^{\mathrm{a}}$ & $40(12.5)^{\mathrm{a}}$ & $17(15.9)^{\mathrm{a}}$ & $12(30.0)^{\mathrm{a}}$ \\
\hline Antihypertensive drug treatment & $133(28.7)$ & $49(28.8)$ & $84(28.6)$ & $89(28.0)$ & $33(31.1)$ & II (27.5) \\
\hline Antidiabetic drug treatment & $18(4.0)$ & $9(5.6)$ & $9(3.1)$ & $7(2.3)^{\mathrm{a}}$ & $8(7.8)^{\mathrm{a}}$ & $3(7.5)^{\mathrm{a}}$ \\
\hline Lipid-lowering drug treatment & $32(7.1)$ & II (6.8) & $21(7.2)$ & $24(7.8)$ & $5(4.9)$ & $3(7.5)$ \\
\hline \multicolumn{7}{|l|}{ Smoking } \\
\hline Never-smoking & I54 (33.0) & $49(28.7)$ & $105(35.6)$ & $112(35.1)^{\mathrm{a}}$ & $32(29.9)^{\mathrm{a}}$ & $10(25.0)^{\mathrm{a}}$ \\
\hline Low previous smoking (<33 pack-years) & $126(27.0)$ & $47(27.5)$ & $79(26.8)$ & $86(27.0)^{\mathrm{a}}$ & $31(29.0)^{\mathrm{a}}$ & $9(22.5)^{\mathrm{a}}$ \\
\hline High previous smoking ( $\geq 33$ pack-years) & $90(19.3)$ & $33(19.3)$ & $57(19.3)$ & $68(21.3)^{\mathrm{a}}$ & $15(14.0)^{\mathrm{a}}$ & $7(17.5)^{\mathrm{a}}$ \\
\hline Current smoking & $96(20.6)$ & $42(24.6)$ & $54(18.3)$ & $53(16.6)^{\mathrm{a}}$ & $29(27.1)^{\mathrm{a}}$ & $14(35.0)^{\mathrm{a}}$ \\
\hline \multicolumn{7}{|l|}{ Alcohol use } \\
\hline Teetotallers & $89(20.6)$ & $40(24.5)$ & $49(18.2)^{\mathrm{a}}$ & $62(21.0)$ & $19(18.8)$ & $8(22.2)$ \\
\hline Moderate users ( $<15$ units/week) & $323(74.6)$ & $114(70.0)$ & $209(77.4)^{\mathrm{a}}$ & $218(73.7)$ & $80(79.2)$ & $25(69.4)$ \\
\hline Heavy users ( $\geq 15$ units/week) & $21(4.9)$ & $9(5.52)$ & $12(4.4)$ & $16(5.4)$ & $2(2.0)$ & $3(8.3)$ \\
\hline \multicolumn{7}{|l|}{$\begin{array}{l}\text { Occupational classification } \\
\text { by age of } 50 \text { years }\end{array}$} \\
\hline High & $78(16.8)$ & $25(14.7)$ & $53(18.0)$ & $56(17.6)$ & $15(14.2)$ & $7(17.5)$ \\
\hline Middle & $176(37.9)$ & $65(38.2)$ & $111(37.6)$ & $115(36.1)$ & $46(43.4)$ & $15(37.5)$ \\
\hline Low & $211(45.4)$ & $80(47.1)$ & $|3|(44.4)$ & $148(46.4)$ & $45(42.5)$ & $18(45.0)$ \\
\hline Physically active & $295(63.3)$ & & & $206(64.6)$ & $70(65.4)$ & $19(47.5)$ \\
\hline \multicolumn{7}{|l|}{ Muscle fibre distribution } \\
\hline Type-I proportion (\%) & $48.4 \pm 15.7$ & $46.0 \pm 15.1^{\mathrm{a}}$ & $49.9 \pm 15.9^{\mathrm{a}}$ & $56.2 \pm 11.8$ & $31.9 \pm 8.8$ & $31.2 \pm 7.0$ \\
\hline Type-lla (\%) & $30.9 \pm 13.1$ & $31.4 \pm 12.6$ & $30.7 \pm 13.4$ & $25.9 \pm 9.4$ & $48.4 \pm 8.4$ & $23.9 \pm 7.1$ \\
\hline Type-IIx (\%) & $20.6 \pm 12.3$ & $22.6 \pm 12.5^{\mathrm{a}}$ & $19.5 \pm 12.0^{\mathrm{a}}$ & $17.9 \pm 10.0$ & $19.7 \pm 10.2$ & $44.9 \pm 6.6$ \\
\hline \multicolumn{7}{|l|}{ Dominant muscle fibre type } \\
\hline Dominant type-I & $319(68.5)$ & $113(66.1)$ & $206(69.8)$ & & & \\
\hline Dominant type-lla & $107(23.0)$ & $37(21.6)$ & $70(23.7)$ & & & \\
\hline Dominant type-IIx & $40(8.6)$ & $21(12.3)^{\mathrm{a}}$ & $19(6.4)^{\mathrm{a}}$ & & & \\
\hline
\end{tabular}

Data are mean $\pm S D$, median (IQR) for skewed variables*, or $n(\%)$.

a $p<0.05$ for differences between groups.

'Occupational classification: Low (labourers, service workers, operatives, salaried craftsmen), Middle (clerical and sales workers, foremen, selfemployed craftsmen, small business proprietors, nurses, elementary school teachers), High (other professionals and academically trained persons. high officials, proprietors and managers of large business and industry). 
A

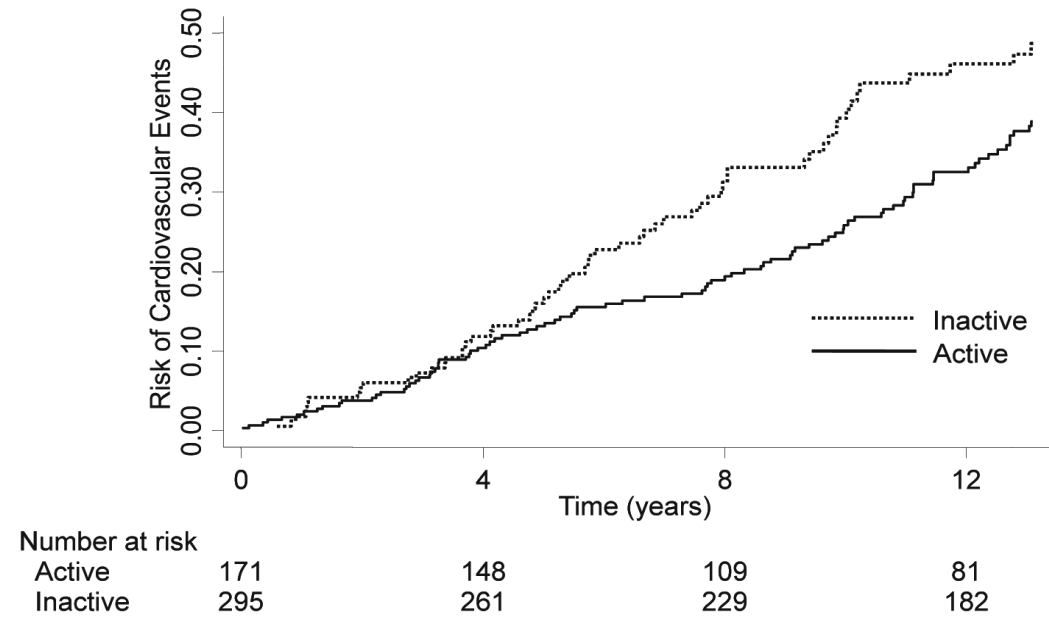

B

Dominant Muscle Fiber Type

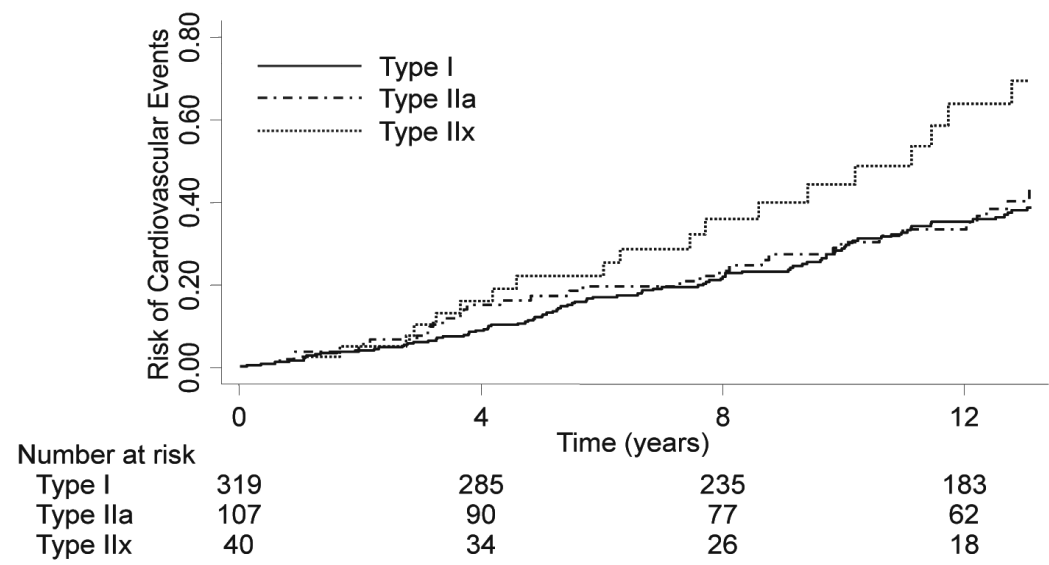

Figure 5. Cumulative incidence of cardiovascular events by levels of physical activity (A) and dominant muscle fibre type (B). 


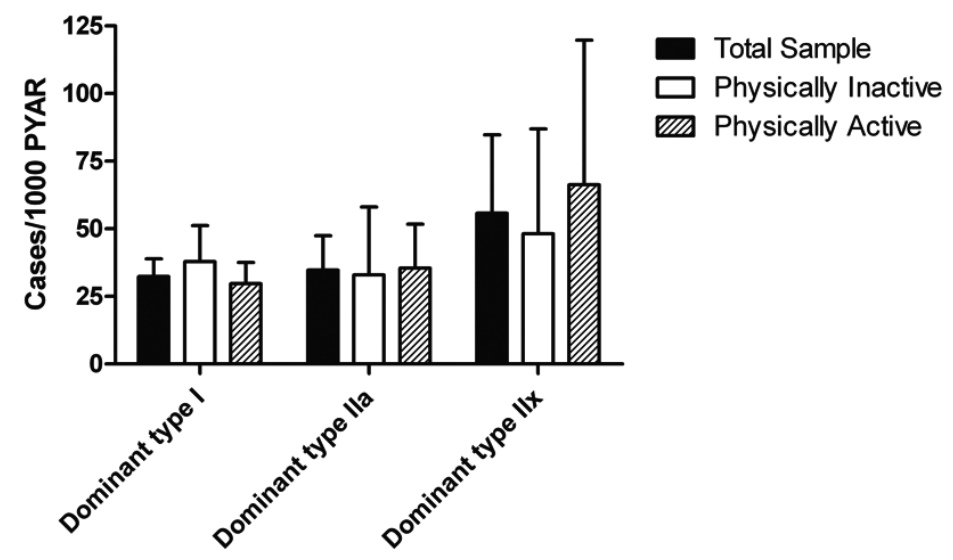

Figure 6. Incidence rates of cardiovascular events - by combinations of levels of physical activity and dominant muscle fibre type. PYAR: person-years at risk.

\section{Muscle morphology and risk of cardiovascular events by physical activity level}

Because the relation of muscle morphology to risk of cardiovascular events was hypothesized to vary by physical activity level, we a priori stratified the sample into physically active and inactive persons. An interaction term of the product of physical activity and dominant muscle fibre group was of borderline statistical significance $(\mathrm{p}=0.09)$. In physically inactive men, we observed no associations of muscle fibre composition with rate of cardiovascular events in any model (Figure 7A). In contrast, the associations of muscle fibre composition to rate of cardiovascular events observed in the total sample were more pronounced among physically active men. In ageadjusted models $\mathrm{A}$ in physically active men, $10 \%$ higher proportion of type-I fibres was associated with a HR of 0.84 [95\% CI 0.74-0.95] for cardiovascular events, and $10 \%$ higher proportion of type-IIx was associated with a HR of 1.24 [95\% CI 1.06-1.45] for cardiovascular events (similar results were observed in models B-H) (figure 7A).

In the physically active, the rate of cardiovascular events among type-IIx dominant men was higher than that in type-I dominant men (HR $2.68[95 \%$ CI 1.41-5.09] in model A with almost identical results in models B-H. TypeIIa dominant men had intermediate risk of cardiovascular events (Figure 7B). 


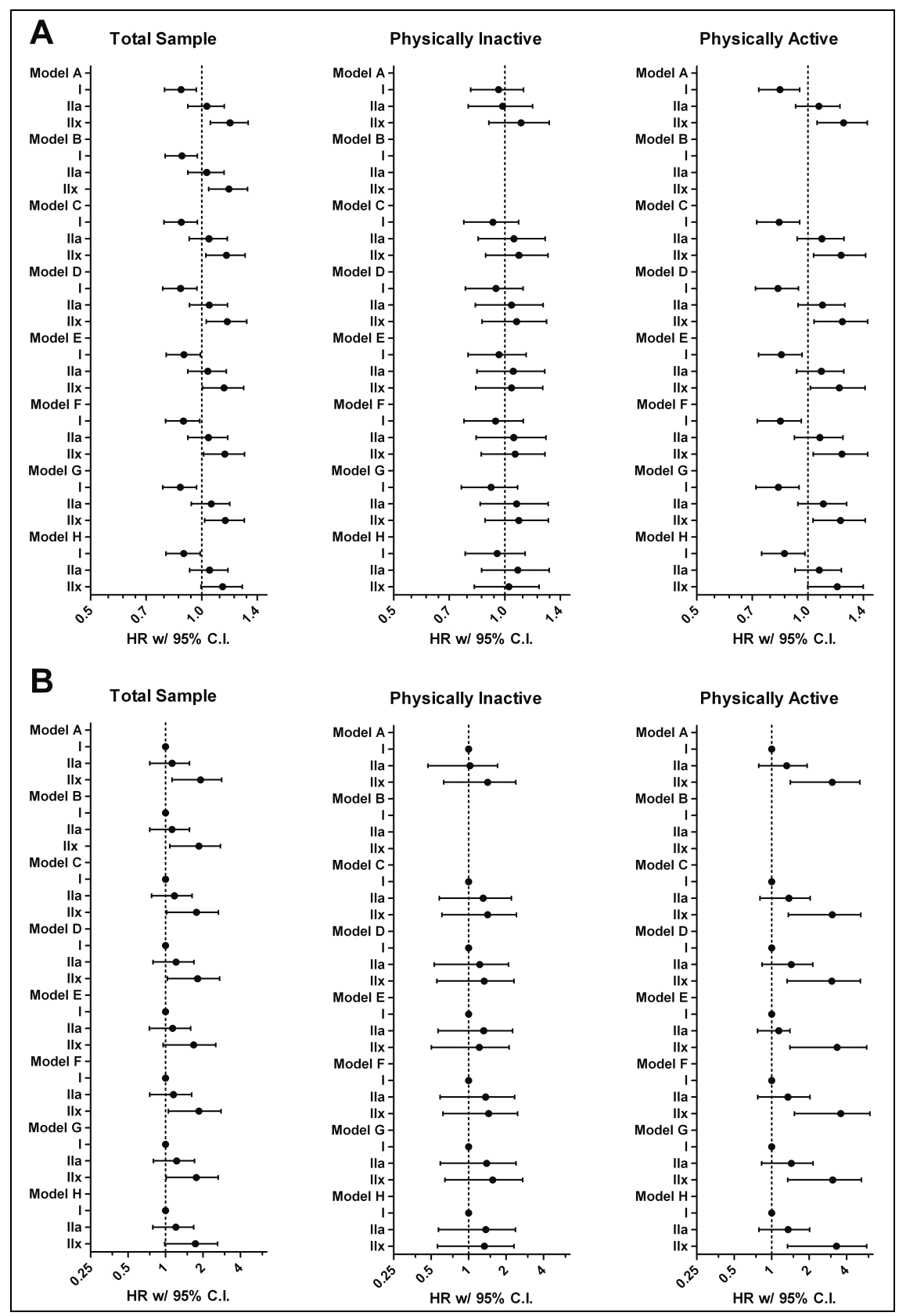


- Figure 7. Risk of cardiovascular events by muscle fibre composition Panel A: Risk of cardiovascular events per $10 \%$ higher proportion of muscle fibre type (I, IIa, IIx). Panel B: Risk of cardiovascular events by groups of dominant muscle fibre type, vs. those with type-I as dominant fibre type. Results are hazard ratios HR (95\% confidence intervals). Models A: Age-adjusted; B: Adjusted for physical activity; C: As model B + SES variables; D: As model C + lipid variables; E: As model $\mathrm{C}+$ glucometabolic variables; $\mathrm{F}$ : As model $\mathrm{C}+$ hemodynamic variables; $\mathrm{G}$ : As model $\mathrm{C}+$ inflammation and oxidative stress variables; $\mathrm{H}$ : As model $\mathrm{C}+$ variables representing all pathways $\mathrm{C}-\mathrm{G}$. Models stratified by physical activity level were not adjusted for physical activity.

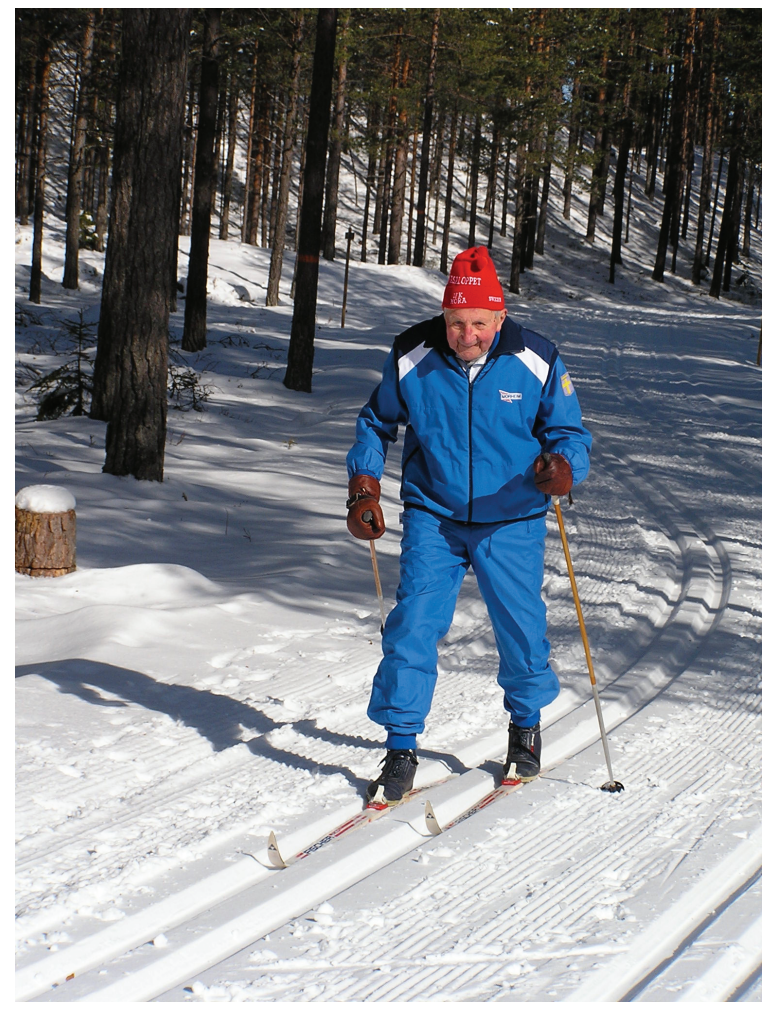

Figure 8. Physical activity is important - also at an older age. Photo: Vasaloppet. 


\section{High levels of total- and leisure time physical activity is associated with lower risk of heart failure (Study II)}

Of 39,805 participants in the National March Cohort, 1,545 had a first hospitalization due to heart failure of any cause during a median follow-up of 13.3 years (497,593 person-years at risk). In the subsample of 39,212 participants without a history of myocardial infarction before baseline, 1,033 experienced non-ischemic (without preceding or concurrent myocardial infarction) heart failure during 486,092 person-years at risk. Compared to participants who did not develop heart failure during follow-up, those who did, were generally older, more often males, had lower level of education, higher BMI and waist-hip ratio and had a higher prevalence of previous myocardial infarction, diabetes, hypertension and lipid disturbances (Table 4).

\section{Leisure-time physical activity}

Median leisure-time physical activity was 2.6 METh/day (IQR 1.3-4.1). Crude models showed lower rates of heart failure of any cause with increasing level of leisure-time physical activity (Table 5). The total effect was similar, and the direct effect slightly smaller. For non-ischemic heart failure, the crude, total and direct effects of leisure-time physical activity were similar to those seen for heart failure of any cause (Table 5). Spline models indicated a diminishing risk of heart failure with increasing leisure-time physical activity up to approximately $3 \mathrm{METh}$ /day (equals the three highest quintiles), above which the curve levelled off (Figure 9). Similar results were observed among participants without previous cardiovascular disease or cardinal symptoms of heart disease (Table 7).

\section{Total physical activity}

Median total physical activity was 36.1 METh/day (IQR 31.3-45.6). Crude models for heart failure of any cause showed a lower risk of heart failure from the first to the second quintile of total physical activity level. No further effect was seen in the higher quintiles (Table 6). Total effects were of similar magnitude, but the direct effect was considerably attenuated. For non-ischemic heart failure the crude and total effect models showed a lower risk of heart failure in the second to fourth quintiles compared to the first quintile, but a smaller effect in the fifth quintile. The direct effect was attenuated (Table 6). Spline models confirmed the highest incidence of heart failure among those with very low total physical activity ( $<30 \mathrm{METh} /$ day). Above $30 \mathrm{METh} /$ day, the curve levelled off (Figure 9). In participants without previous cardiovascular disease or cardinal symptoms of heart disease, no substantial association of total physical activity with risk of heart failure was observed (Table 8). 


\begin{tabular}{|c|c|c|c|c|}
\hline & \multicolumn{2}{|c|}{ Total Sample } & \multicolumn{2}{|c|}{ Without previous myocardial infarction } \\
\hline & $\begin{array}{l}\text { No HF } \\
(n=38,260)\end{array}$ & $\begin{array}{l}\text { HF of any cause } \\
(n=1,545)\end{array}$ & $\begin{array}{c}\text { No HF } \\
(n=38,179)\end{array}$ & $\begin{array}{c}\text { Non-ischemic HF } \\
(n=1,033)\end{array}$ \\
\hline Mean age at entry (SD) & $52.2(14.7)$ & $70.3(8.7)$ & $52.2(14.7)$ & $70.1(9.0)$ \\
\hline \multicolumn{5}{|l|}{ Age classes, $\mathrm{n}(\%)$} \\
\hline $20-30$ & $3,540(9.3)$ & $3(0.2)$ & $3,540(9.3)$ & $3(0.3)$ \\
\hline $30-40$ & $4,850(12.7)$ & $5(0.3)$ & $4,851(12.7)$ & $4(0.4)$ \\
\hline $40-50$ & $7,683(20.1)$ & 30 (1.9) & $7,677(20.1)$ & $23(2.2)$ \\
\hline $50-60$ & $9,434(24.7)$ & $137(8.9)$ & $9,399(24.6)$ & $91(8.8)$ \\
\hline $60-70$ & $8,384(21.9)$ & $480(31.1)$ & $8,317(21.8)$ & $321(31.1)$ \\
\hline $70-95$ & $4,369(11.4)$ & $890(57.6)$ & 4,395 (11.5) & $591(57.2)$ \\
\hline Males, n (\%) & $12,959(33.9)$ & 879 (56.9) & $12,831(33.6)$ & $535(51.8)$ \\
\hline Smoking at baseline, $\mathbf{n}(\%)$ & $2,745(7.8)$ & $73(5.5)$ & $2,750(7.8)$ & $50(5.6)$ \\
\hline \multicolumn{5}{|l|}{ Pack-years, n (\%) } \\
\hline None & $16,862(49.9)$ & $529(44.0)$ & $16,879(50.0)$ & $358(44.4)$ \\
\hline$<4.75$ & $5,788(17.1)$ & $153(12.7)$ & $5,771(17.1)$ & $110(13.7)$ \\
\hline $4.75-13.5$ & $5,619(16.6)$ & $210(17.5)$ & $5,602(16.6)$ & $(16.3)$ \\
\hline$>13.5$ & $5,547(16.4)$ & $311(25.9)$ & $5,477(16.2)$ & $207(25.7)$ \\
\hline Snuff users, $\mathrm{n}(\%)$ & $3,416(10.1)$ & $103(7.8)$ & $3,392(10.0)$ & $62(7.1)$ \\
\hline \multicolumn{5}{|l|}{ Alcohol use, $n$ (\%) } \\
\hline None & $4,795(12.6)$ & $326(21.4)$ & $4,806(12.7)$ & $222(21.9)$ \\
\hline$<4.2$ grams/day & $11,079(29.1)$ & $419(27.6)$ & $11,077(29.2)$ & $269(26.5)$ \\
\hline 4.2-11.7 grams/day & $11,089(29.1)$ & $385(25.3)$ & $11,056(29.1)$ & $257(25.4)$ \\
\hline$>11.7$ grams/day & $11,095(29.2)$ & $391(25.7)$ & $11,037(29.1)$ & $266(26.2)$ \\
\hline \multicolumn{5}{|l|}{ Education, $\mathrm{n}(\%)$} \\
\hline $7-9$ years & $15,008(40.0)$ & $947(63.6)$ & $14,955(39.9)$ & $644(64.7)$ \\
\hline $10-12$ years & $11,332(30.2)$ & $349(23.5)$ & $11,309(30.2)$ & $217(21.8)$ \\
\hline$>12$ years & $11,181(29.8)$ & $192(12.9)$ & $11,178(29.9)$ & $133(13.4)$ \\
\hline Mean Body Mass Index, BMI (SD) & $24.68(3.5)$ & $25.68(3.5)$ & $24.68(3.5)$ & $25.75(3.6)$ \\
\hline \multicolumn{5}{|l|}{ BMI kg/m², n (\%) } \\
\hline$<20$ & $1,988(5.4)$ & $44(3.1)$ & $1,994(5.5)$ & $28(2.9)$ \\
\hline $20-25$ & $19,780(54.0)$ & $612(42.5)$ & $19,740(54.0)$ & $415(43.0)$ \\
\hline $25-30$ & $12,137(33.2)$ & $642(44.6)$ & $12,113(33.2)$ & $415(43.0)$ \\
\hline$>30$ & $2,712(7.4)$ & $141(9.8)$ & $2,691(7.4)$ & $107(11.1)$ \\
\hline Mean waist-hip ratio (SD) & $0.85(0.1)$ & $0.90(0.1)$ & $0.85(0.1)$ & $0.90(0.1)$ \\
\hline Previous myocardial infarction, $n$ (\%) & $449(1.2)$ & $144(9.3)$ & -- & -- \\
\hline Hypertension, n (\%) & $4,782(13.0)$ & $539(38.6)$ & 4,738 (12.9) & $331(35.6)$ \\
\hline Diabetes, n (\%) & $894(2.5)$ & $151(11.1)$ & $901(2.5)$ & $87(9.6)$ \\
\hline Lipid disturbance, $\mathrm{n}(\%)$ & $1,360(3.8)$ & $170(13.2)$ & $1,216(3.4)$ & $83(9.7)$ \\
\hline \multicolumn{5}{|l|}{ Total daily PA , n (\%) } \\
\hline$<30.3 \mathrm{METh} /$ day & $6,830(19.7)$ & $344(27.2)$ & $6,842(19.8)$ & $231(27.6)$ \\
\hline 30.3-33.6 METh/day & $6,990(20.2)$ & $185(14.7)$ & $6,953(20.1)$ & $119(14.2)$ \\
\hline 33.6-38.5 METh/day & $6,962(20.1)$ & $210(16.6)$ & $6,930(20.1)$ & $144(17.2)$ \\
\hline 38.5-47.8 METh/day & $6,944(20.1)$ & $230(18.2)$ & $6,936(20.1)$ & $135(16.1)$ \\
\hline$>47.8 \mathrm{METh} /$ day & 6,879 (19.9) & $294(23.3)$ & 6,863 (19.9) & 209 (24.9) \\
\hline \multicolumn{5}{|l|}{ Leisure time PA , $\mathbf{n}(\%)$} \\
\hline$<0.9 \mathrm{METh} /$ day & $8,254(21.6)$ & $475(30.7)$ & $8,223(21.5)$ & $331(32.0)$ \\
\hline 0.9-1.6 METh/day & $6,887(18.0)$ & $334(21.6)$ & $7,257(19.0)$ & $217(21.0)$ \\
\hline 1.6-2.6 METh/day & $9,290(24.3)$ & $386(25.0)$ & $8,872(23.2)$ & $255(24.7)$ \\
\hline 2.6-3.9 METh/day & $6,302(16.5)$ & $174(11.3)$ & $6,312(16.5)$ & $110(10.7)$ \\
\hline > $3.9 \mathrm{METh} /$ day & $7,527(19.7)$ & $176(11.4)$ & 7,515 (19.7) & $120(11.6)$ \\
\hline
\end{tabular}

HF: Heart Failure; METh: metabolic equivalent turnover hours; SD: Standard deviation 
A. Total Physical Activty

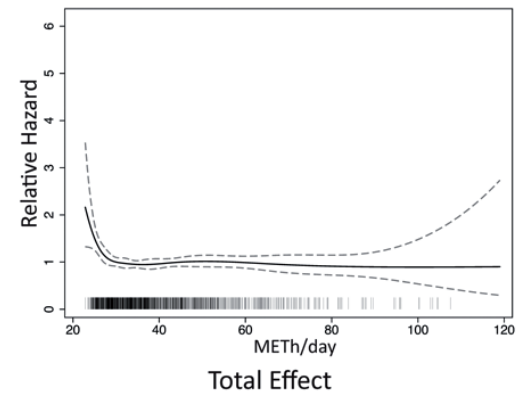

\section{B. Leisure Time Physical Activity}

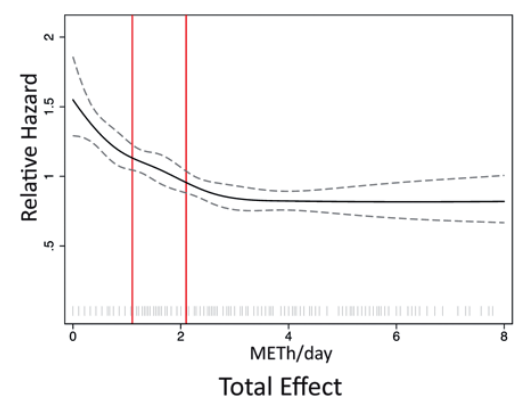

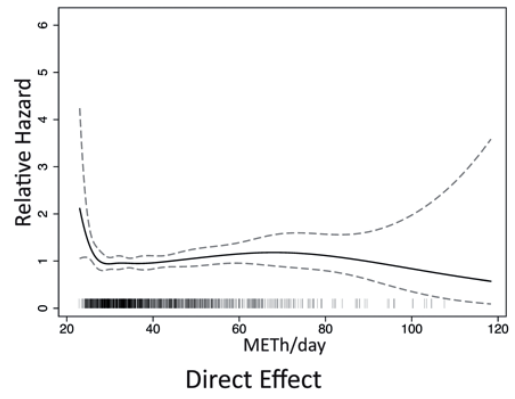

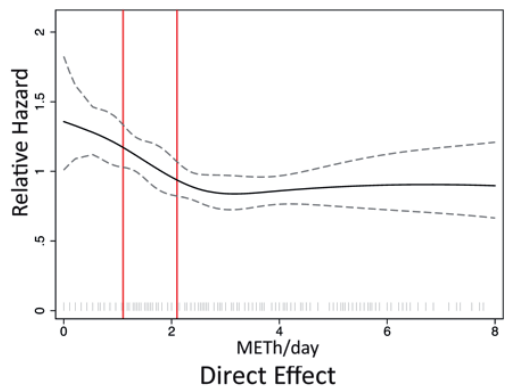

Figure 9. Spline plots of dose-response associations of total and leisure-time physical activity with risk of heart failure of any cause. Spike plots (in the bottom of the graphs) illustrate the distribution of cases in the sample. Similar associations were observed with non-ischemic heart failure. Note the different axes. Red lines (leisuretime physical activity) indicate the interval of the World Health Organization recommendations of leisure-time physical. 
Table 5. Risk of heart failure by level of leisure-time physical activity

\begin{tabular}{|c|c|c|c|c|}
\hline \multirow[b]{2}{*}{ Quintile } & \multicolumn{4}{|c|}{ Heart failure of any cause } \\
\hline & METh/day & Crude effect & Total Effect* & Direct effect ${ }^{\#}$ \\
\hline $1^{\text {st }}$ & $<1.2$ & 1 (ref) & 1 (ref) & 1 (ref) \\
\hline $2^{\text {nd }}$ & $1.2-1.9$ & $0.86(0.73-1.02)$ & $0.89(0.75-1.05)$ & $0.93(0.79-1.09)$ \\
\hline $3^{\text {rd }}$ & $1.9-3.0$ & $0.70(0.59-0.83)$ & $0.72(0.61-0.84)$ & $0.79(0.67-0.94)$ \\
\hline $4^{\text {th }}$ & $3.0-4.7$ & $0.61(0.50-0.74)$ & $0.63(0.52-0.77)$ & $0.73(0.60-0.89)$ \\
\hline \multirow[t]{3}{*}{$5^{\text {th }}$} & $>4.7$ & $0.52(0.42-0.63)$ & $0.54(0.44-0.66)$ & $0.65(0.53-0.81)$ \\
\hline & P-value for trend & $<0.01$ & $<0.01$ & $<0.01$ \\
\hline & \multicolumn{4}{|c|}{ Non-ischemic heart failure } \\
\hline Quintile & METh/day & Crude effect & Total effect* & Direct effect $\#$ \\
\hline $1^{\text {st }}$ & $<1.2$ & 1 (ref) & 1 (ref) & 1 (ref) \\
\hline $2^{\text {nd }}$ & $1.2-1.9$ & $0.78(0.63-0.96)$ & $0.79(0.64-0.97)$ & $0.83(0.67-1.03)$ \\
\hline $3^{\text {rd }}$ & $1.9-3.0$ & $0.72(0.59-0.87)$ & $0.72(0.59-0.87)$ & $0.80(0.66-0.98)$ \\
\hline $4^{\text {th }}$ & $3.0-4.7$ & $0.56(0.45-0.69)$ & $0.56(0.45-0.70)$ & $0.66(0.53-0.81)$ \\
\hline \multirow[t]{2}{*}{$5^{\text {th }}$} & $>4.7$ & $0.50(0.40-0.63)$ & $0.51(0.40-0.64)$ & $0.61(0.48-0.78)$ \\
\hline & P-value for trend & $<0.01$ & $<0.01$ & $<0.01$ \\
\hline
\end{tabular}

$\wedge$ Adjusted for age and sex; *Adjusted for age, sex, education and previous myocardial infarction; "Adjusted for age, sex, alcohol use, BMI, diabetes, hypertension, myocardial infarction during follow-up, previous myocardial infarction, smoking, snuff use and waist hip ratio; METh: Metabolic energy turnover hours

Table 6. Risk of heart failure by level of total physical activity

\begin{tabular}{lllll}
\hline Quintile & Heart failure of any cause & & \\
& METh/day & Crude effect & Total effect* & Direct effect \\
\hline & & & & \\
\hline $1^{\text {st }}$ & $<30.5$ & 1 (ref) & 1 (ref) & 1 (ref) \\
$2^{\text {nd }}$ & $30.5-33.9$ & $0.79(0.65-0.95)$ & $0.79(0.65-0.95)$ & $0.82(0.68-1.00)$ \\
$3^{\text {rd }}$ & $33.9-39.1$ & $0.78(0.65-0.94)$ & $0.80(0.67-0.97)$ & $0.87(0.72-1.04)$ \\
$4^{\text {th }}$ & $39.1-48.7$ & $0.78(0.65-0.93)$ & $0.79(0.66-0.94)$ & $0.87(0.73-1.05)$ \\
$5^{\text {th }}$ & $>48.7$ & $0.81(0.69-0.95)$ & $0.81(0.69-0.95)$ & $0.90(0.76-1.06)$ \\
& P-value for trend & 0.08 & 0.08 & 0.59 \\
\hline & Non-ischemic heart failure & & & \\
Quintile $^{\text {th }}$ & METh/day & Crude effect & Total effect* & Direct effect \\
\hline $1^{\text {st }}$ & $<30.5$ & $1($ ref $)$ & $1($ ref $)$ & 1 (ref) \\
$2^{\text {nd }}$ & $30.5-33.9$ & $0.80(0.63-1.01)$ & $0.81(0.63-1.02)$ & $0.84(0.66-1.07)$ \\
$3^{\text {rd }}$ & $33.9-39.1$ & $0.79(0.64-0.99)$ & $0.79(0.64-0.99)$ & $0.87(0.70-1.09)$ \\
$4^{\text {th }}$ & $39.1-48.7$ & $0.77(0.62-0.95)$ & $0.76(0.61-0.94)$ & $0.86(0.69-1.06)$ \\
$5^{\text {th }}$ & $>48.7$ & $0.89(0.73-1.09)$ & $0.87(0.72-1.06)$ & $0.98(0.80-1.19)$ \\
& P-value for trend & 0.66 & 0.48 & 0.77 \\
\hline
\end{tabular}

$\wedge$ Adjusted for age and sex; *Adjusted for age, sex, education and previous myocardial infarction; "Adjusted for age, sex, alcohol use, BMI, diabetes, hypertension, myocardial infarction during follow-up, previous myocardial infarction, smoking, snuff use and waist hip ratio; METh: Metabolic energy turnover hours 
Table 7. Risk of heart failure by level of leisure-time physical activity in participants without symptoms of or known heart disease

\begin{tabular}{|c|c|c|c|c|}
\hline \multirow[b]{2}{*}{ Quintile } & \multicolumn{4}{|c|}{ Heart failure of any cause } \\
\hline & METh/day & Crude effect & Total Effect* & Direct effect ${ }^{\#}$ \\
\hline $1^{\text {st }}$ & $<1.2$ & 1 (ref) & 1 (ref) & 1 (ref) \\
\hline $2^{\text {nd }}$ & $1.2-1.9$ & $0.75(0.59-0.95)$ & $0.75(0.59-0.96)$ & $0.79(0.61-1.02)$ \\
\hline $3^{\text {rd }}$ & $1.9-3.0$ & $0.69(0.56-0.85)$ & $0.69(0.56-0.85)$ & $0.74(0.60-0.91)$ \\
\hline $4^{\text {th }}$ & $3.0-4.7$ & $0.66(0.52-0.83)$ & $0.66(0.53-0.83)$ & $0.73(0.58-0.93)$ \\
\hline \multirow[t]{3}{*}{$5^{\text {th }}$} & $>4.7$ & $0.53(0.41-0.69)$ & $0.53(0.41-0.69)$ & $0.62(0.48-0.80)$ \\
\hline & P-value for trend & $<0.01$ & $<0.01$ & $<0.01$ \\
\hline & \multicolumn{4}{|c|}{ Non-ischemic heart failure } \\
\hline Quintile & METh/day & Crude effect & Total effect* & Direct effect ${ }^{\#}$ \\
\hline $1^{\text {st }}$ & $<1.2$ & 1 (ref) & 1 (ref) & 1 (ref) \\
\hline $2^{\text {nd }}$ & $1.2-1.9$ & $0.69(0.51-0.93)$ & $0.69(0.51-0.94)$ & $0.73(0.53-0.99)$ \\
\hline $3^{\text {rd }}$ & $1.9-3.0$ & $0.74(0.57-0.95)$ & $0.74(0.56-0.95)$ & $0.80(0.62-1.02)$ \\
\hline $4^{\text {th }}$ & $3.0-4.7$ & $0.64(0.50-0.82)$ & $0.65(0.50-0.83)$ & $0.72(0.56-0.93)$ \\
\hline \multirow[t]{2}{*}{$5^{\text {th }}$} & $>4.7$ & $0.50(0.36-0.69)$ & $0.50(0.36-0.69)$ & $0.58(0.42-0.79)$ \\
\hline & P-value for trend & $<0.01$ & $<0.01$ & $<0.01$ \\
\hline
\end{tabular}

$\wedge$ Adjusted for age and sex; *Adjusted for age, sex, education and previous myocardial infarction; ${ }^{\#}$ Adjusted for age, sex, alcohol use, BMI, diabetes, hypertension, myocardial infarction during follow-up, previous myocardial infarction, smoking, snuff use and waist hip ratio METh: Metabolic energy turnover hours

Table 8. Risk of heart failure by level of total physical activity in participants without symptoms of or known heart disease

\begin{tabular}{|c|c|c|c|c|}
\hline & Heart failure of any cause & & & \\
\hline Quintile & METh/day & Crude effect & Total effect* & Direct effect ${ }^{\#}$ \\
\hline $1^{\text {st }}$ & $<30.5$ & 1 (ref) & 1 (ref) & 1 (ref) \\
\hline $2^{\text {nd }}$ & $30.5-33.9$ & $0.93(0.71-1.21)$ & $0.93(0.71-1.22)$ & $0.98(0.75-1.28)$ \\
\hline $3^{\text {rd }}$ & 33.9-39.1 & $0.88(0.67-1.14)$ & $0.87(0.67-1.14)$ & $0.95(0.73-1.24)$ \\
\hline $4^{\text {th }}$ & $39.1-48.7$ & $0.91(0.71-1.17)$ & $0.90(0.70-1.16)$ & $1.03(0.79-1.33)$ \\
\hline \multirow[t]{3}{*}{$5^{\text {th }}$} & $>48.7$ & $1.09(0.86-1.36)$ & $1.06(0.84-1.33)$ & $1.21(0.95-1.52)$ \\
\hline & P-value for trend & 0.26 & 0.39 & 0.06 \\
\hline & Non-ischemic heart failure & & & \\
\hline Quintile & METh/day & Crude effect & Total effect* & Direct effect ${ }^{\#}$ \\
\hline $1^{\text {st }}$ & $<30.5$ & 1 (ref) & 1 (ref) & 1 (ref) \\
\hline $2^{\text {nd }}$ & $30.5-33.9$ & $1.00(0.74-1.35)$ & $1.00(0.74-1.35)$ & $1.05(0.78-1.42)$ \\
\hline $3^{\text {rd }}$ & $33.9-39.1$ & $0.84(0.61-1.15)$ & $0.83(0.61-1.14)$ & $0.91(0.66-1.25)$ \\
\hline $4^{\text {th }}$ & $39.1-48.7$ & $0.96(0.71-1.28)$ & $0.95(0.71-1.27)$ & $1.07(0.79-1.44)$ \\
\hline \multirow[t]{2}{*}{$5^{\text {th }}$} & $>48.7$ & $1.21(0.93-1.58)$ & $1.18(0.90-1.54)$ & $1.32(1.01-1.73)$ \\
\hline & P-value for trend & 0.07 & 0.11 & 0.02 \\
\hline
\end{tabular}

$\wedge$ Adjusted for age and sex; *Adjusted for age, sex, education and previous myocardial infarction; ${ }^{\#}$ Adjusted for age, sex, alcohol use, BMI, diabetes, hypertension, myocardial infarction during follow-up, previous myocardial infarction, smoking, snuff use and waist hip ratio METh: Metabolic energy turnover hours 


\section{Performance and numbers of participations in Vasaloppet are associated with higher risk of arrhythmias (Study III)}

Baseline characteristics of the participants in Vasaloppet 1989-98 are shown in Table 9. For the primary outcome (any arrhythmia) the median follow-up time was 9.7 years (minimum 0.01 years; maximum 16.8 years). Mean age at inclusion was 38.5 (SD 12.2) years, and mean age of first diagnosis was $56.8(\mathrm{SD} 13.5)$ years

Table 9. Baseline Characteristics

\begin{tabular}{|c|c|c|c|c|}
\hline & n skiers & $\mathbf{n}$ cases & Person-years at risk & $\begin{array}{c}\text { Incidence rate of the } \\
\text { primary outcome } \\
(95 \% \text { CI)/10,000 } \\
\text { PYAR }\end{array}$ \\
\hline Total Sample & 52,755 & 919 & 513,496 & $17.9(16.8-19.1)$ \\
\hline \multicolumn{5}{|l|}{ Age (years) } \\
\hline $15-24$ & 6,258 & 30 & 64,867 & $4.6(3.2-6.6)$ \\
\hline $25-34$ & 17,288 & 106 & 169,553 & $6.3(5.2-7.6)$ \\
\hline $35-44$ & 12,086 & 131 & 119,665 & $10.9(9.2-13.0)$ \\
\hline $45-54$ & 11,328 & 264 & 108,401 & $24.4(21.6-27.5)$ \\
\hline $55-64$ & 4,546 & 245 & 41,101 & $59.6(52.6-67.6)$ \\
\hline $65+$ & 1,249 & 143 & 10,962 & $130.4(110.7-153.7)$ \\
\hline \multicolumn{5}{|l|}{$\begin{array}{l}\text { Number of completed } \\
\text { races }\end{array}$} \\
\hline 1 & 27,515 & 393 & 287,873 & $13.7(12.4-15.1)$ \\
\hline 2 & 9,838 & 166 & 94,457 & $17.6(15.1-20.5)$ \\
\hline $3-4$ & 8,390 & 172 & 75,326 & $22.8(19.7-26.5)$ \\
\hline$\geq 5$ & 7,012 & 188 & 56,930 & $33.0(28.6-38.1)$ \\
\hline \multicolumn{5}{|l|}{$\begin{array}{l}\text { Finishing time (\% of } \\
\text { winner time) }\end{array}$} \\
\hline $100-160$ & 9,411 & 159 & 87,944 & $18.1(15.5-21.1)$ \\
\hline $161-200$ & 17,098 & 311 & 164,364 & $19.0(17.0-21.2)$ \\
\hline $201-240$ & 15,673 & 292 & 154,437 & $20.5(16.9-21.3)$ \\
\hline$>240$ & 10,573 & 157 & 107,804 & $14.9(12.5-17.0)$ \\
\hline \multicolumn{5}{|l|}{ Education level } \\
\hline Low & 11,215 & 250 & 108,798 & $23.0(20.3-26.0)$ \\
\hline Medium & 22,539 & 324 & 222,317 & $14.6(13.1-16.3)$ \\
\hline High & 15,929 & 299 & 155,832 & $19.2(17.1-21.5)$ \\
\hline \multicolumn{5}{|l|}{ Occupation } \\
\hline Blue-collar & 18,071 & 302 & 178,801 & $16.9(15.1-18.9)$ \\
\hline $\begin{array}{l}\text { Lower-middle White- } \\
\text { collar }\end{array}$ & 18,293 & 341 & 179,680 & $18.9(17.0-21.1)$ \\
\hline High White-collar & 7,292 & 176 & 70,361 & $24.9(21.5-28.9)$ \\
\hline Entrepreneur & 2,768 & 61 & 27,249 & $22.3(17.4-28.7)$ \\
\hline
\end{tabular}

CI, confidence interval; PYAR, person-years at risk. The incidence rate presented is that of the primary outcome any arrhythmias. 


\section{Any arrhythmias}

Among the 52,755 participants in Vasaloppet during the period 1989-98919 cases of arrhythmia were reported (incidence rate: 17.9; 95\% CI 16.819.1/10,000 PYAR; total PYAR 513,496). Cumulative incidence of arrhythmias by number of completed races and finishing time is shown in Figure 10. Adjusting for age, education and occupational status, we observed higher incidence of arrhythmias with increasing number of races (HR 1.30; 95\% CI $1.08-1.58$; for $\geq 5$ vs. 1 completed races) and by faster finishing time (HR 1.30; 95\% CI 1.04-1.62; for $100-160 \%$ vs. $>240 \%$ of winning time) (Figure 11). Treating exposure as a continuous variable resulted in a HR of 1.06 (95\% CI 0.99-1.13) by each step of "finishing time group" and a HR of 1.10 (95\% CI 1.03-1.16) by each step of "number of races" group. A model only adjusting for age was also tested showing similar results (data not shown). Noteworthy, because of the natural loss of performance with increasing age, the number of elderly athletes in the fastest finishing time groups was limited.

Table 10. List of bradyarrhythmia diagnoses

\begin{tabular}{lccccc}
\hline Diagnosis & \multicolumn{2}{c}{ Diagnosis position } & & Total \\
& Primary & Secondary 1 & Secondary 2 & Secondary 3 & \\
\hline $\begin{array}{l}\text { I44.1 Atrioventricular block, second de- } \\
\text { gree }\end{array}$ & 16 & 8 & 6 & 1 & 31 \\
I44.2 Atrioventricular block, complete & 23 & 7 & 2 & 2 & 34 \\
I45.2 Bifascicular block & & & 2 & & 2 \\
I45.3 Trifascicular block & 3 & 2 & 1 & & 1 \\
I45.9 Conduction disorder, unspecified & 33 & 15 & & 1 & 49 \\
I49.5 Sick sinus syndrome & 75 & 32 & 11 & 4 & 122 \\
Total & & & & 5 \\
\hline
\end{tabular}

Three patients were diagnosed with both atrioventricular blocks grade II and III. 


\section{Finishing Time Group}

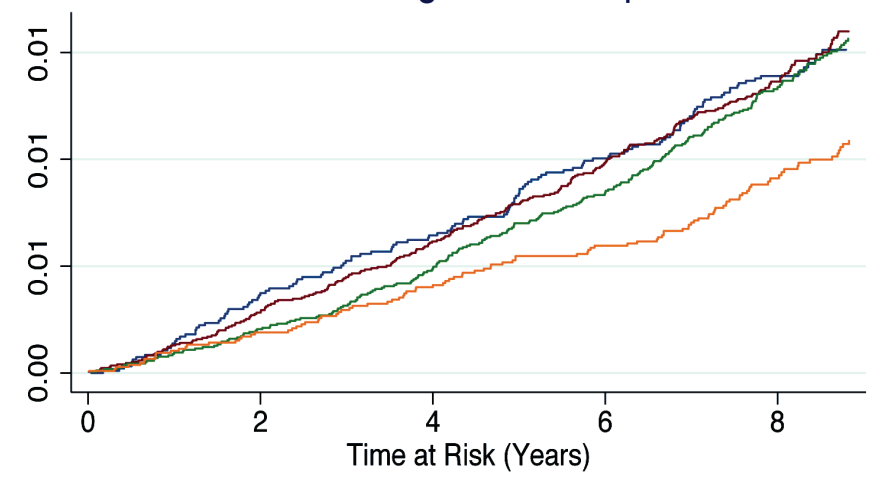

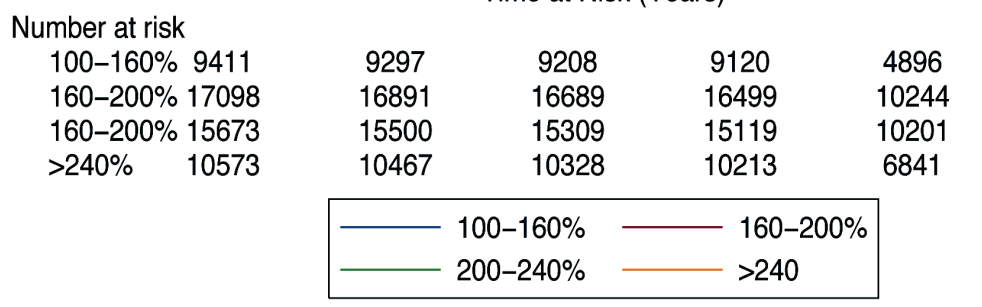

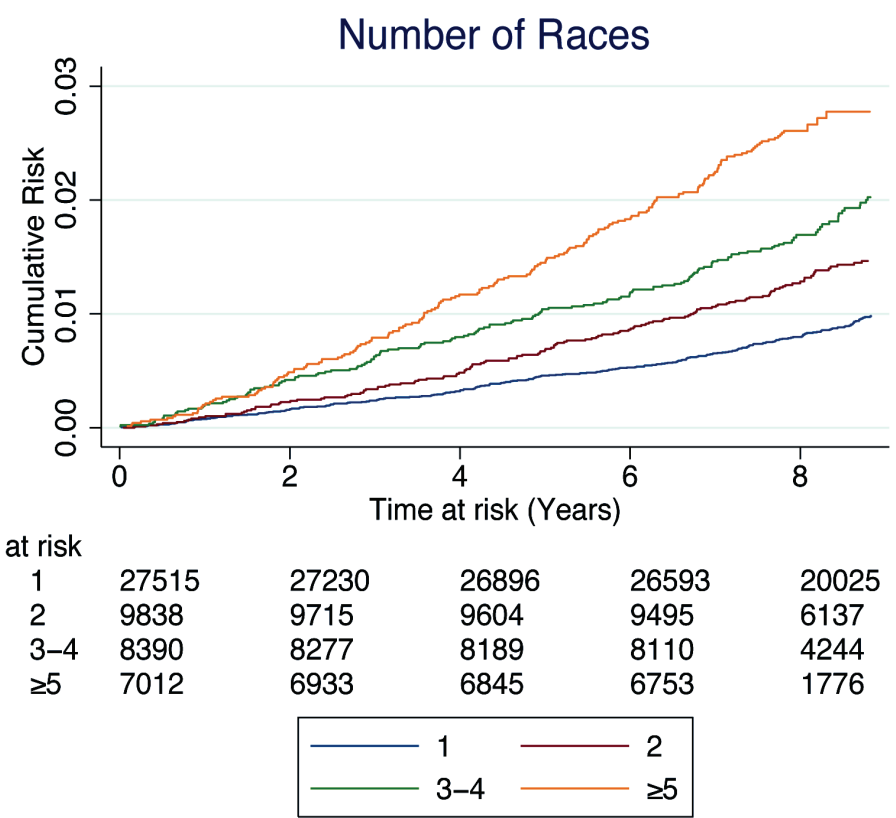

Figure 10. Cumulative incidence of any arrhythmia by finishing time group in per cent of winning time and number of completed races during the period 1989-98. 
Finis hing Time Group

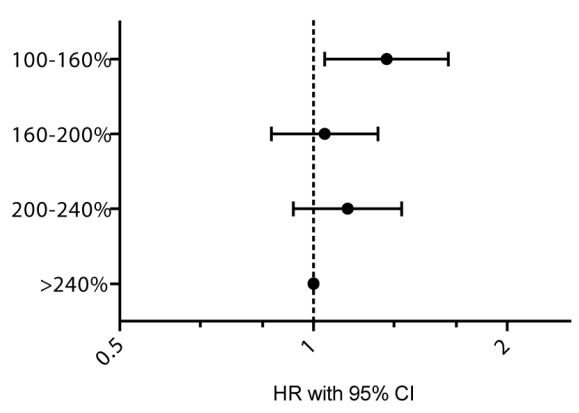

Number of Races

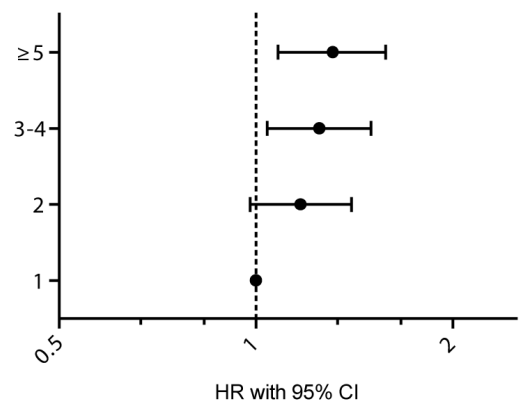

Figure 11. Hazard ratios of any arrhythmia with $95 \%$ confidence intervals (log scale) by finishing time group in percent of winning time and number of previous races. Model adjusted for age, occupation and education level.

\section{Bradyarrhythmias}

During follow-up 119 participants were diagnosed with a bradyarrhythmia (incidence rate: 2.3 ; 95\% CI 1.9-2.8 / 10,000 person-years at risk); mainly grade II and III atrioventricular blocks and sick sinus syndromes (Table 10). When adjusting for age, education and occupational status, higher risk of bradyarrhythmias was observed with increasing number of races (HR 2.10; 95\% CI 1.28-3.47; for $\geq 5$ vs. 1 completed races) and with faster finishing times (HR 1.85; 95\% CI 0.97-3.54; for $100-160 \%$ vs. $240 \%$ of winning time) (Tables 11 and 12). Treating exposure as a continuous variable resulted in a HR of 1.29 (95\% CI 1.10-1.52) by each step of "number of races" group and a HR of 1.16 (95\% CI $0.95-1.40)$ by each step of "finishing time group". As a sensitivity analysis, we excluded potentially non-pathological bradyarrhythmias (atrioventricular blocks II and bi- and tri-fascicular blocks) from the outcome, with comparable results.

\section{Atrial fibrillation and flutter}

The most frequent arrhythmia was atrial fibrillation, which occurred in 681 skiers (13.2; 95\% CI 12.3-14.3/ 10,000 person-years at risk). In a model adjusted for age, educational and occupational status, we observed higher incidence of atrial fibrillation with higher number of races (HR 1.29; 95\% CI 1.04-1.61 for $\geq 5$ vs. 1 completed races) and a tendency to higher incidence of atrial fibrillation with faster finishing times (HR 1.20; CI 0.93-1.55; for $100-160 \%$ vs. $240 \%$ of winning time) (Tables 11 and 12). Treating exposure as a continuous variable resulted in a HR of 1.09 ; $95 \%$ CI 1.02-1.17 by each step of "number of races" group and a HR of 1.04; 95\% CI 0.96-1.13 by each step of "finishing time group". 
Table 11 Risk of secondary outcomes by finishing time group

\begin{tabular}{|c|c|c|c|c|}
\hline & $\begin{array}{l}\text { Atrial Fibrillation } \\
\quad(n=681, \\
\text { PYAR=514,550) }\end{array}$ & $\begin{array}{c}\text { Bradyarrhythmias } \\
(n=119, \\
\text { PYAR=516,905) }\end{array}$ & $\begin{array}{c}\text { Other SVT } \\
\text { (n=105, PYAR } \\
516,9908)\end{array}$ & $\begin{array}{c}\text { VT/VF/SCD } \\
(n=90 ; \\
\text { PYAR=517,057) }\end{array}$ \\
\hline$>\mathbf{2 4 0 \%}$ & 1.00 (ref) & 1.00 (ref) & 1.00 (ref) & 1.00 (ref) \\
\hline $200-240 \%$ & $1.02(0.82-1.28)$ & $1.44(0.81-2.59)$ & $1.65(0.94-2.91)$ & $1.46(0.78-2.72)$ \\
\hline $160-200 \%$ & $0.98(0.79-1.22)$ & $1.29(0.72-2.31)$ & $1.09(0.60-1.99)$ & $1.03(0.54-1.96)$ \\
\hline $100-160 \%$ & $1.20(0.93-1.55)$ & $1.85(0.97-3.54)$ & $1.38(0.71-2.69)$ & $1.19(0.57-2.52)$ \\
\hline Per category & $1.04(0.96-1.13)$ & $1.16(0.95-1.40)$ & $0.98(0.81-1.19)$ & $0.99(0.79-1.22)$ \\
\hline
\end{tabular}

Data are hazard ratios with $95 \%$ confidence intervals, by groups of finishing time in percent of winning time. Results adjusted for age, occupation and education level. PYAR, Personyears at risk.

\section{Other arrhythmias}

The secondary endpoints of other SVT $(n=105)$ and VT/VF/SCD $(n=90)$ were analysed in the same way. No associations of number of completed races or finishing time group with risk of SVT or VT/VF/SCD were found (Tables 11 and 12).

Table 12. Risk of secondary outcomes by number of completed races

\begin{tabular}{lllll}
\hline & $\begin{array}{c}\text { Atrial Fibrillation } \\
(n=681, \\
\text { PYAR=514,550) }\end{array}$ & $\begin{array}{c}\text { Bradyarrhythmias } \\
(n=119, \\
\text { PYAR=516,905) }\end{array}$ & $\begin{array}{c}\text { Other SVT } \\
(n=105, \\
\text { PYAR 516,9908) }\end{array}$ & $\begin{array}{c}\text { VT/VF/SCD } \\
(\mathbf{n}=\mathbf{9 0} ; \\
\text { PYAR=517,057) }\end{array}$ \\
\hline $\mathbf{1}$ & $1.00($ ref) & $1.00($ ref $)$ & $1.00($ ref $)$ & $1.00($ ref $)$ \\
$\mathbf{2}$ & $1.22(0.99-1.51)$ & $1.23(0.70-2.16)$ & $0.96(0.56-1.65)$ & $1.32(0.75-2.34)$ \\
$\mathbf{3 - 4}$ & $1.27(1.02-1.57)$ & $1.76(1.05-2.94)$ & $1.31(0.78-2.21)$ & $0.98(0.51-1.86)$ \\
$\mathbf{2 5}$ & $1.29(1.04-1.61)$ & $2.10(1.28-3.47)$ & $0.56(0.26-1.21)$ & $1.53(0.85-2.76)$ \\
Per category & $1.09(1.02-1.17)$ & $1.29(1.10-1.52)$ & $0.94(0.77-1.14)$ & $1.12(0.92-1.35)$ \\
\hline
\end{tabular}

Data are hazard ratios with $95 \%$ confidence intervals, by number of completed races. Results adjusted for age, occupation and education level. PYAR, Person-years at risk. 


\section{Exercise capacity and muscle strength in adolescence and risk of vascular disease and arrhythmias (Study IV)}

In a cohort of 1.26 millions 18 -years old men the participants were followed until a median age of 44.6 years (median time at risk 26.3 years). This resulted in 29.8 millions person-years at risk. Baseline characteristics are shown in Table 13.

\section{Vascular disease}

During follow-up, we identified 26,088 vascular disease events (Ischemic heart disease: 12,188; Heart failure: 3,949; Stroke: 7,350; Cardiovascular death: 5,873; a person could contribute to more than one secondary endpoint). Cumulative incidence of vascular disease is shown in Figure 12. We observed an inverse association of exercise capacity with risk of vascular disease, with a more pronounced association after adjusting for blood pressure and weight (Figure 13; Table 14 and 15). The association was of similar strength with all of the secondary endpoints; ischemic heart disease, heart failure, stroke and cardiovascular death (Figure 14; Table 16).

Similarly, we found an inverse association of muscle strength with risk of vascular disease, although of smaller magnitude than that of exercise capacity (Figure 13 + Table 14 and 15). Again, associations were more pronounced in models adjusting for blood pressure and weight than in those without these covariates (Table 14 and 15). The associations with cardiovascular death and heart failure were stronger than those with stroke and ischemic heart disease (Figure 14; Table 16).

There was no evidence of a deviation from a multiplicative effect of exercise capacity and muscle strength; their joint effects are shown in Figure 12 and Table 14.
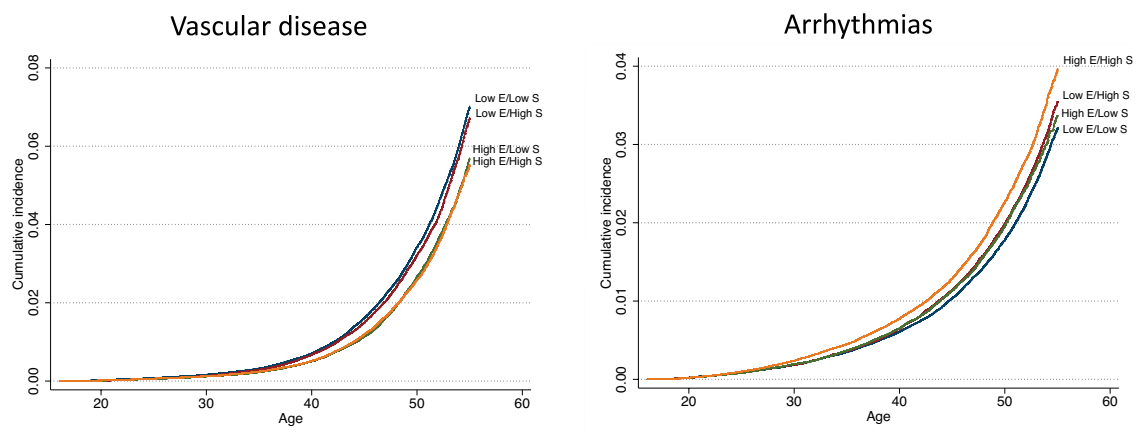

Figure 12. Unadjusted cumulative incidences of vascular disease and arrhythmias by joint groups of exercise capacity and muscle strength defined as high/low by median values. E: Exercise capacity S: Muscle Strength 
Table 13. Baseline characteristics

\begin{tabular}{|c|c|c|c|c|c|}
\hline & $\begin{array}{l}\text { Total Sample } \\
(n=1,122,255)\end{array}$ & $\begin{array}{l}\text { Low exercise ca- } \\
\text { pacity/Low muscle } \\
\text { strength } \\
(n=326,462)\end{array}$ & $\begin{array}{l}\text { Low exercise } \\
\text { capacity/High } \\
\text { muscle strength } \\
\text { (n=246,767) }\end{array}$ & $\begin{array}{l}\text { High exercise ca- } \\
\text { pacity/Low muscle } \\
\text { strength } \\
(\mathrm{n}=\mathbf{2 1 8 , 1 5 6 )}\end{array}$ & $\begin{array}{l}\text { High exercise } \\
\text { capacity/High } \\
\text { muscle strength } \\
(n=330,870)\end{array}$ \\
\hline Age at conscription & $18.3(0.7)$ & $18.3(0.8)$ & $18.4(0.9)$ & $18.2(0.6)$ & $18.3(0.6)$ \\
\hline Height (cm) & $179.1(6.6)$ & $176.3(6.4)$ & $179.5(6.1)$ & $178.8(6.1)$ & $181.8(6.1)$ \\
\hline Weight (kg) & $69.8(10.4)$ & $64.1(9.2)$ & $70.1(10.3)$ & $69.5(8.7)$ & $75.4(9.6)$ \\
\hline $\begin{array}{l}\text { Muscle strength - } \\
\text { Handgrip (N) }\end{array}$ & $616(98)$ & $529(57)$ & $681(62)$ & $547(47)$ & $701(68)$ \\
\hline Exercise capacity (w) & $261(47)$ & $220(26)$ & $228(22)$ & $292(29)$ & $301(34)$ \\
\hline $\begin{array}{l}\text { Systolic Blood pres- } \\
\text { sure }\end{array}$ & $129(11)$ & $127(11)$ & $128(11)$ & $129(11)$ & $130(11)$ \\
\hline $\begin{array}{l}\text { Diastolic blood pres- } \\
\text { sure }\end{array}$ & $67(10)$ & $67(10)$ & $68(10)$ & $66(11)$ & $66(10)$ \\
\hline \multicolumn{6}{|l|}{ Educational level* } \\
\hline $\begin{array}{l}\text { Primary school < } \\
9 \text { years }\end{array}$ & $0.5 \%$ & $0.7 \%$ & $0.8 \%$ & $0.2 \%$ & $0.3 \%$ \\
\hline $\begin{array}{l}\text { Primary school } 9 \\
\text { years }\end{array}$ & $12.2 \%$ & $15.0 \%$ & $18.8 \%$ & $6.6 \%$ & $8.7 \%$ \\
\hline $\begin{array}{l}\text { Secondary school } \\
<2 \text { years }\end{array}$ & $37.0 \%$ & $39.3 \%$ & $44.5 \%$ & $29.8 \%$ & $34.5 \%$ \\
\hline $\begin{array}{l}\text { Secondary school } \\
2-3 \text { years }\end{array}$ & $15.8 \%$ & $15.6 \%$ & $13.8 \%$ & $17.1 \%$ & $16.5 \%$ \\
\hline $\begin{array}{l}\text { Higher education } \\
>2 \text { years }\end{array}$ & $15.1 \%$ & $13.1 \%$ & $11.4 \%$ & $18.5 \%$ & $17.8 \%$ \\
\hline $\begin{array}{l}\text { Higher education } \\
>\text { 3years }\end{array}$ & $17.8 \%$ & $15.1 \%$ & $10.0 \%$ & $25.6 \%$ & $20.7 \%$ \\
\hline $\mathrm{PhD}$ & $1.5 \%$ & $1.3 \%$ & $0.7 \%$ & $2.3 \%$ & $1.6 \%$ \\
\hline
\end{tabular}

Data are Mean (SD) or \%. * Conscripts highest registered educational level of the year 2010.

\section{Arrhythmias}

During follow-up, we identified 17,312 arrhythmias (Atrial fibrillation/flutter: 9,668; Bradyarrhythmias 1,384; Supraventricular tachycardias: 3,278; Ventricular arrhythmias/sudden cardiac deaths 1,630; Unspecified arrhythmias 1,352). Cumulative incidence of arrhythmias is shown in Figure 12 , which indicates that arrhythmias on average occurred at a younger age than vascular disease events. We found a U-shaped association of exercise capacity with risk of arrhythmias. The association was similar after additionally adjusting for blood pressure, weight and ischemic heart disease (Figure 13; Table 14 and 15). This pattern was driven by an association of higher exercise capacity with higher risk of atrial fibrillation/flutter and a U-shaped association with bradyarrhythmias (Figure 15; Table 17). No associations of exercise capacity with supraventricular arrhythmias or ventricular arrhythmias/sudden cardiac deaths were found (Figure 15; Table 17). 
Table 14. Incidence rates and cox proportional hazard ratios $(95 \%$ CI) for vascular disease and arrhythmias, comparing joint groups of maximal exercise capacity and muscle strength defined as high/low by median values.

\begin{tabular}{|c|c|c|c|c|}
\hline & $\begin{array}{l}\text { Low exercise capac- } \\
\text { ity/Low muscle } \\
\text { strength }\end{array}$ & $\begin{array}{l}\text { Low exercise capac- } \\
\text { ity/High muscle } \\
\text { strength }\end{array}$ & $\begin{array}{l}\text { High exercise ca- } \\
\text { pacity/Low muscle } \\
\text { strength }\end{array}$ & $\begin{array}{l}\text { High exercise capacity/ } \\
\text { High muscle strength }\end{array}$ \\
\hline Number at risk & 324,416 & 223,530 & 216,716 & 328,643 \\
\hline \multicolumn{5}{|l|}{ Vascular disease } \\
\hline Number of events & 9,512 & 6,798 & 3,630 & 5,715 \\
\hline Incidence rate ${ }^{\mathrm{a}}$ & $10.9(10.7-11.2)$ & $11.0(10.7-11.2)$ & $6.6(6.4-6.8)$ & $6.8(6.6-7.0)$ \\
\hline Model A [HR $(95 \% \mathrm{Cl})]^{\mathrm{b}}$ & 1.00 (ref) & $0.96(0.93-0.99)$ & $0.84(0.81-0.87)$ & $0.85(0.82-0.88)$ \\
\hline Model B $[\mathrm{HR}(95 \% \mathrm{Cl})]^{\mathrm{c}}$ & 1.00 (ref) & $0.84(0.81-0.87)$ & $0.75(0.73-0.79)$ & $0.67(0.65-0.70)$ \\
\hline \multicolumn{5}{|l|}{ Arrhythmias } \\
\hline Number of events & 4,867 & 4329 & 2,810 & 5,092 \\
\hline Incidence rate ${ }^{a}$ & $5.6(5.4-5.8)$ & $6.4(6.2-6.6)$ & $5.1(4.9-5.3)$ & $6.1(5.9-6.3)$ \\
\hline Model A [HR $(95 \% \mathrm{Cl})]^{\mathrm{b}}$ & 1.00 (ref) & $0.99(0.95-1.03)$ & $0.99(0.95-1.04)$ & $1.05(1.01-1.10)$ \\
\hline Model B [HR $(95 \% \mathrm{CI})]^{\mathrm{c}}$ & 1.00 (ref) & $0.91(0.87-0.95)$ & $0.95(0.90-1.00)$ & $0.92(0.88-0.97)$ \\
\hline
\end{tabular}

HR: hazard ratio; $95 \% \mathrm{Cl}: 95 \%$ confidence interval; ${ }^{a}$ per 10,000 person-years at risk; ${ }^{b}$ Adjusted for age, conscription date, region, education level, height and muscle strength/exercise capacity (muscle strength adjusted for exercise capacity, and vice versa); ${ }^{\mathrm{c}} \mathrm{Addition}-$ ally adjusted for systolic and diastolic blood pressure, weight and ischemic heart disease (for arrhythmia outcomes only)

Higher muscle strength was associated with lower risk of arrhythmias. This association was more pronounced after adjusting for weight, blood pressure and ischemic heart disease (Figure 13; Table 14 and 15). The main associations were of higher muscle strength with lower risk of bradyarrhythmia and ventricular arrhythmias/cardiac arrest (Figure 15; Table 17). No associations of muscle strength with atrial fibrillation and supraventricular arrhythmias were found.

There was no evidence of a deviation from a multiplicative effect of exercise capacity and muscle strength; their joint effects are shown in Table 15. 

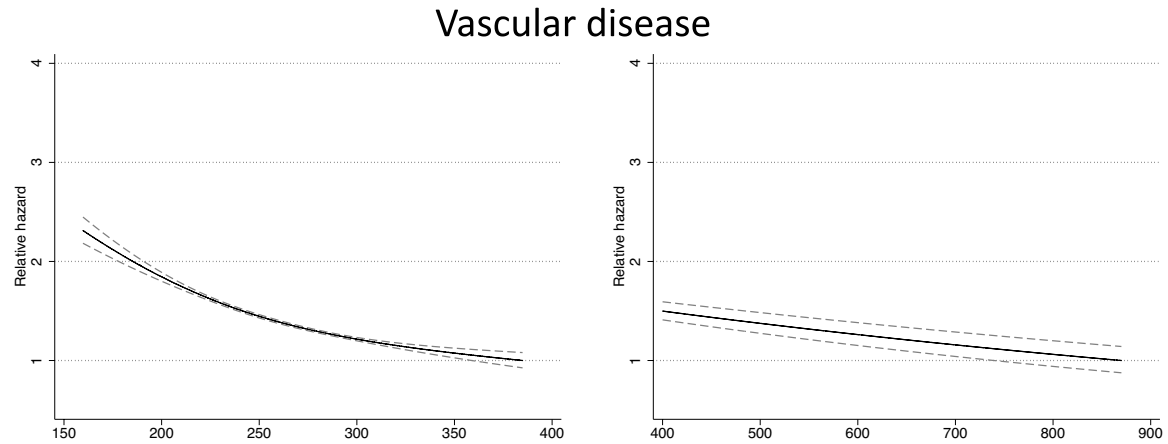

\section{Arrhythmias}

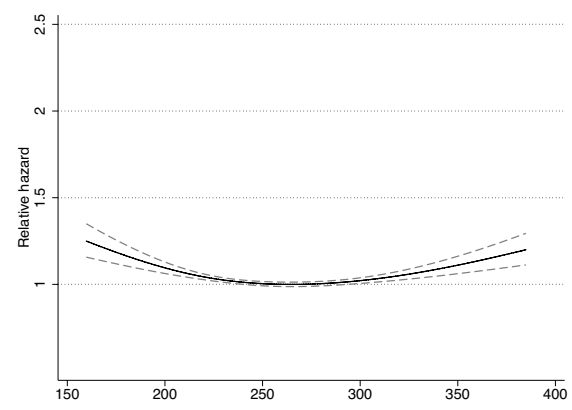

Exercise capacity (W)

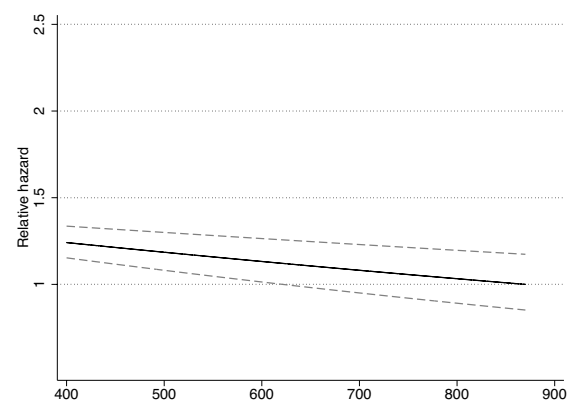

Muscle strength $(\mathrm{N})$

Figure 13. Relations of exercise capacity and muscle strength to risk of vascular disease and arrhythmias. Solid line represents relative hazard and dashed lines are 95\% confidence interval limits; from multivariable regression spline Cox proportional hazards. Model B adjusted for age, conscription date, region, education level, height and muscle strength/exercise capacity (muscle strength adjusted for exercise capacity, and vice versa) systolic and diastolic blood pressure, weight and ischemic heart disease (for arrhythmia outcomes only). Only observations between 1 and 99 percentiles are shown. 


\section{Ischemic heart disease}
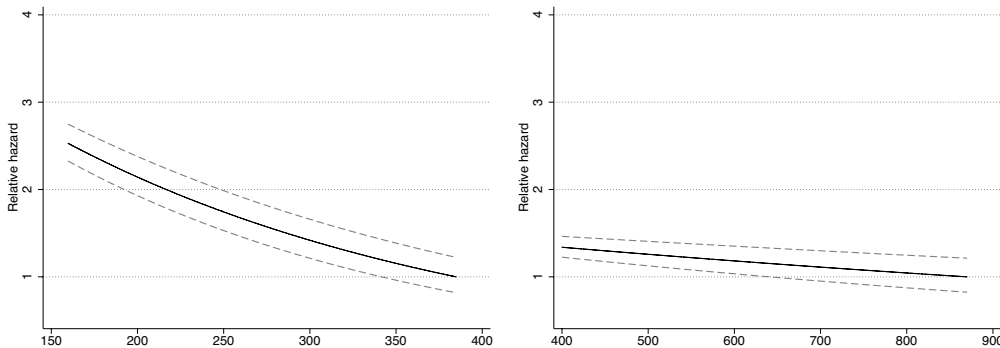

Heart failure
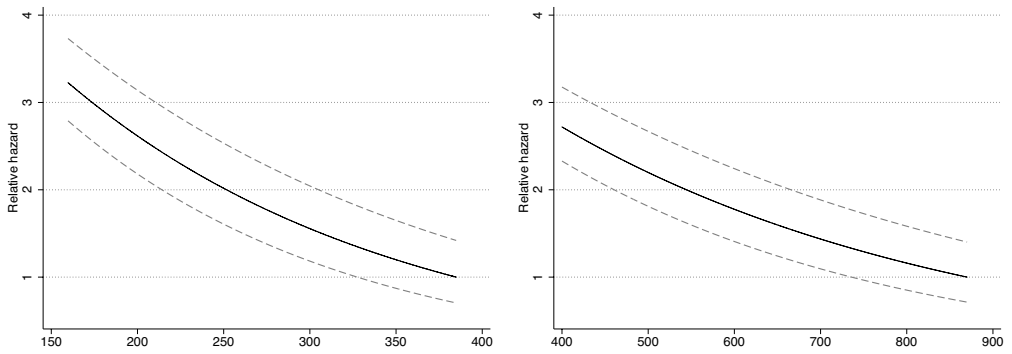

Stroke
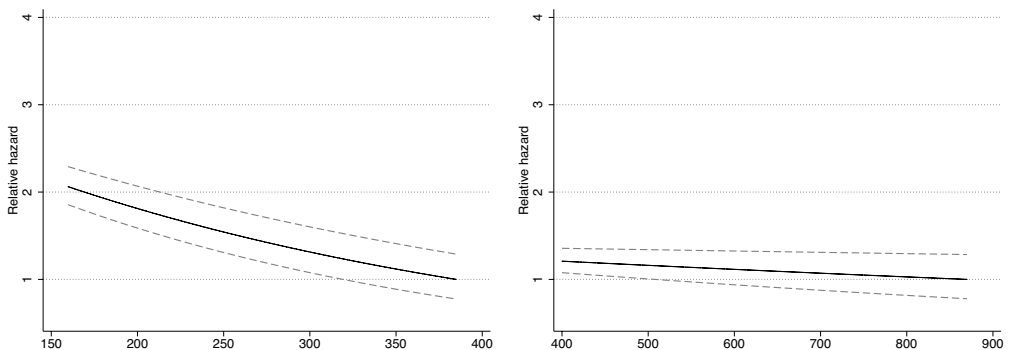

Cardiovascular death
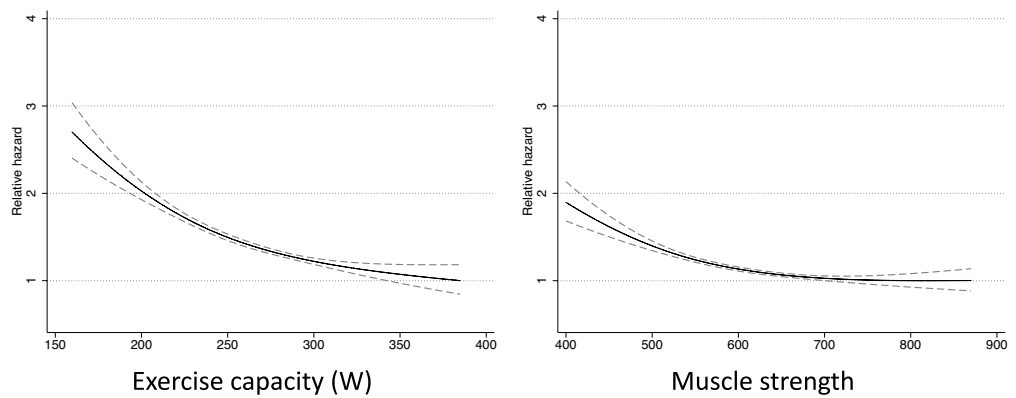

Figure 14 Relations of exercise capacity and muscle strength to risk of secondary endpoints of vascular disease. Solid line represents relative hazard and dashed lines are $95 \%$ confidence interval limits, from multivariable regression spline Cox proportional hazards Model B adjusted for age, conscription date, region, education level, height and muscle strength/exercise capacity (muscle strength adjusted for exercise capacity, and vice versa) systolic and diastolic blood pressure and weight. Only observations between 1 and 99 percentiles are shown. 
Atrial fibrillation
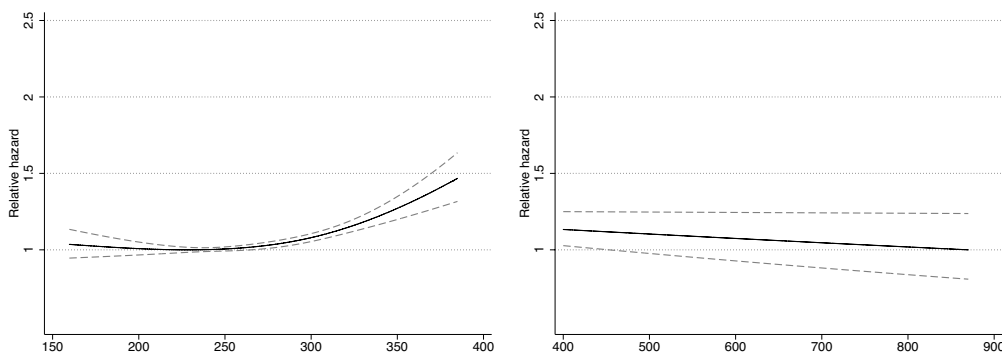

Bradyarrhythmia
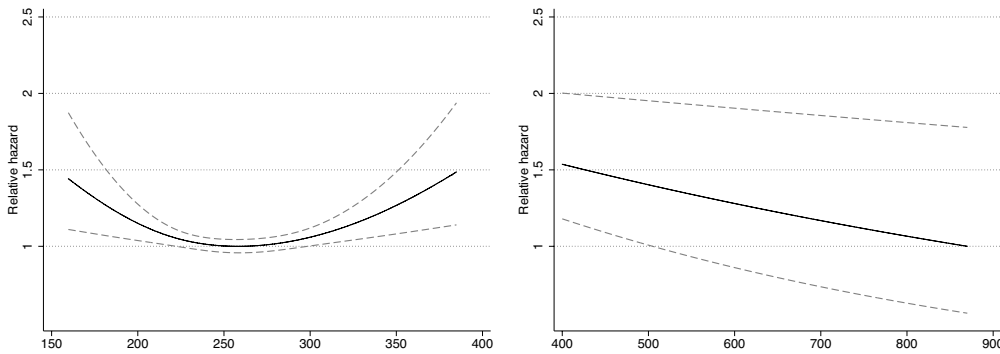

Supraventricular tachycardias
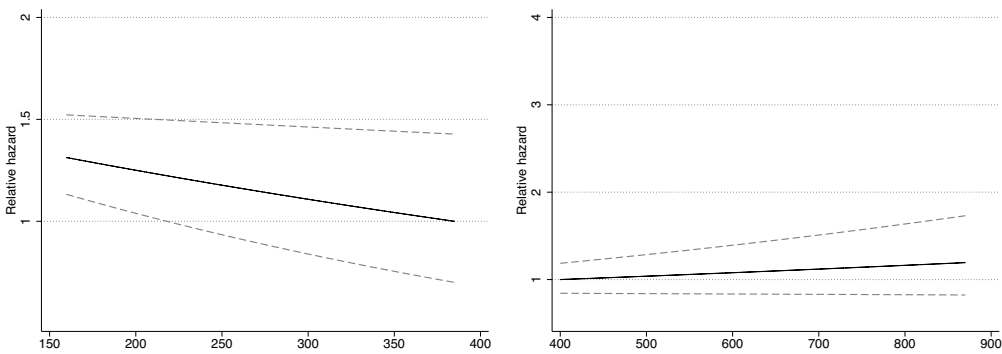

Ventricular arrhythmias/Sudden cardiac death
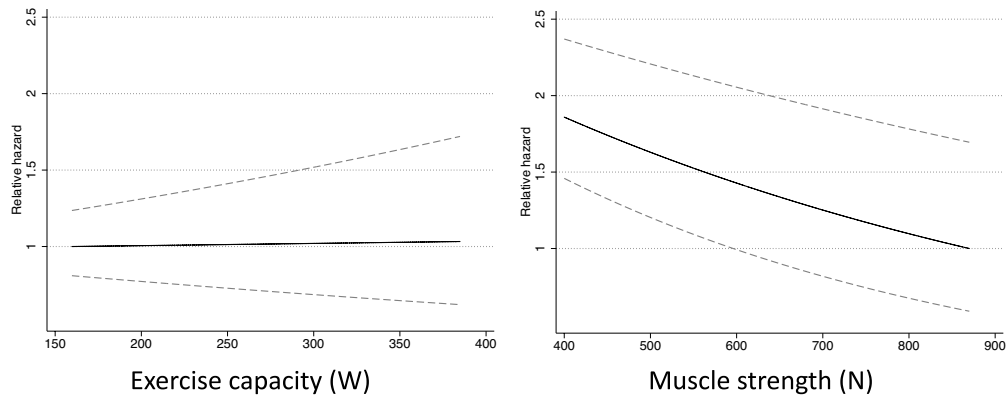

Figure 15. Relations of exercise capacity and muscle strength to risk of secondary endpoints of arrhythmias. Solid line represents relative hazard and dashed lines are 95\% confidence interval limits; from multivariable regression spline Cox proportional hazards Model B Adjusted for age, conscription date, region, education level, height and muscle strength/exercise capacity (muscle strength adjusted for exercise capacity, and vice versa) systolic and diastolic blood pressure, weight and ischemic heart disease. Only observations between 1 and 99 percentiles are shown. 
Table 15. Cox proportional hazard ratios $(95 \%$ CI) for vascular disease and arrhythmias comparing fifths of exercise capacity and muscle strength.

\begin{tabular}{ccccc}
\hline & \multicolumn{2}{c}{ Vascular disease } & Arrhythmia \\
\hline Exercise capacity (in fifths) & Model A* & Model B** & Model A* & Model B** \\
1st & 1.00 (ref) & 1.00 (ref) & 1.00 (ref) & 1.00 (ref) \\
2nd & $0.92(0.89-0.95)$ & $0.85(0.82-0.88)$ & $0.93(0.90-0.99)$ & $0.91(0.87-0.96)$ \\
3rd & $0.90(0.87-0.93)$ & $0.79(0.76-0.82)$ & $0.97(0.93-1.02)$ & $0.91(0.87-0.96)$ \\
4th & $0.81(0.78-0.84)$ & $0.70(0.67-0.73)$ & $0.97(0.92-1.02)$ & $0.91(0.86-0.96)$ \\
5th & $0.77(0.73-0.80)$ & $0.64(0.61-0.67)$ & $1.07(1.01-1.13)$ & $0.99(0.94-1.04)$ \\
Per category & $0.94(0.93-0.95)$ & $0.90(0.89-0.90)$ & $1.02(1.00-1.03)$ & $1.00(0.98-1.01)$ \\
& & & & Model A* \\
Muscle Strength (in fifths) & Model A* & Model B** & 1.00 (ref) & 1.00 (ref) \\
1st & $1.00($ ref) & $1.00($ ref) & $0.92(0.87-0.96)$ & $0.89(0.85-0.93)$ \\
2nd & $0.96(0.93-1.00)$ & $0.92(0.89-0.95)$ & $0.95(0.90-1.00)$ & $0.90(0.86-0.95)$ \\
3rd & $0.94(0.90-0.98)$ & $0.86(0.82-0.90)$ & $0.95(0.90-0.99)$ & $0.87(0.83-0.92)$ \\
4th & $0.95(0.91-0.99)$ & $0.83(0.80-0.87)$ & $0.95)$ & $0.87(0.83-0.91)$ \\
5th & $0.99(0.95-1.03)$ & $0.79(0.76-0.83)$ & $0.99(0.94-1.04)$ & $0.97(0.96-0.98)$ \\
Per category & $1.00(0.99-1.01)$ & $0.95(0.94 .0 .95)$ & $1.00(0.99-1.02)$ &
\end{tabular}

* adjusted for age, conscription date, region, height, education level and muscle strength/exercise capacity (muscle strength adjusted for exercise capacity, and vice versa).

** Additionally adjusted for systolic and diastolic blood pressure, weight and ischemic heart disease (arrhythmias only). 
Table 16. Cox proportional hazard ratios $(95 \%$ CI) for secondary endpoints of vascular disease comparing fifths of exercise capacity and muscle strength.

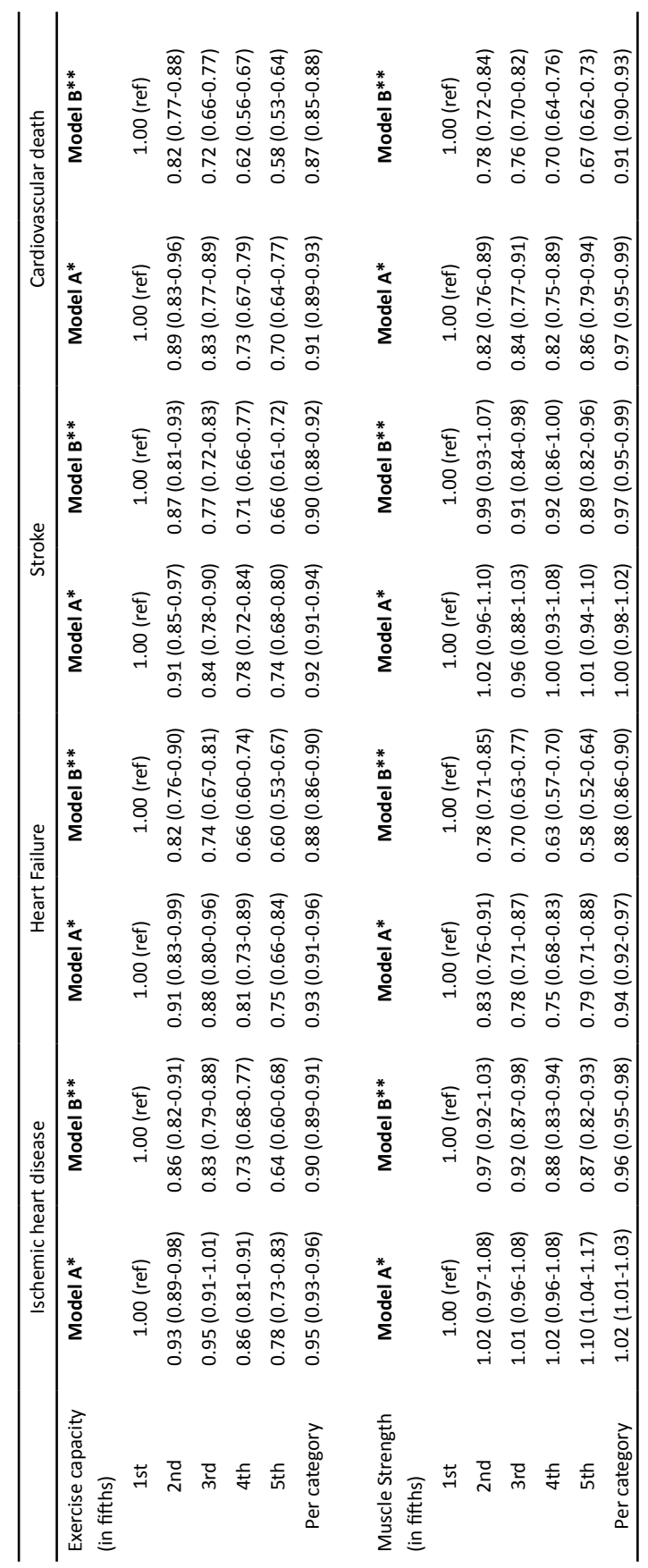


Table 17. Cox proportional hazard ratios (95\% CI) for secondary endpoints of arrhythmias, comparing fifths of exercise capacity and muscle strength

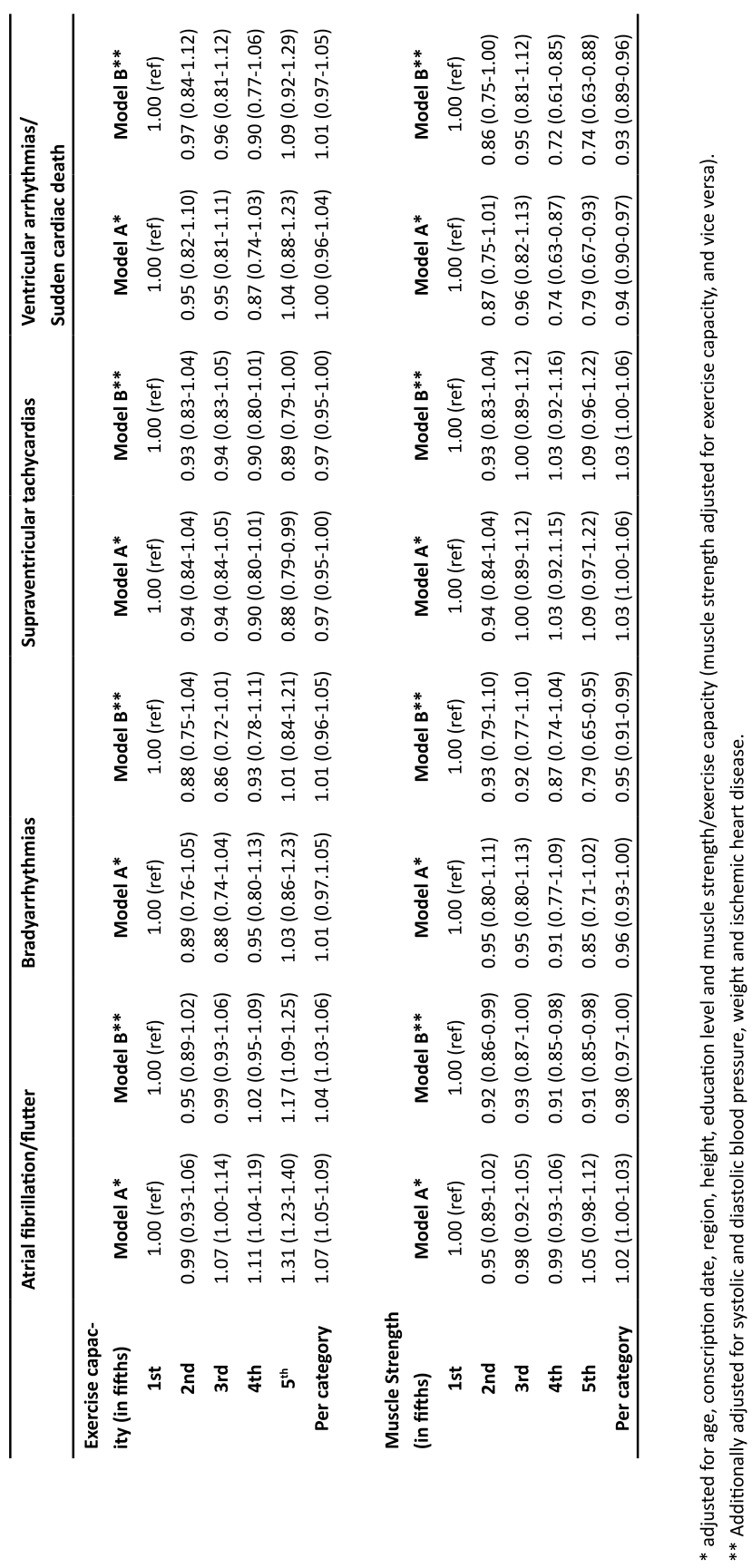




\section{Discussion}

\section{Main findings}

In Study I we found that skeletal muscle morphology is associated with risk of cardiovascular events in a cohort of 71-year-old men without pre-existing cardiovascular disease. We found that high proportion of type-I (slowtwitch, oxidative) skeletal muscle fibres was associated with lower risk of cardiovascular disease, while high proportion of type-IIx (very fast-twitch, glycolytic) muscle fibres was associated with higher risk of cardiovascular disease. Of note, these associations were only seen among physically active men. While earlier studies have shown associations of skeletal muscle morphology with cardiovascular risk factors, ${ }^{58,113-116}$ we investigated the direct association of skeletal muscle morphology with cardiovascular disease for the first time in a prospective cohort study.

In Study II we observed an inverse dose-response association of leisure-time physical activity with the risk of developing heart failure. This was mainly seen in the lowest interval 0-3 METh/day with little additional effect above $3 \mathrm{METh} /$ day. These results were consistent after adjusting for a large number of known potential confounding factors. Likewise, higher total physical activity was associated with lower risk of heart failure. Nevertheless, the effect was smaller and considerably attenuated after adjusting for confounding variables. The effect of both high leisure-time and total physical activity was similar for heart failure of any cause and for non-ischemic heart failure. A few other large cohort studies have investigated relations of physical activity with risk of heart failure with similar results. ${ }^{117-120} \mathrm{We}$ have, however, by use of a recently developed energy expenditure questionnaire on total physical activity, and addition of intensity to leisure time physical activity, been able to plot the shape of the dose-response relations of physical activity and risk of heart failure.

Study III shows an increased risk of developing atrial fibrillation and bradyarrhythmias among those who had completed most races of Vasaloppet during a ten years period. The study confirms earlier smaller case-control studies that have shown increased risk of atrial fibrillation/flutter in athletes, ${ }^{43-46 \text {, }}$ 121-123 and extends current knowledge by providing cohort study data on persons in the higher end of the distribution of physical activity. The study fur- 
ther adds new knowledge of the relations of high levels of physical activity with risk of bradyarrhythmias.

In Study IV we found that among 18-year-old men, both higher exercise capacity and muscle strength were independently associated with lower risk of developing vascular disease later in life. The associations were seen across a range of major vascular disease events (ischemic heart disease, heart failure, stroke and cardiovascular death). However, only weak associations of muscle strength with risk of ischemic heart disease and risk of stroke were observed. We further found a U-shaped association of exercise capacity with risk of arrhythmias. This association was driven by a higher risk of atrial fibrillation with higher exercise capacity and a U-shaped association with bradyarrhythmias. Additionally, we found an association of higher muscle strength with lower risk of arrhythmias. This association was mainly caused by a lower risk of bradyarrhythmias and ventricular arrhythmias with higher muscle strength. This confirms earlier studies of middleaged and elderly. Further, the study for the first time relates objective measures of cardiorespiratory fitness to increased risk of atrial fibrillation/flutter.

\section{Physical activity and vascular disease}

Three studies from this thesis investigate associations of physical activity or exercise capacity with risk of vascular disease. All studies support earlier findings of lower incidence of vascular disease by higher levels of physical activity or exercise capacity. ${ }^{6-8,10-13}$ Furthermore study IV supports earlier findings of lower incidence of vascular events with higher muscle strength. ${ }^{18-26}$ The latter was somewhat surprisingly driven by a lower rate of heart failure and cardiovascular death while the associations of muscle strength with ischemic heart disease and stroke were of considerable lower magnitude. High amounts of physical activity have been associated with lower risk of hypertension, ${ }^{49,}{ }^{124}$ diabetes mellitus ${ }^{125,126}$ and more favourable lipid profile. ${ }^{56,57}$ Furthermore, a low amount of physical activity has been associated with poorer vascular health, ${ }^{127}$ autonomic dysfunction ${ }^{87}$ and higher systemic inflammation. ${ }^{128,129}$ Of note there may exist a link from skeletal muscle to lower systemic inflammation, since skeletal muscles are known to act as an endocrine organ by secreting cytokines as a response to an acute bout of exercise. ${ }^{130}$ Whether the cytokine response directly is involved in the anti-inflammatory effect of exercise is still debated, but it is suggested that at least IL-6 has some anti-inflammatory properties when not accompanied by an elevation of TNF- $\alpha .{ }^{131}$ In study I we explored how some inflammatory variables, related to low-grade systemic inflammation, affected the association of skeletal muscle with risk of cardiovascular disease. Inflammatory markers did not affect the result to any major extent, suggesting that this pathway is not important for the association between skeletal muscle mor- 
phology and cardiovascular disease. Nevertheless, the relation between skeletal muscle signalling and inflammation is complex and to date only partly understood, and exercise-induced changes in the inflammatory response are likely not fully reflected in the single measurement of cytokines in this study. In summary, the effect of physical activity is only partly mediated by a reduction of traditional risk factors of vascular disease. However, an hitherto unexplained effect of physical activity on risk of vascular disease exists, motivating studies of novel risk factors.

\section{The pro-arrhythmic effect of exercise}

It is generally accepted that arrhythmias depend on triggers, modulators and a substrates. Most atrial fibrillation episodes start with an extra systole from the pulmonary vein or left atrium. ${ }^{132}$ The finding of increased premature ventricular complexes in athletes suggests that athletes also could have triggers in the form of more premature atrial complexes; ${ }^{133,134}$ but the evidence is inconsistent. ${ }^{135,136}$ The autonomic nervous system may be a modulator of atrial arrhythmias since endurance trained athletes have vagal cardiac predominance. ${ }^{136}$ This shortens and increases dispersion of the atrial refractory period, creating conditions for atrial re-entry. ${ }^{137}$ Vagally initiated atrial fibrillation during sleep is very common in patients with lone atrial fibrillation, which we suppose is the dominant atrial fibrillation variant among trained athletes. ${ }^{138}$ Chronic volume and pressure overload may increase fibrosis and dilation of the atrium, which act as a substrate for atrial fibrillation. ${ }^{139}$ The prolonged strain of long-term endurance sports could induce similar atrial changes, which could be the first step on the path to developing atrial fibrillation. This is supported by studies showing that among veteran athletes, biomarkers of collagen equilibrium are disrupted and favouring fibrosis development. ${ }^{140}$ Further, animal models have shown dilated atria with increased fibrosis after excessive training. ${ }^{141,142}$ Earlier case-control studies report higher incidence of atrial fibrillation in endurance sports trained athletes but the relation has not been investigated in large-scale cohorts studies. ${ }^{43-46}$

The study of participants in Vasaloppet (Study III) showed an about $30 \%$ increased risk of atrial fibrillation among participants who had completed five or more races compared to those who only completed one or two races during a ten years period. Age-adjusted relative performance only showed a non-significant effect in the fastest group. This suggests that the accumulated amount of training is more important than actual fitness, which depends not only on cardiorespiratory fitness but is a combination of physical, physiological, biomechanical and psychological characteristics of the athlete.

The finding in Study IV that high exercise capacity in adolescence was associated by an increased risk of subsequent development of atrial fibrillation 
may let one to speculate that the observed effect may be due to several factors, such as training; an effect of factors in childhood or adolescence; or even an effect of genetic factors. We know from earlier studies that active children also are more active as adults, ${ }^{143}$ suggesting that active children have increased propensity to high physical activity later in life. Altogether, this supports that the accumulated amount of training during life may be important for the risk of developing atrial fibrillation. However, these studies are of observational nature and conclusions of causality should be drawn very carefully. It is possible that other factors linked to the exposure rather than the amount of exercise in later life contributes to the associations.

Distinctly or mildly abnormal ECGs have been observed in as much as 50$60 \%$ of all athletes. ${ }^{144}$ Sinus bradycardia, grade I AV block and grade II Mobitz type I AV block should be considered as normal findings, ${ }^{144-148}$ but even the incidence of pathological AV-block grade III are reported more frequently among athletes than in the general population. ${ }^{147}$ Further, one earlier study reports a higher rate of subclinical sinus node dysfunction among retired elite cyclists. ${ }^{135}$ While the effect of exercise on risk of atrial fibrillation is novel, the finding of an approximately two-fold higher risk of subsequent hospitalization for bradyarrhythmias in both the group of athletes completing most races of Vasaloppet and among those with best performance in the race novel. Of note, in order to capture clinically relevant bradyarrhythmias (i.e. potentially requiring a pacemaker), sinus bradycardia and grade I atrioventricular block were not included in this outcome. However, the use of ICD codes did not provide the opportunity to differ between atrioventricular blocks II Mobitz type I and II. For this reason, it is possible that some normal variants are included as pathological findings but grade II atrioventricular block only represents $23 \%$ of the bradyarrhythmia cases, and the results were consistent after excluding potentially non-pathological bradyarrhythmias (AV blocks II and bi- and tri-fascicular blocks) from the outcome. The finding is also supported by the study of conscripts (Study IV) by a Ushaped association of exercise capacity with risk of bradyarrhythmias to exercise capacity. The spline plot shows that the conscripts with the lowest risk of bradyarrhythmias had intermediate exercise capacity. Although the effect is small, this indicates an increased risk of bradyarrhythmias both in poorly and in well-trained persons. It is possible that the higher risk of bradyarrhythmias in persons with low exercise capacity could be a consequence of higher risk of vascular diseases. Interestingly, there may be a link between bradycardia and increased risk of atrial fibrillation since atrial size, long PQ time and bradycardia seem to be risk factors for atrial fibrillation among endurance trained athletes. ${ }^{122}$ In brief, a history of high amount of endurance training is associated with higher risk of atrial fibrillation and bradyarrhythmias. The relative increase of atrial fibrillation could seem modest, but the prevalence of atrial fibrillation among 85-year-old individu- 
als is as high as $14 \%,{ }^{149}$ and the public health impact of even a small relative increase of atrial fibrillation is considerable. Proposed mechanisms of endurance training and resistance training on risk of vascular disease and arrhythmias are shown in figure 16.

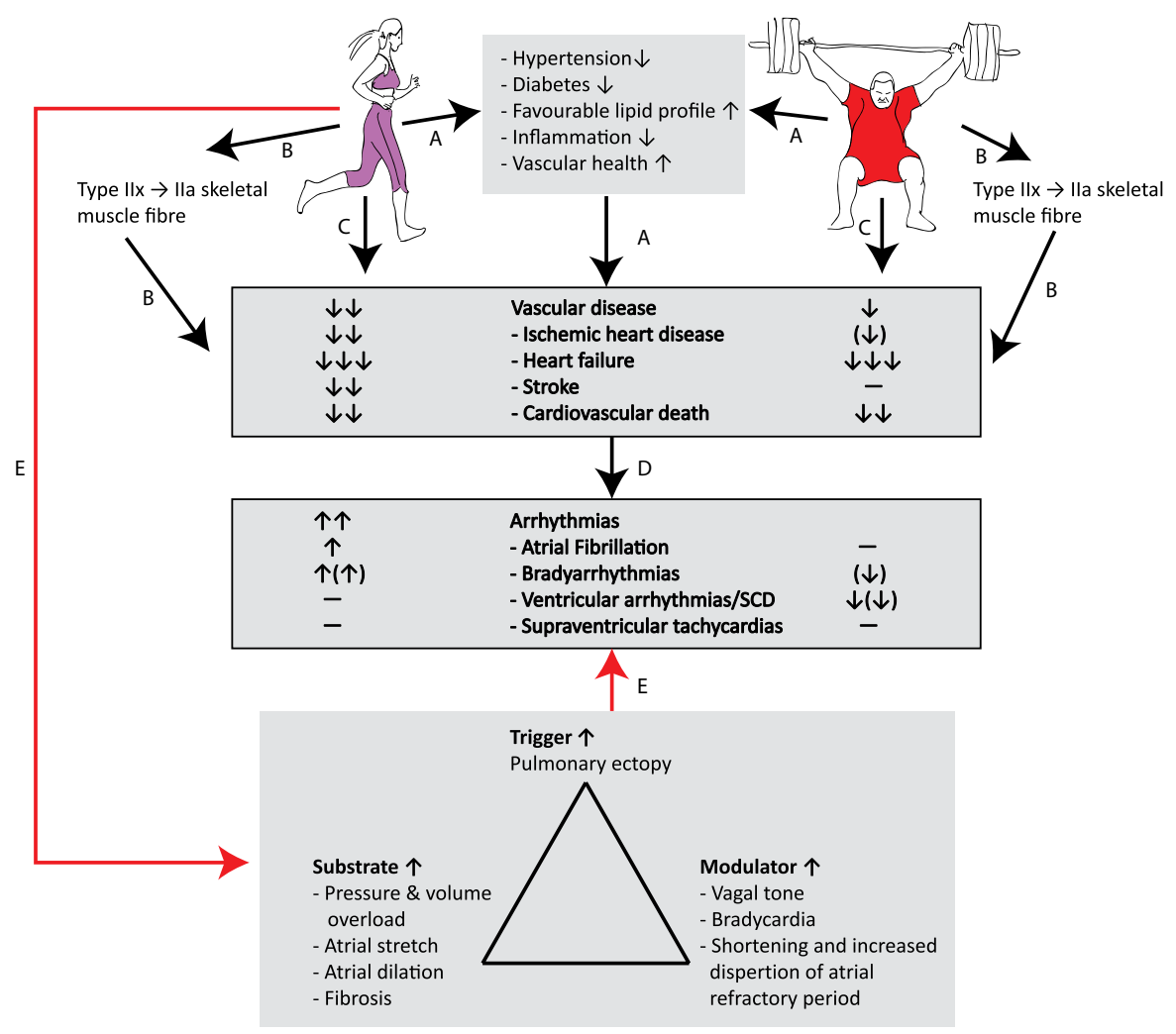

Figure 16 Proposed mechanisms of endurance training and resistance training on risk of vascular disease and arrhythmias. A: Both endurance training and resistance training lead to a reduction of vascular disease risk factors, leading to lower incidence of these diseases. B: Both endurance training and resistance training leads to transition of skeletal muscle fibre composition by increasing levels of type IIa fibres at the expense of type IIx fibres. This leads to a lower incidence of vascular disease. C: An unexplained effect is however still present D: The lower incidence of vascular disease leads to lower incidence of arrhythmias. E: Endurance training increases triggers, substrates and modulators. The total impact of endurance training is an increased risk of atrial fibrillation and bradyarrhythmias.

\section{Better to be strong or fit?}

One of the overarching hypotheses we wanted to test was that endurance training and resistance training might lead to different cardiac risk profiles as a consequence of different cardiac adaptations. The athletes heart hypothesis suggest that specific types of training lead to specific cardiac adaptations; in 
that endurance-trained athletes tend to develop eccentric left ventricular changes as response to volume load and resistance-trained athletes tend to develop concentric left ventricular changes as a response to pressure load. The latter largely mimics the changes seen among hypertensive patients ${ }^{29,150}$ and one could speculate that this will lead to a higher risk of heart failure as seen among hypertension patients.

In study I of men without any cardiovascular disease we hypothesized that the muscle fibre type may reflect which type of exercise the person has preferred and may hence also reflect cardiac adaptation to that exercise. However, adjusting for hemodynamic variables such as left ventricular mass, did not affect the result of the study, suggesting that athlete's heart-like phenomena did not explain the relation of skeletal muscle morphology to cardiovascular events. This contrasts a smaller scale Finnish study showing that low amount of type-I muscle fibre predicts unfavourable left heart geometry, weigh gain and hypertension. ${ }^{114}$ Yet, interpretation of heart geometry among elderly is not straightforward and little is known about how risk factors that may be important in the young heart, may affect the aging heart.

In study II of the associations of leisure time and total physical activity with risk of heart failure, we found that the association of leisure time physical activity with heart failure was greater than that of total physical activity. Leisure-time physical activity - which is mostly endurance exercise, leading to a reduction of systemic vascular resistance - might be more protective than work-related physical activity which mostly is of a resistance training character (e.g. heavy lifting). Work-related activity might partly explain the differences between leisure-time and total activity observed. Although the sensitivity analyses may indicate a U-shaped association between total physical activity and risk of heart failure, confidence intervals were wide and non-conclusive.

Study IV of conscripts investigates how exercise capacity and muscle strength is related to risk of vascular diseases including heart failure. Although other factors than training affects both exercise capacity and muscle strength, we believe there is some relation between the two types of training and the two fitness measures. High levels of exercise capacity are expected to be seen in person with high amount of endurance training; high levels of muscle strength are expected to be seen among persons with high amount of resistance training. While high exercise capacity was strongly associated with a lower risk of all secondary endpoints of vascular disease, there was almost no association of muscle strength with ischemic heart disease and stroke. Surprisingly, we found a very strong association of higher muscle strength with lower risk of heart failure, which contradicted our original hypothesis. In conclusion, all studies support a lower risk of vascular disease 
by higher levels of physical activity no matter of modality. Nevertheless, the beneficial association seems to be largest for endurance training. Potential health benefits or adverse effects of different modalities of training are summarized in table 18

\section{Can you exercise too much?}

As a clinician you are often faced with the question: "Can you exercise too much?" The answer depends on many factors. Athletes with pre-existing heart disease have higher risk of sudden cardiac death and many countries have applied screening programs in order to identify individuals at risk. The Swedish National Board of Health and Welfare recommends, in accordance with the recommendations of the European Society of Cardiology, that all athletes competing at elite level should have a physical evaluation including personal and family medical history, physical examination, and resting ECG. Only if these investigations reveal abnormal findings, further examinations (like echocardiography or stress testing) should be performed. ${ }^{151}$ The specific sports associations define which athletes who are regarded as elite. What specific heart conditions that disqualify athletes to participate at competitive level are stated in the recommendations of European Society of Cardiology. ${ }^{152}$

Study II-IV evaluated different levels of physical activity or fitness measures in samples of a wide range of the Swedish population. We found a lower incidence of a wide range of major cardiovascular diseases by increasing exercise capacity. Further, we found a protective effect of both total and leisure time physical activity and muscle strength on heart failure. These positive effects of physical activity are strongest in people with relatively low physical activity, but a protective effect is seen throughout the whole spectrum of physical activity/exercise capacity levels. In contrast we find an higher risk of arrhythmias by higher performance and number of completed races in Vasaloppet during a ten-years period. Furthermore, higher exercise capacity in adolescence was asssociated to a higher risk of atrial fibrillation later in life. Importantly, this was not accompagnied by a higher incidence of stroke, the most serious complication of atrial fibrillation. Further, we do not find an higher risk of the potentially lethal ventricular arrhythmia or sudden cardiac death. To summarize, although there are specific groups who should avoid competitive sports because of higher risk of sudden cardiac death, and endurance trained individuals seems to a have higher incidence of arrhythmias, the total impact of exercise on the population is associated with lower risk of disease. The effect of exercise on vascular diseases is highest among persons with low physical activity, but an effect is seen through the whole spectrum of physical activity. 


\section{Strengths and weaknesses of the studies}

All of the studies in this thesis are designed as cohort studies. Although cohort studies are considered as the most reliable type of observational studies, the study design is per se observational and must be considered to be hypothesis-generating and therefore no firm causal conclusions can be drawn from the studies. However, when several studies come to the same conclusions that may suggest causal relations. Further, if such studies are later combined in meta-analyses, they are considered being of high evidence level.

It is possible that some of the associations we found are results of reverse causation. Study I explored muscle morphology finding lower risk of cardiovascular disease with higher amount of type I fibres while type IIx fibres were associated with adverse prognosis. Chronic diseases (like chronic heart failure, severe angina pectoris or chronic obstructive lung disease) frequently lead to skeletal muscle morphology adaptions characterized by atrophy, declining capillary density and decreased strength, but also a higher proportion of type-II fibres. ${ }^{99-101}$ It is also likely that persons with one of these chronic diseases have lower physical activity and they may also be associated with later cardiovascular events, these conditions may both confound our results and lead to competing risk. In study II reverse causation may exist since pre-existing disease could lead to lower performance in Vasaloppet. In study III we explored the possibility that chronic diseases led to lower physical activity (i.e. reverse causation) by performing a sensitivity analysis. We excluded all participants with previous cardiovascular disease or participants who had experienced chest pain, palpitations or breathlessness before inclusion, and reanalysed the data starting follow-up two years after baseline. In study IV the early inclusion age of the participants minimizes the risk of reverse causation by pre-existing cardiac disease.

One of the fundamental challenges of observational studies is how to deal with confounding variables (variables related to both exposure and outcome). To estimate an unbiased effect of an exposure on an outcome one has to condition on potential confounding variables. Nevertheless, conditioning on some variables may in itself introduce bias. Of note, no matter how many variables included in the study, there is always a risk of not including an important confounder leading to residual confounding (potential confounding by factors or variables not yet considered in the analysis - these may be directly observable or not ${ }^{153}$ ). 
Table 18. Summarizing table of potential health benefit or adverse effects of endurance training or resistance training.

\begin{tabular}{|c|c|c|}
\hline Study & Resistance training & Endurance training \\
\hline$\overline{\mathrm{I}}$ & $\begin{array}{l}+ \\
\text { Resistance training leads to lower } \\
\text { amount of type IIx fibres that are } \\
\text { associated with higher risk of cardio- } \\
\text { vascular events. }\end{array}$ & $\begin{array}{l}+ \\
\text { Endurance training leads to de- } \\
\text { creased amount of type IIx fibres that } \\
\text { are associated with higher risk of } \\
\text { cardiovascular events. } \\
(+) \\
\text { If the amount of endurance training } \\
\text { during the past is reflected in higher } \\
\text { proportion of type I fibres it leads to } \\
\text { lower risk of cardiovascular events. } \\
\text { This is however hypothetical, and } \\
\text { evidence is sparse. }\end{array}$ \\
\hline II & $\begin{array}{l}\text { (-) } \\
\text { A sensitivity analysis of persons } \\
\text { without cardiac symptoms showed a } \\
\text { tendency to higher risk of heart fail- } \\
\text { ure by high total physical activity, } \\
\text { which was assumed mainly to be } \\
\text { driven by work-time physical activity, } \\
\text { which tends to be of resistance char- } \\
\text { acter. However, wide confidence } \\
\text { interval and non conclusive }\end{array}$ & $\begin{array}{l}++ \\
\text { The lowest risk was seen with high } \\
\text { levels of leisure time physical activi- } \\
\text { ty. Leisure time sports activity is } \\
\text { assumed to be mostly of endurance } \\
\text { type }\end{array}$ \\
\hline III & & $\begin{array}{l}\text {-- } \\
\text { Higher number of completed races } \\
\text { was associated with higher incidence } \\
\text { of any arrhythmias, atrial fibrillation } \\
\text { and bradyarrhythmias. } \\
\text { Performance in the race was associ- } \\
\text { ated with higher risk of brady- } \\
\text { arrhythmias. }\end{array}$ \\
\hline IV & $\begin{array}{l}++ \\
\text { Associated with lower risk of the } \\
\text { combined endpoint vascular diseases. } \\
+++ \\
\text { Considerable association with lower } \\
\text { risk of heart failure and cardiovascu- } \\
\text { lar death. } \\
++ \\
\text { Considerable association with lower } \\
\text { risk of ventricular arrhythmi- } \\
\text { as/cardiac arrest, but wide confidence } \\
\text { intervals. } \\
+ \\
\text { Limited associations with lower risk } \\
\text { of ischemic heart disease and stroke. }\end{array}$ & $\begin{array}{l}\text { Associated with lower risk of a large } \\
\text { number of vascular diseases. } \\
- \\
\text { Associated with higher risk of atrial } \\
\text { fibrillation and possibly brady- } \\
\text { arrhythmias. }\end{array}$ \\
\hline
\end{tabular}


The different measurements of physical activity and exercise capacity in the studies have different advantages and limitations. While questionnaires are not exact measures of physical activity, they have been proven to give a fairly good reflection of physical activity level. This means that you need to be careful in selecting questionnaires. We have ensured that the questionnaires used in thesis studies were validated at least to some extent. In study I the questionnaire of physical activity has been shown to be correlated to exercise capacity. ${ }^{106}$ In study II the energy expenditure questionnaire has been validated to be reproducible. ${ }^{154}$ However, common for the two questionnaires are that they have not been evaluated to objective measures of physical activity such as motion sensors or doubly labelled water. In study IV we evaluated exercise capacity by use of bicycle ergometry that is considered to be one of the best tests of exercise capacity. Nevertheless, what do we really want to measure? If we consider maximal exercise capacity as a measure of physical activity before the test, this would be biased by for example genetic or dietary factors. Furthermore, we do not know how changes in exercise capacity later in life influences the risk of disease or if you can consider a person with high exercise capacity in adolescence also having high exercise capacity later in life.

In study III we assumed that the number of completed races was related to amount of training, and that performance in the race was related to cardiorespiratory fitness. Since performance not only is related to cardiorespiratory fitness, but also physical, physiological, biomechanical and psychological characteristics of the athlete, it is possible that we over- or underestimate cardiorespiratory fitness. Furthermore, many participants are likely committed to other sports activities during the summer. Indeed, in an earlier study of this population, $79.1 \%$ participants, compared to $29.5 \%$ in the normal population, reported strenuous exercise over the last year. ${ }^{155}$ Hence, the exposure measure may reflect all-year activity, which on the other hand may be viewed as a strength.

The population samples used in the studies are all unique. In study I we had access to the worlds largest collection of muscle biopsies in a populationbased study. Study II had access to a novel way of evaluating total physical activity. In Study III the sample consisted of over 52,000 athletes ranging from recreational to elite athletes and study IV had information of more than 1,2 million physical examinations, including exercise capacity and muscle strength, of 18-year-old men, The studies cover a wide range of the Swedish population but in study I and IV only men were included, and in study III the number of women was limited. The generalizability from these studies to women, other ethnic groups or ages is unknown. The studies used linkages to nation wide registers to obtain the cardiovascular outcome data. This approach minimizes lost-to-follow-up and by use of the In-patient Register 
includes only events severe enough to motivate hospitalization. Consequently the accuracy of diagnoses are expected to be good. ${ }^{156}$ 


\section{Conclusions}

Skeletal muscle morphology was associated with risk of cardiovascular disease. High levels of type-I skeletal muscle fibres were associated with low risk of cardiovascular disease, while high levels of type IIx skeletal muscle fibres were associated with high risk of cardiovascular disease. The potential mechanistic pathways still remain unknown.

Leisure-time physical activity was inversely related to risk of developing heart failure. A dose-response association was present, with decreasing risk with increasing level of leisure-time physical activity. Only little additional benefit was present above $3 \mathrm{METh} /$ day. This corresponds well with general recommendations of at least 150 min moderate intensity physical activity per week. Most of the effect was direct, with little observed mediation by other investigated risk factors. Total physical activity was also inversely related to risk of developing heart failure. The largest effect was seen in the lower end of the physical activity distribution with little additional effect in the higher end of physical activity distribution.

Finishing time and number of races in a $90 \mathrm{~km}$ skiing event during a ten years follow-up was associated with higher risk of arrhythmias. This was mainly driven by a higher risk of atrial fibrillation and bradyarrhythmias. No association between number of completed races or finishing time and other SVT or dangerous arrhythmias such as VT/VF/SCD was observed.

Higher exercise capacity and higher muscle strength in late adolescence were independently associated with lower risk of subsequent vascular disease in a large cohort of young men. It is possible that different modes of training do not differ substantially in their potential of preventing vascular disease. We observed a U-shaped association of exercise capacity with risk of arrhythmias, driven by a direct association with higher risk of atrial fibrillation/flutter and also a similar U-shaped association with risk of bradyarrhythmias. Higher muscle strength was associated with lower risk of arrhythmias, driven by a lower risk of bradyarrhythmias and ventricular arrhythmias. The lower risk of vascular events with higher exercise capacity did not appear to be outweighed by higher risk of arrhythmias. 
Summarized, the studies in this thesis suggest an association of physical activity level with risk of atrial fibrillation, mainly at high levels of physical activity and mainly with endurance-type exercise. The increased risk of atrial fibrillation seems not to lead to an increased risk of stroke. In contrast, we observed lower risk of vascular diseases with higher physical activity, exercise capacity and muscle strength. The total impact of higher physical activity on cardiovascular disease is positive. 


\section{Acknowledgements}

I wish to express my sincere gratitude and appreciation to all those who helped me complete this thesis, with special thanks to:

My supervisor Johan for introducing me to epidemiology, sharing your extensive knowledge, teaching me Stata-programming, stimulating thoughtprovoking discussions and not to forget to introduce me to Uppsala Storband. I am forever grateful!

My co-supervisor Claes for valuable discussions and comments. For support and encouraging comments when meeting in the corridor.

Daniela for good team-work on the National March Cohort manuscript.

My co-authors for great comments and letting me work with your excellent material.

The research group for good advices and support, stimulating discussions and to always dare to question the truth.

My colleagues at department of Cardiology.

All patients and participants of the studies - especially the 512 men in the ULSAM cohort, who under much pain gave us access small to samples of their Vastus Lateralis muscle.

The geriatric fund for finical support.

Karina for discussions of studies and statistics, proofreading and most of all - your love.

Jonatan, Tobias and Vilma for being my wonderful kids.

My family and friends. 


\section{Reference List}

1. IOC Medical Commission. Endurance in Sport. 2nd ed: Blackwell Science; 2000.

2. Fleck SJ, W.J. K. Designing resistance training programs. 2004.

3. World Health O. Global health risks: mortality and burden of disease attributable to selected major risks: WHO Library Cataloguing-inPublication Data; 2009.

4. Morris JN, Heady JA, Raffle PA, Roberts CG, Parks JW. Coronary heart-disease and physical activity of work. Lancet 1953;265(6795):1053-7; contd.

5. Paffenbarger RS, Jr., Blair SN, Lee IM. A history of physical activity, cardiovascular health and longevity: the scientific contributions of Jeremy N Morris, DSc, DPH, FRCP. Int J Epidemiol 2001;30(5):118492.

6. Nocon M, Hiemann T, Muller-Riemenschneider F, Thalau F, Roll S, Willich SN. Association of physical activity with all-cause and cardiovascular mortality: a systematic review and meta-analysis. Eur $\mathbf{J}$ Cardiovasc Prev Rehabil 2008;15(3):239-46.

7. Rosengren A, Wilhelmsen L. Physical activity protects against coronary death and deaths from all causes in middle-aged men. Evidence from a 20 -year follow-up of the primary prevention study in Goteborg. Ann Epidemiol 1997;7(1):69-75.

8. Sattelmair J, Pertman J, Ding EL, Kohl HW, 3rd, Haskell W, Lee IM. Dose response between physical activity and risk of coronary heart disease: a meta-analysis. Circulation 2011;124(7):789-95.

9. Booth FW, Laye MJ, Roberts MD. Lifetime sedentary living accelerates some aspects of secondary aging. J Appl Physiol 2011;111(5):1497-504. 
10. Blair SN, Kohl HW, 3rd, Paffenbarger RS, Jr., Clark DG, Cooper KH, Gibbons LW. Physical fitness and all-cause mortality. A prospective study of healthy men and women. JAMA 1989;262(17):2395-401.

11. Kokkinos P, Myers J, Kokkinos JP, Pittaras A, Narayan P, Manolis A, Karasik P, Greenberg M, Papademetriou V, Singh S. Exercise capacity and mortality in black and white men. Circulation 2008;117(5):614-22.

12. Erikssen G, Liestol K, Bjornholt J, Thaulow E, Sandvik L, Erikssen J. Changes in physical fitness and changes in mortality. Lancet 1998;352(9130):759-62.

13. Blair SN, Kohl HW, 3rd, Barlow CE, Paffenbarger RS, Jr., Gibbons LW, Macera CA. Changes in physical fitness and all-cause mortality. A prospective study of healthy and unhealthy men. JAMA 1995;273(14):1093-8.

14. Lee DC, Artero EG, Sui X, Blair SN. Mortality trends in the general population: the importance of cardiorespiratory fitness. J Psychopharmacol 2010;24(4 Suppl):27-35.

15. Ortega FB, Ruiz JR, Castillo MJ, Sjostrom M. Physical fitness in childhood and adolescence: a powerful marker of health. Int $\mathrm{J}$ Obes (Lond) 2008;32(1):1-11.

16. Lee S, Bacha F, Gungor N, Arslanian SA. Cardiorespiratory fitness in youth: relationship to insulin sensitivity and beta-cell function. Obesity (Silver Spring) 2006;14(9):1579-85.

17. Berman LJ, Weigensberg MJ, Spruijt-Metz D. Physical activity is related to insulin sensitivity in children and adolescents, independent of adiposity: a review of the literature. Diabetes Metab Res Rev 2012;28(5):395-408.

18. Artero EG, Lee DC, Ruiz JR, Sui X, Ortega FB, Church TS, Lavie CJ, Castillo MJ, Blair SN. A prospective study of muscular strength and allcause mortality in men with hypertension. J Am Coll Cardiol 2011;57(18):1831-7.

19. Ruiz JR, Sui X, Lobelo F, Morrow JR, Jr., Jackson AW, Sjostrom M, Blair SN. Association between muscular strength and mortality in men: prospective cohort study. BMJ 2008;337:a439.

20. Sasaki H, Kasagi F, Yamada M, Fujita S. Grip strength predicts causespecific mortality in middle-aged and elderly persons. Am J Med 2007;120(4):337-42. 
21. Gale CR, Martyn CN, Cooper C, Sayer AA. Grip strength, body composition, and mortality. Int J Epidemiol 2007;36(1):228-35.

22. Metter EJ, Talbot LA, Schrager M, Conwit R. Skeletal muscle strength as a predictor of all-cause mortality in healthy men. J Gerontol A Biol Sci Med Sci 2002;57(10):B359-65.

23. Katzmarzyk PT, Craig CL. Musculoskeletal fitness and risk of mortality. Med Sci Sports Exerc 2002;34(5):740-4.

24. Rantanen T, Harris T, Leveille SG, Visser M, Foley D, Masaki K, Guralnik JM. Muscle strength and body mass index as long-term predictors of mortality in initially healthy men. J Gerontol A Biol Sci Med Sci 2000;55(3):M168-73.

25. Rantanen T, Masaki K, He Q, Ross GW, Willcox BJ, White L. Midlife muscle strength and human longevity up to age 100 years: a 44-year prospective study among a decedent cohort. Age (Dordr) 2012;34(3):563-70.

26. Ortega FB, Silventoinen K, Tynelius P, Rasmussen F. Muscular strength in male adolescents and premature death: cohort study of one million participants. BMJ 2012;345:e7279.

27. Artero EG, Lee DC, Lavie CJ, Espana-Romero V, Sui X, Church TS, Blair SN. Effects of muscular strength on cardiovascular risk factors and prognosis. J Cardiopulm Rehabil Prev 2012;32(6):351-8.

28. Lightfoot JT. Current understanding of the genetic basis for physical activity. J Nutr 2011;141(3):526-30.

29. Fagard R. Athlete's heart. Heart 2003;89(12):1455-61.

30. MacDougall JD, Tuxen D, Sale DG, Moroz JR, Sutton JR. Arterial blood pressure response to heavy resistance exercise. J Appl Physiol 1985;58(3):785-90.

31. Morganroth J, Maron BJ, Henry WL, Epstein SE. Comparative left ventricular dimensions in trained athletes. Ann Intern Med 1975;82(4):521-4.

32. Maron BJ. Structural features of the athlete heart as defined by echocardiography. J Am Coll Cardiol. 1986;7(1):190-203. 
33. Verdecchia P, Angeli F, Achilli P, Castellani C, Broccatelli A, Gattobigio R, Cavallini C. Echocardiographic left ventricular hypertrophy in hypertension: marker for future events or mediator of events? Curr Opin Cardiol 2007;22(4):329-34.

34. Naylor LH, George K, O'Driscoll G, Green DJ. The athlete's heart: a contemporary appraisal of the 'Morganroth hypothesis'. Sports Med 2008;38(1):69-90.

35. Spence AL, Naylor LH, Carter HH, Buck CL, Dembo L, Murray CP, Watson P, Oxborough D, George KP, Green DJ. A prospective randomised longitudinal MRI study of left ventricular adaptation to endurance and resistance exercise training in humans. J Physiol 2011;589(Pt 22):5443-52.

36. Vogelsang TW, Hanel B, Kristoffersen US, Petersen CL, Mehlsen J, Holmquist N, Larsson B, Kjaer A. Effect of eight weeks of endurance exercise training on right and left ventricular volume and mass in untrained obese subjects: a longitudinal MRI study. Scand J Med Sci Sports 2008;18(3):354-9.

37. Corrado D, Basso C, Rizzoli G, Schiavon M, Thiene G. Does sports activity enhance the risk of sudden death in adolescents and young adults? J Am Coll Cardiol 2003;42(11):1959-63.

38. Link MS, Mark Estes NA, 3rd. Sudden cardiac death in athletes. Prog Cardiovasc Dis 2008;51(1):44-57.

39. Maron BJ, Thompson PD, Ackerman MJ, Balady G, Berger S, Cohen D, Dimeff R, Douglas PS, Glover DW, Hutter AM, Jr., Krauss MD, Maron MS, Mitten MJ, Roberts WO, Puffer JC. Recommendations and Considerations Related to Preparticipation Screening for Cardiovascular Abnormalities in Competitive Athletes: 2007 Update: A Scientific Statement From the American Heart Association Council on Nutrition, Physical Activity, and Metabolism: Endorsed by the American College of Cardiology Foundation. Circulation 2007;115(12):1643-1655.

40. Farahmand B, Hallmarker U, Brobert GP, Ahlbom A. Acute mortality during long-distance ski races (Vasaloppet). Scand J Med Sci Sports 2007;17(4):356-61.

41. Pelliccia A, Maron BJ, Di Paolo FM, Biffi A, Quattrini FM, Pisicchio C, Roselli A, Caselli S, Culasso F. Prevalence and clinical significance of left atrial remodeling in competitive athletes. J Am Coll Cardiol 2005;46(4):690-6. 
42. Pelliccia A, Culasso F, Di Paolo FM, Maron BJ. Physiologic left ventricular cavity dilatation in elite athletes. Ann Intern Med 1999;130(1):23-31.

43. Karjalainen J, Kujala UM, Kaprio J, Sarna S, Viitasalo M. Lone atrial fibrillation in vigorously exercising middle aged men: case-control study. BMJ 1998;316(7147):1784-5.

44. Elosua R, Arquer A, Mont L, Sambola A, Molina L, Garcia-Moran E, Brugada J, Marrugat J. Sport practice and the risk of lone atrial fibrillation: a case-control study. Int J Cardiol 2006;108(3):332-7.

45. Heidbuchel H, Anne W, Willems R, Adriaenssens B, Van de Werf F, Ector H. Endurance sports is a risk factor for atrial fibrillation after ablation for atrial flutter. Int J Cardiol 2006;107(1):67-72.

46. Molina L, Mont L, Marrugat J, Berruezo A, Brugada J, Bruguera J, Rebato C, Elosua R. Long-term endurance sport practice increases the incidence of lone atrial fibrillation in men: a follow-up study. Europace 2008;10(5):618-623.

47. Flegel KM, Shipley MJ, Rose G. Risk of stroke in non-rheumatic atrial fibrillation. Lancet 1987;1(8532):526-9.

48. Wolf PA, Dawber TR, Thomas HE, Jr., Kannel WB. Epidemiologic assessment of chronic atrial fibrillation and risk of stroke: the Framingham study. Neurology 1978;28(10):973-7.

49. Frisoli TM, Schmieder RE, Grodzicki T, Messerli FH. Beyond salt: lifestyle modifications and blood pressure. Eur Heart J 2011;32(24):3081-7.

50. Cornelissen VA, Fagard RH. Effects of endurance training on blood pressure, blood pressure-regulating mechanisms, and cardiovascular risk factors. Hypertension 2005;46(4):667-75.

51. Cornelissen VA, Fagard RH, Coeckelberghs E, Vanhees L. Impact of resistance training on blood pressure and other cardiovascular risk factors: a meta-analysis of randomized, controlled trials. Hypertension 2011;58(5):950-8.

52. Jeon CY, Lokken RP, Hu FB, van Dam RM. Physical activity of moderate intensity and risk of type 2 diabetes: a systematic review. Diabetes Care 2007;30(3):744-52. 
53. Frosig C, Richter EA. Improved Insulin Sensitivity After Exercise: Focus on Insulin Signaling. Obesity 2009;17(n3s):S15-S20.

54. Kennedy JW, Hirshman MF, Gervino EV, Ocel JV, Forse RA, Hoenig SJ, Aronson D, Goodyear LJ, Horton ES. Acute exercise induces GLUT4 translocation in skeletal muscle of normal human subjects and subjects with type 2 diabetes. Diabetes 1999;48(5):1192-1197.

55. Perseghin G, Price TB, Petersen KF, Roden M, Cline GW, Gerow K, Rothman DL, Shulman GI. Increased glucose transport-phosphorylation and muscle glycogen synthesis after exercise training in insulinresistant subjects. N Engl J Med 1996;335(18):1357-62.

56. Kujala UM, Makinen VP, Heinonen I, Soininen P, Kangas AJ, Leskinen TH, Rahkila P, Wurtz P, Kovanen V, Cheng S, Sipila S, Hirvensalo M, Telama R, Tammelin T, Savolainen MJ, Pouta A, O'Reilly PF, Mantyselka P, Viikari J, Kahonen M, Lehtimaki T, Elliott P, Vanhala MJ, Raitakari OT, Jarvelin MR, Kaprio J, Kainulainen H, Ala-Korpela M. Long-term leisure-time physical activity and serum metabolome. Circulation 2013;127(3):340-8.

57. Kraus WE, Houmard JA, Duscha BD, Knetzger KJ, Wharton MB, McCartney JS, Bales CW, Henes S, Samsa GP, Otvos JD, Kulkarni KR, Slentz CA. Effects of the amount and intensity of exercise on plasma lipoproteins. N Engl J Med 2002;347(19):1483-92.

58. Tikkanen HO, Naveri H, Harkonen M. Skeletal muscle fiber distribution influences serum high-density lipoprotein cholesterol level. Atherosclerosis 1996;120(1-2):1-5.

59. Tikkanen HO, Hamalainen E, Harkonen M. Significance of skeletal muscle properties on fitness, long-term physical training and serum lipids. Atherosclerosis 1999;142(2):367-78.

60. Landmesser U, Hornig B, Drexler H. Endothelial function: a critical determinant in atherosclerosis? Circulation 2004;109(21 Suppl 1):II2733.

61. Moyna NM, Thompson PD. The effect of physical activity on endothelial function in man. Acta Physiol Scand 2004;180(2):113-23.

62. Pahkala K, Heinonen OJ, Simell O, Viikari JS, Ronnemaa T, Niinikoski H, Raitakari OT. Association of physical activity with vascular endothelial function and intima-media thickness. Circulation 2011;124(18):1956-63. 
63. Ghisi GL, Durieux A, Pinho R, Benetti M. Physical exercise and endothelial dysfunction. Arq Bras Cardiol 2010;95(5):e130-7.

64. Duncan BB, Schmidt MI, Pankow JS, Ballantyne CM, Couper D, Vigo A, Hoogeveen R, Folsom AR, Heiss G. Low-grade systemic inflammation and the development of type 2 diabetes: the atherosclerosis risk in communities study. Diabetes 2003;52(7):1799805.

65. Pradhan AD, Manson JE, Rifai N, Buring JE, Ridker PM. C-reactive protein, interleukin 6 , and risk of developing type 2 diabetes mellitus. JAMA 2001;286(3):327-34.

66. Barzilay JI, Abraham L, Heckbert SR, Cushman M, Kuller LH, Resnick HE, Tracy RP. The relation of markers of inflammation to the development of glucose disorders in the elderly: the Cardiovascular Health Study. Diabetes 2001;50(10):2384-9.

67. Han TS, Sattar N, Williams K, Gonzalez-Villalpando C, Lean ME, Haffner SM. Prospective study of C-reactive protein in relation to the development of diabetes and metabolic syndrome in the Mexico City Diabetes Study. Diabetes Care 2002;25(11):2016-21.

68. Vozarova B, Weyer C, Lindsay RS, Pratley RE, Bogardus C, Tataranni PA. High white blood cell count is associated with a worsening of insulin sensitivity and predicts the development of type 2 diabetes. Diabetes 2002;51(2):455-61.

69. Freeman DJ, Norrie J, Caslake MJ, Gaw A, Ford I, Lowe GD, O'Reilly DS, Packard CJ, Sattar N. C-reactive protein is an independent predictor of risk for the development of diabetes in the West of Scotland Coronary Prevention Study. Diabetes 2002;51(5):1596-600.

70. Ford ES. Leukocyte count, erythrocyte sedimentation rate, and diabetes incidence in a national sample of US adults. Am $\mathrm{J}$ Epidemiol 2002;155(1):57-64.

71. Nakanishi N, Yoshida H, Matsuo Y, Suzuki K, Tatara K. White bloodcell count and the risk of impaired fasting glucose or Type II diabetes in middle-aged Japanese men. Diabetologia 2002;45(1):42-8.

72. Festa A, D'Agostino R, Jr., Tracy RP, Haffner SM. Elevated levels of acute-phase proteins and plasminogen activator inhibitor-1 predict the development of type 2 diabetes: the insulin resistance atherosclerosis study. Diabetes 2002;51(4):1131-7. 
73. Bruunsgaard H, Andersen-Ranberg K, Hjelmborg JB, Pedersen BK, Jeune B. Elevated levels of tumor necrosis factor alpha and mortality in centenarians. Am J Med 2003;115(4):278-83.

74. Bruunsgaard H, Ladelund S, Pedersen AN, Schroll M, Jorgensen T, Pedersen BK. Predicting death from tumour necrosis factor-alpha and interleukin-6 in 80-year-old people. Clin Exp Immunol 2003;132(1):2431.

75. Harris TB, Ferrucci L, Tracy RP, Corti MC, Wacholder S, Ettinger WH, Jr., Heimovitz H, Cohen HJ, Wallace R. Associations of elevated interleukin-6 and C-reactive protein levels with mortality in the elderly. Am J Med 1999;106(5):506-12.

76. Volpato S, Guralnik JM, Ferrucci L, Balfour J, Chaves P, Fried LP, Harris TB. Cardiovascular disease, interleukin-6, and risk of mortality in older women: the women's health and aging study. Circulation 2001;103(7):947-53.

77. Reuben DB, Cheh AI, Harris TB, Ferrucci L, Rowe JW, Tracy RP, Seeman TE. Peripheral blood markers of inflammation predict mortality and functional decline in high-functioning community-dwelling older persons. J Am Geriatr Soc 2002;50(4):638-44.

78. Roubenoff R, Parise H, Payette HA, Abad LW, D'Agostino R, Jacques PF, Wilson PW, Dinarello CA, Harris TB. Cytokines, insulin-like growth factor 1, sarcopenia, and mortality in very old communitydwelling men and women: the Framingham Heart Study. Am J Med 2003;115(6):429-35.

79. Mooradian AD, Reed RL, Osterweil D, Scuderi P. Detectable serum levels of tumor necrosis factor alpha may predict early mortality in elderly institutionalized patients. J Am Geriatr Soc 1991;39(9):891-4.

80. Rosenthal AJ, McMurtry CT, Sanders KM, Jacobs M, Thompson D, Adler RA. The soluble interleukin-2 receptor predicts mortality in older hospitalized men. J Am Geriatr Soc 1997;45(11):1362-4.

81. Weijenberg MP, Feskens EJ, Kromhout D. White blood cell count and the risk of coronary heart disease and all-cause mortality in elderly men. Arterioscler Thromb Vasc Biol 1996;16(4):499-503.

82. Cappola AR, Xue QL, Ferrucci L, Guralnik JM, Volpato S, Fried LP. Insulin-like growth factor I and interleukin-6 contribute synergistically to disability and mortality in older women. J Clin Endocrinol Metab 2003;88(5):2019-25. 
83. Yeh SS, Hafner A, Chang CK, Levine DM, Parker TS, Schuster MW. Risk factors relating blood markers of inflammation and nutritional status to survival in cachectic geriatric patients in a randomized clinical trial. J Am Geriatr Soc 2004;52(10):1708-12.

84. Reilly MP, Rohatgi A, McMahon K, Wolfe ML, Pinto SC, Rhodes T, Girman C, Rader DJ. Plasma cytokines, metabolic syndrome, and atherosclerosis in humans. J Investig Med 2007;55(1):26-35.

85. Pedersen BK. The diseasome of physical inactivity--and the role of myokines in muscle--fat cross talk. J Physiol 2009;587(Pt 23):5559-68.

86. Hopps E, Canino B, Caimi G. Effects of exercise on inflammation markers in type 2 diabetic subjects. Acta Diabetol 2011;48(3):183-9.

87. Joyner MJ, Green DJ. Exercise protects the cardiovascular system: effects beyond traditional risk factors. J Physiol 2009;587(23):55515558.

88. Harridge SDR. Plasticity of human skeletal muscle: gene expression to in vivo function. Exp Physiol 2007;92(5):783-797.

89. Bottinelli R, Reggiani C. Human skeletal muscle fibres: molecular and functional diversity. Prog Biophys Mol Biol 2000;73(2-4):195-262.

90. Staron RS, Hagerman FC, Hikida RS, Murray TF, Hostler DP, Crill MT, Ragg KE, Toma K. Fiber Type Composition of the Vastus Lateralis Muscle of Young Men and Women. J Histochem Cytochem 2000;48(5):623-629.

91. Gollnick PD, Armstrong RB, Saubert CWt, Piehl K, Saltin B. Enzyme activity and fiber composition in skeletal muscle of untrained and trained men. J Appl Physiol 1972;33(3):312-9.

92. Campos GE, Luecke TJ, Wendeln HK, Toma K, Hagerman FC, Murray TF, Ragg KE, Ratamess NA, Kraemer WJ, Staron RS. Muscular adaptations in response to three different resistance-training regimens: specificity of repetition maximum training zones. Eur J Appl Physiol 2002;88(1-2):50-60.

93. Sharman MJ, Newton RU, Triplett-McBride T, McGuigan MR, McBride JM, Hakkinen A, Hakkinen K, Kraemer WJ. Changes in myosin heavy chain composition with heavy resistance training in 60to 75-year-old men and women. Eur J Appl Physiol 2001;84(1-2):12732 . 
94. Short KR, Vittone JL, Bigelow ML, Proctor DN, Coenen-Schimke JM, Rys P, Nair KS. Changes in myosin heavy chain mRNA and protein expression in human skeletal muscle with age and endurance exercise training. J Appl Physiol 2005;99(1):95-102.

95. Borina E, Pellegrino MA, D'Antona G, Bottinelli R. Myosin and actin content of human skeletal muscle fibers following 35 days bed rest. Scand J Med Sci Sports 2010;20(1):65-73.

96. Daugaard JR, Nielsen JN, Kristiansen S, Andersen JL, Hargreaves M, Richter EA. Fiber type-specific expression of GLUT4 in human skeletal muscle: influence of exercise training. Diabetes 2000;49(7):1092-1095.

97. Putman CT, Martins KJ, Gallo ME, Lopaschuk GD, Pearcey JA, MacLean IM, Saranchuk RJ, Pette D. Alpha-catalytic subunits of 5'AMP-activated protein kinase display fiber-specific expression and are upregulated by chronic low-frequency stimulation in rat muscle. Am J Physiol Regul Integr Comp Physiol 2007;293(3):R1325-34.

98. Lee-Young RS, Canny BJ, Myers DE, McConell GK. AMPK activation is fiber type specific in human skeletal muscle: effects of exercise and short-term exercise training. J Appl Physiol 2009;107(1):283-9.

99. Georgiadou P, Adamopoulos S. Skeletal muscle abnormalities in chronic heart failure. Curr Heart Fail Rep 2012;9(2):128-32.

100. Ferguson RJ, Taylor AW, Cote P, Charlebois J, Dinelle Y, Peronnet F, De Champlain J, Bourassa MG. Skeletal muscle and cardiac changes with training in patients with angina pectoris. Am $\mathrm{J}$ Physiol 1982;243(5):H830-6.

101. Whittom F, Jobin J, Simard PM, Leblanc P, Simard C, Bernard S, Belleau R, Maltais F. Histochemical and morphological characteristics of the vastus lateralis muscle in patients with chronic obstructive pulmonary disease. Med Sci Sports Exerc 1998;30(10):1467-74.

102. Ingelsson E, Arnlov J, Sundstrom J, Lind L. The validity of a diagnosis of heart failure in a hospital discharge register. Eur J Heart Fail 2005;7(5):787-791.

103. Westerterp KR. Assessment of physical activity: a critical appraisal. Eur J Appl Physiol 2009;105(6):823-8.

104. Lochen ML, Rasmussen K. The Tromso study: physical fitness, self reported physical activity, and their relationship to other coronary risk factors. J Epidemiol.Community Health 1992;46(2):103-107. 
105. Sequeira MM, Rickenbach M, Wietlisbach V, Tullen B, Schutz Y. Physical activity assessment using a pedometer and its comparison with a questionnaire in a large population survey. Am J Epidemiol 1995;142(9):989-99.

106. Michaelsson K, Olofsson H, Jensevik K, Larsson S, Mallmin H, Berglund L, Vessby B, Melhus H. Leisure physical activity and the risk of fracture in men. PLoS Med 2007;4(6):e199.

107. Lagerros YT, Bellocco R, Adami HO, Nyren O. Measures of physical activity and their correlates: the Swedish National March Cohort. Eur J Epidemiol 2009;24(4):161-9.

108. Malek MH, Berger DE, Housh TJ, Coburn JW, Beck TW. Validity of VO2max equations for aerobically trained males and females. Med Sci Sports Exerc 2004;36(8):1427-32.

109. Storer TW, Davis JA, Caiozzo VJ. Accurate prediction of VO2max in cycle ergometry. Med Sci Sports Exerc 1990;22(5):704-12.

110. Heimburger O, Qureshi AR, Blaner WS, Berglund L, Stenvinkel P. Hand-grip muscle strength, lean body mass, and plasma proteins as markers of nutritional status in patients with chronic renal failure close to start of dialysis therapy. Am J Kidney Dis 2000;36(6):1213-25.

111. Shin H, Liu PY, Panton LB, Ilich JZ. Physical Performance in Relation to Body Composition and Bone Mineral Density in Healthy, Overweight, and Obese Postmenopausal Women. J Geriatr Phys Ther 2013.

112. Taaffe DR, Cauley JA, Danielson M, Nevitt MC, Lang TF, Bauer DC, Harris TB. Race and sex effects on the association between muscle strength, soft tissue, and bone mineral density in healthy elders: the Health, Aging, and Body Composition Study. J Bone Miner Res 2001;16(7):1343-52.

113. Hernelahti M, Tikkanen HO, Karjalainen J, Kujala UM. Muscle fibertype distribution as a predictor of blood pressure: a 19-year follow-up study. Hypertension 2005;45(5):1019-23.

114. Karjalainen J, Tikkanen H, Hernelahti M, Kujala UM. Muscle fibertype distribution predicts weight gain and unfavorable left ventricular geometry: a 19 year follow-up study. BMC Cardiovasc Disord 2006;6:2. 
115. Tikkanen HO, Hamalainen E, Sarna S, Adlercreutz H, Harkonen M. Associations between skeletal muscle properties, physical fitness, physical activity and coronary heart disease risk factors in men. Atherosclerosis 1998;137(2):377-89.

116. Tikkanen HO, Harkonen M, Naveri H, Hamalainen E, Elovainio R, Sarna S, Frick MH. Relationship of skeletal muscle fiber type to serum high density lipoprotein cholesterol and apolipoprotein A-I levels. Atherosclerosis 1991;90(1):49-57.

117. Hu G, Jousilahti P, Antikainen R, Katzmarzyk PT, Tuomilehto J. Joint Effects of Physical Activity, Body Mass Index, Waist Circumference, and Waist-to-Hip Ratio on the Risk of Heart Failure. Circulation 2010;121(2):237-244.

118. Wang Y, Tuomilehto J, Jousilahti P, Antikainen R, Mahonen M, Katzmarzyk PT, Hu G. Occupational, commuting, and leisure-time physical activity in relation to heart failure among finnish men and women. J Am Coll Cardiol 2010;56(14):1140-8.

119. Kenchaiah S, Sesso HD, Gaziano JM. Body mass index and vigorous physical activity and the risk of heart failure among men. Circulation 2009;119(1):44-52.

120. He J, Ogden LG, Bazzano LA, Vupputuri S, Loria C, Whelton PK. Risk factors for congestive heart failure in US men and women: NHANES I epidemiologic follow-up study. Arch Intern Med 2001;161(7):9961002.

121. Aizer A, Gaziano JM, Cook NR, Manson JE, Buring JE, Albert CM. Relation of vigorous exercise to risk of atrial fibrillation. Am J Cardiol 2009;103(11):1572-7.

122. Grimsmo J, Grundvold I, Maehlum S, Arnesen H. High prevalence of atrial fibrillation in long-term endurance cross-country skiers: echocardiographic findings and possible predictors - a 28-30 years follow-up study. Eur J Cardiovasc Prev Rehabil 2010;17(1):100-5.

123. Claessen G, Colyn E, La Gerche A, Koopman P, Alzand B, Garweg C, Willems R, Nuyens D, Heidbuchel H. Long-term endurance sport is a risk factor for development of lone atrial flutter. Heart 2011;97(11):918-22.

124. Whelton SP, Chin A, Xin X, He J. Effect of aerobic exercise on blood pressure: a meta-analysis of randomized, controlled trials. Ann Intern Med 2002;136(7):493-503. 
125. Hedman, Berglund, Essén G, Reneland, Lithell. Relationships between muscle morphology and insulin sensitivity are improved after adjustment for intra-individual variability in 70-year-old men. Acta Physiologica Scandinavica 2000;169(2):125-132.

126. Colberg SR, Sigal RJ, Fernhall B, Regensteiner JG, Blissmer BJ, Rubin RR, Chasan-Taber L, Albright AL, Braun B, American College of Sports M, American Diabetes A. Exercise and type 2 diabetes: the American College of Sports Medicine and the American Diabetes Association: joint position statement. Diabetes Care 2010;33(12):e14767.

127. Green DJ, Spence A, Rowley N, Thijssen DH, Naylor LH. Vascular adaptation in athletes: is there an 'athlete's artery'? Exp Physiol 2012;97(3):295-304.

128. Andersen K, Pedersen BK. The role of inflammation in vascular insulin resistance with focus on IL-6. Horm Metab Res 2008;40(9):635-9.

129. Wannamethee SG, Lowe GDO, Whincup PH, Rumley A, Walker M, Lennon L. Physical Activity and Hemostatic and Inflammatory Variables in Elderly Men. Circulation 2002;105(15):1785-1790.

130. Pedersen BK, Febbraio MA. Muscles, exercise and obesity: skeletal muscle as a secretory organ. Nat Rev Endocrinol 2012;8(8):457-65.

131. Pedersen BK. Exercise-induced myokines and their role in chronic diseases. Brain Behav Immun 2011;25(5):811-6.

132. Haissaguerre M, Jais P, Shah DC, Takahashi A, Hocini M, Quiniou G, Garrigue S, Le Mouroux A, Le Metayer P, Clementy J. Spontaneous initiation of atrial fibrillation by ectopic beats originating in the pulmonary veins. N Engl J Med 1998;339(10):659-66.

133. Palatini P, Maraglino G, Sperti G, Calzavara A, Libardoni M, Pessina AC, Dal Palu C. Prevalence and possible mechanisms of ventricular arrhythmias in athletes. Am Heart J 1985;110(3):560-7.

134. Biffi A, Maron BJ, Culasso F, Verdile L, Fernando F, Di Giacinto B, Di Paolo FM, Spataro A, Delise P, Pelliccia A. Patterns of ventricular tachyarrhythmias associated with training, deconditioning and retraining in elite athletes without cardiovascular abnormalities. Am J Cardiol 2011;107(5):697-703. 
135. Baldesberger S, Bauersfeld U, Candinas R, Seifert B, Zuber M, Ritter M, Jenni R, Oechslin E, Luthi P, Scharf C, Marti B, Attenhofer Jost $\mathrm{CH}$. Sinus node disease and arrhythmias in the long-term follow-up of former professional cyclists. Eur Heart J 2008;29(1):71-8.

136. Wilhelm M, Roten L, Tanner H, Wilhelm I, Schmid JP, Saner H. Atrial remodeling, autonomic tone, and lifetime training hours in nonelite athletes. Am J Cardiol 2011;108(4):580-5.

137. Mont L, Elosua R, Brugada J. Endurance sport practice as a risk factor for atrial fibrillation and atrial flutter. Europace 2009;11(1):11-17.

138. Mont Ls, Tamborero D, Elosua R, Molina I, Coll-Vinent B, Sitges M, Vidal B, Scalise A, Tejeira A, Berruezo A, Brugada J. Physical activity, height, and left atrial size are independent risk factors for lone atrial fibrillation in middle-aged healthy individuals. Europace 2008;10(1):15-20.

139. Allessie M, Ausma J, Schotten U. Electrical, contractile and structural remodeling during atrial fibrillation. Cardiovasc Res 2002;54(2):23046.

140. Lindsay MM, Dunn FG. Biochemical evidence of myocardial fibrosis in veteran endurance athletes. Br J Sports Med 2007;41(7):447-52.

141. Benito B, Gay-Jordi G, Serrano-Mollar A, Guasch E, Shi Y, Tardif JC, Brugada J, Nattel S, Mont L. Cardiac arrhythmogenic remodeling in a rat model of long-term intensive exercise training. Circulation 2011;123(1):13-22.

142. Guasch E, Benito B, Qi X, Cifelli C, Naud P, Shi Y, Mighiu A, Tardif JC, Tadevosyan A, Chen Y, Gillis MA, Iwasaki YK, Dobrev D, Mont L, Heximer S, Nattel S. Atrial fibrillation promotion by endurance exercise: demonstration and mechanistic exploration in an animal model. J Am Coll Cardiol 2013;62(1):68-77.

143. Telama R. Tracking of physical activity from childhood to adulthood: a review. Obes Facts 2009;2(3):187-95.

144. Pelliccia A, Maron BJ, Culasso F, Di Paolo FM, Spataro A, Biffi A, Caselli G, Piovano P. Clinical Significance of Abnormal Electrocardiographic Patterns in Trained Athletes. Circulation 2000;102(3):278-284. 
145. Bjornstad HH, Bjornstad TH, Urheim S, Hoff PI, Smith G, Maron BJ. Long-term assessment of electrocardiographic and echocardiographic findings in Norwegian elite endurance athletes. Cardiology 2009;112(3):234-41.

146. Jensen-Urstad K, Bouvier F, Saltin B, Jensen-Urstad M. High prevalence of arrhythmias in elderly male athletes with a lifelong history of regular strenuous exercise. Heart 1998;79(2):161-164.

147. Zehender M, Meinertz T, Keul J, Just H. ECG variants and cardiac arrhythmias in athletes: clinical relevance and prognostic importance. Am Heart J 1990;119(6):1378-91.

148. Kobza R, Cuculi F, Abacherli R, Toggweiler S, Suter Y, Frey F, Schmid JJ, Erne P. Twelve-lead electrocardiography in the young: physiologic and pathologic abnormalities. Heart Rhythm 2012;9(12):2018-22.

149. Friberg L, Bergfeldt L. Atrial fibrillation prevalence revisited. J Intern Med 2013;274(5):461-468.

150. Pluim BM, Zwinderman AH, van der Laarse A, van der Wall EE. The athlete's heart. A meta-analysis of cardiac structure and function. Circulation 2000;101(3):336-44.

151. Corrado D, Pelliccia A, Bjornstad HH, Vanhees L, Biffi A, Borjesson M, Panhuyzen-Goedkoop N, Deligiannis A, Solberg E, Dugmore D, Mellwig KP, Assanelli D, Delise P, van-Buuren F, Anastasakis A, Heidbuchel H, Hoffmann E, Fagard R, Priori SG, Basso C, Arbustini E, Blomstrom-Lundqvist C, McKenna WJ, Thiene G, Study Group of Sport Cardiology of the Working Group of Cardiac R, Exercise P, the Working Group of M, Pericardial Diseases of the European Society of C. Cardiovascular pre-participation screening of young competitive athletes for prevention of sudden death: proposal for a common European protocol. Consensus Statement of the Study Group of Sport Cardiology of the Working Group of Cardiac Rehabilitation and Exercise Physiology and the Working Group of Myocardial and Pericardial Diseases of the European Society of Cardiology. Eur Heart J 2005;26(5):516-24. 
152. Pelliccia A, Fagard R, Bjornstad HH, Anastassakis A, Arbustini E, Assanelli D, Biffi A, Borjesson M, Carre F, Corrado D, Delise P, Dorwarth U, Hirth A, Heidbuchel H, Hoffmann E, Mellwig KP, Panhuyzen-Goedkoop N, Pisani A, Solberg EE, van-Buuren F, Vanhees L, Blomstrom-Lundqvist C, Deligiannis A, Dugmore D, Glikson M, Hoff PI, Hoffmann A, Hoffmann E, Horstkotte D, Nordrehaug JE, Oudhof J, McKenna WJ, Penco M, Priori S, Reybrouck T, Senden J, Spataro A, Thiene G, Study Group of Sports Cardiology of the Working Group of Cardiac R, Exercise P, Working Group of M, Pericardial Diseases of the European Society of C. Recommendations for competitive sports participation in athletes with cardiovascular disease: a consensus document from the Study Group of Sports Cardiology of the Working Group of Cardiac Rehabilitation and Exercise Physiology and the Working Group of Myocardial and Pericardial Diseases of the European Society of Cardiology. Eur Heart J 2005;26(14):1422-45.

153. Last JMe. Dictionary of Epidemiology. 3rd ed. New York: Oxford University Press, New Yor.

154. Lagerros YT, Mucci LA, Bellocco R, Nyren O, Balter O, Balter KA. Validity and reliability of self-reported total energy expenditure using a novel instrument. Eur J Epidemiol 2006;21(3):227-36.

155. Farahmand BY, Ahlbom A, Ekblom O, Ekblom B, Hallmarker U, Aronson D, Brobert GP. Mortality amongst participants in Vasaloppet: a classical long-distance ski race in Sweden. $J$ Intern Med 2003;253(3):276-83.

156. Ludvigsson JF, Andersson E, Ekbom A, Feychting M, Kim JL, Reuterwall C, Heurgren $M$, Olausson PO. External review and validation of the Swedish national inpatient register. BMC Public Health 2011;11:450. 



\section{Acta Universitatis Upsaliensis}

Digital Comprehensive Summaries of Uppsala Dissertations from the Faculty of Medicine 972

Editor: The Dean of the Faculty of Medicine

A doctoral dissertation from the Faculty of Medicine, Uppsala University, is usually a summary of a number of papers. A few copies of the complete dissertation are kept at major Swedish research libraries, while the summary alone is distributed internationally through the series Digital Comprehensive Summaries of Uppsala Dissertations from the Faculty of Medicine. 